\title{
COMMUNICATION INSTINCT: HUSSERL AND THE EMBODIED TEMPORALITY OF THE SOCIAL
}

\author{
by \\ Boris Pantev \\ Master of Arts, University of Toronto, Toronto, Ontario, Canada 2006 \\ Master of Arts, Sofia University, Sofia, Bulgaria 2000
}

\begin{abstract}
A dissertation presented to Ryerson University and York University in partial fulfillment of the requirements for the degree of Doctor of Philosophy in the Program of Communication and Culture.
\end{abstract}

Toronto, Ontario, Canada, 2016

(C) Boris Pantev 2016 


\section{AUTHOR'S DECLARATION FOR ELECTRONIC SUBMISSION OF A DISSERTATION}

I hereby declare that I am the sole author of this dissertation. This is a true copy of the dissertation, including any required final revisions, as accepted by my examiners.

I authorize Ryerson University to lend this dissertation to other institutions or individuals for the purpose of scholarly research

I further authorize Ryerson University to reproduce this dissertation by photocopying or by other means, in total or in part, at the request of other institutions or individuals for the purpose of scholarly research.

I understand that my dissertation may be made electronically available to the public. 


\title{
DISSERTATION ABSTRACT
}

\section{Communication Instinct: Husserl and the Embodied Temporality of the Social}

\author{
Boris Pantev \\ Doctor of Philosophy 2016 \\ Joint Graduate Program in Communication and Culture \\ Ryerson University and York University
}

This dissertation revisits the question of the temporal constitution of sociality. What is the role of subjective time-experience in the understanding of other people and the formation of communicative environment? This problem is considered in a generativephenomenological context. The investigation traces analytically the "stages" of communicative constitution: from the explicit intentional modes of interaction back to the pre-affective and habitualized social sense-accomplishments.

The task is approached through a systematic exposition of Edmund Husserl's generative concept of communication proper (Mitteilung, Kommunikation). A widespread view in the classical and more recent phenomenological scholarship is that Husserl's concept of communication must be derivative of the more fundamental categories of empathy and intersubjectivity (Einfühlung and Intersubjektivität; Schütz 1957; Held 1972; Zahavi 1996). The theoretical potential of the concept of communication for a phenomenology of sociality has thus been largely overlooked. The dissertation challenges this long-established model and attempts to reaffirm the central constitutive role of communication, to redefine its function in contradistinction with that of empathy. It does 
so by considering Husserl's later "genetic phenomenology" where temporal experiences are construed in the background of the sphere of "primal flowing living present" (urströmende lebendige Gegenwart). On this basis, the notion of communication is uncovered as transcendentally rooted in the structure of pre-conscious instinctual Ineinander. This perspective is radicalized and validated through an extensive analysis of Levinas's implicit debate with Husserl regarding the temporal constitution of alterity and also translated into a problem of the ethical meaning of objective forms of social communication.

The central argument of the dissertation is that an interpretation of Husserl's concept of communication in connection with the notions of primal temporal flow, instincts, and pre-intentional passive synthesis affords the elaboration of a generativephenomenological concept of "intermonadic communication" which grounds empathy rather than deriving from it. Such an interpretation might further prove productive for the study of both nonverbal interaction (also in relation to treatments of autism) and the developmental basis of social behaviour. Its potential to validate an ethical theory of interpersonal understanding is also affirmed through a comparative analysis of Husserl and Levinas's concepts of subjectivity, sensibility and common time. 


\section{Acknowledgements}

Many people have helped the creation of this work in various ways. Above all, I am thankful to my supervisor, R. Bruce Elder, who encouraged me to follow my original intuitions about the significance of the project. He gave me his full support throughout the course of the work's development and shielded my freedom to complete it in a way I found most suitable. John O'Neill, who was my co-supervisor until the illness deterred him from his academic duties, taught me to stand up for my boldest ideas and showed me how creative the field of social phenomenology could be. I can't express my appreciation enough for his inspiring and competent advice. I am truly grateful to Kym Maclaren who, as one of my readers, reviewed the dissertation more attentively that anyone else. Her detailed critical commentaries gave me the strongest impetus to revise and reinforce the argument. I also greatly appreciate the help of my other reader, Temenuga Trifonova. Her astute edits made me see better the text as one integral whole.

I am exceptionally indebted to Robert Gibbs for his long-term insight and support. During my time at the University of Toronto he provided invaluable intellectual guidance, especially into Levinas's thought. As an external examiner for my Ph.D. defense, he was one of the people who best understood the intentions of my work.

Thanks are also due to Asher Horowitz and John Caruana who during the course of my graduate studies at York University and Ryerson University read earliest versions of some parts of the text and encouraged me to continue working in the same direction. John was also a very appreciative and perceptive reader as my second external examiner. 
I am most of all grateful to my family whose unconditional support was essential throughout the years of my graduate studies. My father, George Pantev, and my stepmother, Nikoleta Pantev, have always trusted unquestionably my scholarly endeavors. They have consistently encouraged me and have been behind me in every possible way. My sister, Yoli Terziyska, has been an invaluable and deeply understanding friend with whom I have shared my most intimate fears and enthusiasm about my work. My mother, Raynichka Georgieva, has early on understood my innate necessity to do philosophy. Her commitment has been instrumental for the development of my mature scholarly outlook. Rayne, I hope you are able to feel, despite the terrible distance the illness imposed between us, my infinite gratitude. I dedicate this work to you.

I can't thank enough my friends, Lilia Topouzova and William Nelson whose unswerving support has been both a personal and a professional mainstay for many years. Without their attentive reading of early manuscripts of this dissertation, its completion would not be possible. I also owe a lot to my friends Martin Watson, Luba Encheva, Nina Knezevic, and Aysegul Koc with whom I have discussed at length aspects of my work, shared difficult moments of writing, personal ordeals, and excitements.

My Ph.D. research has been supported by several Ontario Graduate Scholarships, Rogers Scholarship and the funding of the Communication and Culture Program at Ryerson University.

I'd also like to thank Paul Moore, the director of the Communication and Culture program at Ryerson and Jo Ann Mackie, the program administrator for their continued kind assistance. 


\section{Table of Contents}

Author's Declaration $\quad$ ii

Dissertation Abstract $\quad$ iii

Acknowledgements $\quad \mathrm{V}$

Method of Citation $\quad \mathrm{x}$

$\begin{array}{ll}\text { Introduction } & 1\end{array}$

Chapter 1: Immanent Temporality and Primal Flow: Foundations of $\begin{array}{ll}\text { Husserl's Theory of Communication Proper } & 10\end{array}$

1. The Tripartite Structure of Consciousness 12

2. Four Reductions 17

3. Transcendence and the Paradoxes of Lived Experience 27

4. The Silhouette of Immanent Time 40

5. The Stream and the Flow 47

Chapter 2: $\quad$ Empathy, Intersubjectivity, and Intermonadic

$\begin{array}{ll}\text { Communication } & 58\end{array}$

1. Reduction and Primal Institution 60

2. Intersubjective Style $\quad 64$

3. Reciprocity 71

$\begin{array}{ll}\text { 4. Overlaying } & 78\end{array}$

Chapter 3: $\quad$ The Emergence of the Generative Concept of Communication 87

$\begin{array}{ll}\text { 1. Systematic Considerations } & 88\end{array}$ 
2. Negative Definition of Communicative Acts 91

3. Positive Definition of Communicative Acts 93

4. Personal Intersubjective Becoming: Empathy, Communication, $\begin{array}{ll}\text { or Instinct } & 100\end{array}$

5. Personal Love 106

6. Individual Style and Intersubjective Ineinander 112

7. The Primal "We" and Personal Unities of a Higher Order 118

8. Conclusion 131

Chapter 4: $\quad$ Infinite and Generative Time: Levinas and Husserl on 134 Communicative Temporality

I. The Sensible Constitution of Subjectivity in Totality and Infinity 136

1. The Intentional Structure of the Face and Its Temporal

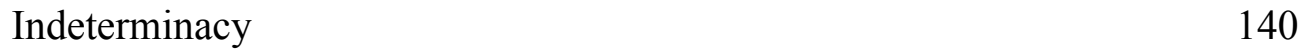

2. Affectivity and Infinite Time 145

II. The Ethical Reconstitution of Subjectivity in Levinas and Husserl 153

1. Ipseity and Ego 155

2. Phenomenological and Ethical Reduction 161

3. Substitution and the Interiority of the Will 166

4. Illeity and Telos 171

III. The Problem of Communication in Levinas and Husserl 179

1. Ethical and Phenomenological Reduction 180

2. Proximity and Primal Impression 185

3. Substitution or Institution 189 
Notes

Bibliography 


\section{Method of Citation}

All references to works by Husserl follow the standard German edition: Husserliana Gesammelte Werke (Hua) vols. 1-42. References to this edition are given in parentheses within the body of the text in the format: (Hua volume, page/page in the English translation if available). Unless an English translation is available, all translations of Husserl's texts are my own. References to Levinas's books Totality and Infinity: An Essay on Exteriority (TI) and Otherwise than Being or Beyond Essence (OB) are given parenthetically within the main text with the abbreviation followed by the page number. All other sources are referenced in endnotes in the format: (author's last name [space] publication year). 


\section{INTRODUCTION}

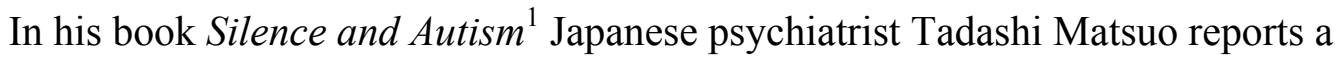
representative sample of optimal autism spectrum disorder treatments involving silent therapeutic interaction. One of the cases that initially motivated this approach was that of the patient $\mathrm{T}$. who had a classic autistic disorder with considerable difficulties in social interaction and communication. Upon admission to Matsuo's clinic, the patient had undergone two unsuccessful treatments in other hospitals and resisted both nonverbal and linguistic forms of interpersonal engagement. He spent most of his time lying in bed in a strained posture, staring at the ceiling. He demonstrated acute tension in social situations manifested in bodily comportment and facial expressions, and was ostensibly unable to reflect on his autistic condition. Matsuo made numerous attempts to engage him in a "safe" communicative exchange. The patient, however, remained unresponsive. The therapist could opt for nothing but to stay next to him and spend quiet time in his company. Initially, this approach generated an atmosphere of anxiety. Matsuo noticed signs of T. rejecting his presence and resisting the treatment altogether. The silence between them became "unbearable"; later Matsuo refers to it as "Silence I."

Matsuo had to abandon any therapeutic strategy for interactive engagement. The therapist would simply remain in the room with the patient and let the session hour pass. In the course of time however, Matsuo began noticing something quite curious. In the moments when he did not intentionally attend to the patient, trying for example to 
observe his behaviour or involve him in joint activities, but instead ignored him and sank into his own thoughts, the patient would in fact show a degree of tolerance to his presence. The lack of intentional empathic attendance on the part of the therapist had apparently relived the affective tension between them. Thus Matsuo gradually began to spend their sessions in what he later describes as a "non-objective disinterested silence." The psychiatrist would often fall asleep lying next to T. and would sleep in the course of the whole session. Upon waking up, he would find the patient sleeping or resting in a relaxed mood.

Slowly, small developments in T.'s style of behaviour began to occur. T.'s facial expression and bodily comportment became less rigid and he seemed to be getting used to Matsuo's companionship. The duration of their meetings naturally extended to an average of three hours a day. T.'s condition started showing slow but steady improvement. On the fiftieth day of the treatment, Matsuo smiled faintly to him and offered to share a tangerine. The patient passively accepted the gesture. Two months later, Matsuo suggested that they go for a walk in the hospital's courtyard. T. followed him despite the great efforts this involved. Soon after, they were able to share a bench and eat together in silence. This was already a different type of silence. What Matsuo called "Silence II," already implied not a rejection but an embodied and passively habitualized common situation. After a number of complications including several failed attempts to motivate $\mathrm{T}$. to speak and a miscarried attempt to bring him back home, $\mathrm{T}$. began to articulate brief, gestural or verbal, responses concerning his condition. Soon Matsuo managed to initiate short conversations and shortly after that, $\mathrm{T}$. was moved to a common room where he was apperantly comfortable with the new social environment. 
During the following six months, the patient was gradually able to regain his linguistic communication competences and eventually expressed a desire to return home. Matsuo assumed that $\mathrm{T}$. has achieved an optimal stage of recovery. After T. was discharged from the clinic, he lived with his parents, worked as a fisherman and demonstrated highlyfunctional social skills as well as overall practical adaptation.

What was it that took place in Silence II that changed so radically the course of T.'s treatment? Why did not Matsuo's explicit therapeutic approach, which relies on empathetic interactive contact, succeed? When Matsuo continued the therapy despite giving up his initial strategy, a distinct mode of communication came about. What is the nature of this mode of communication? By leaving aside their awareness of each other's behaviour and mental states and discounting their direct interactive attitude, Matsuo and T. receded to a peculiar kind of passive and implicit engagement. What we notice is that the dominant characteristic of this relationship is the overall lack of intentional disposition for interpersonal understanding.

This observation alone suffices to discover, or at least suspect, a potential important challenge for a great deal of contemporary social cognition research. In recent years, questions about the organization of "embodied social interaction," "direct intersubjective perception" and "empathy" have been increasingly moving to the center of scholarly interest. Interdisciplinary investigations coming from fields such as phenomenology, theory of mind, developmental and social psychology, social neuroscience, and dynamic systems theory have emphasized the central role of direct embodied and enactive processes for the formation of interpersonal understanding. ${ }^{2}$ The reason why Matsuo's case might motivate an objection in principle to a large part of this 
research is that it reveals a sphere of passive and pre-affective intercorporeal engagement. The decisive role this sphere played in the recovery of Matsuo's patient cannot be accounted for through a conceptual framework based on social interaction and empathy. The access to this sphere requires, on the contrary, a reduction of this conceptual framework. Quite aptly, Matsuo realized the necessity to withdraw from the general attitudes of empathy and interactive affective stimulation. It was this provisional withdrawal that enabled his patient to subsequently regain his affective and explicit communicative capacities and to increase his empathic abilities. Matsuo himself explains the process in the following way: "the therapist (initially) weakens the intended I-Thou relationship as much as possible [...], thus the proper passive intersubjectivity between the patient and the doctor is restored and the I-Thou relationship as based on the lifeworld could be built up over time."

With a reference to this and similar psychiatric cases, this dissertation undertakes a phenomenological investigation of the pre-empathetic constitution of interpersonal communication. The currently predominant theoretical framework of social cognition research does not provide the necessary analytical ground for such an investigation. The present study explores the question of pre-empathetic communication through a systematic exposition of Edmund Husserl's "genetic-phenomenological" theory of communication in the context of his accounts of temporality and instinct. In his abundant manuscripts Husserl lays out a multifaceted and dynamic correlation between the notion of communication (Kommunikation, Mitteilung) and those of empathy (Einfühlung) and intersubjectivity (Intersubjektivität). The central argument of the dissertation is that the interpretation of this correlation in view of his accounts of pre-intentional 
temporalization, instincts, and passive synthesis affords the elaboration of a phenomenological concept of communication which grounds empathy rather than deriving from it. This concept might prove productive for both the study of nonverbal interaction (also in relation to treatments of autism and schizophrenia) and the understanding of the developmental ground of social life in general. Its potential to validate an ethical conception of interpersonal understanding is also affirmed through a comparative analysis of Husserl's and Levinas's concepts of subjectivity, sensibility and common time.

\section{Problematic and Methodological Considerations}

Husserl's corpus of work presents an abundant conglomerate of themes, problems and methodological threads. While, in its broad framework and layering, it retains a loose but lucid coherence, its significant breadth requires a specification of the particular plane in which the investigation is to be conducted. Thus several problematic and methodological considerations need to be taken into account in the pursuit of the task at hand.

However, their sole purpose is to mark out the parameters of this plane and to situate the present work in a more definite context associated with a specific conceptual apparatus. In this sense, not all of the indicators below find explicit place and coverage in the inquiry.

1. Static, Genetic, and Generative Intersubjectivity. Husserl is renowned both within and outside the phenomenological tradition for his groundbreaking work on empathy. This work, however, has more often been criticized than acclaimed. One of the most prominent critiques has been mounted by Alfred Schütz, and one of its aspects 
concerns precisely the relationship between intersubjectivity and communication. Schütz reproaches Husserl for his attempt in Ideas II to ground intersubjectivity upon communication. Such grounding, he claims, is impossible "since all communication requires events in the natural world and [... ] already presupposes [an] intersubjectivity” ${ }^{4}$ on the basis of which can only the natural world be constituted. In outlining his critique, however, Schütz ignores a fundamental methodological and thematic distinction in Husserl's mature work, namely the distinction between static, genetic, and generative analyses. ${ }^{5}$ Unlike the static approach, which explicates the foundation for the transcendental subjective validity of empathy as already given in experience, the genetic and generative approaches ${ }^{6}$ demonstrate the transcendental temporal origin for the concrete becoming of the intersubjective relation. Communication as a developmental phenomenon therefore can be traced back to primary stages of constitutive accomplishments.

2. Reconstruction names the method Husserl elaborates in accordance to the genetic way of grounding experiences. It follows the inquiry of questioning back (Rückfrage) into a past of genetic experiences. Since such a genetic past concerns the very development of the ego that performs the procedure, memory by itself cannot provide us with an access to the constitutive geneses of the recollecting consciousness. These geneses lie hidden in a "dark horizon." On the basis of a phase of consciousness specially isolated through a reduction then, we are able to (re)construct the inaccessible "primordialities." For example, in a manuscript remarkably entitled "The Child: The First Empathy," Husserl explains how the perceptual experiences of the neonate become objects of a "later construction of an entire perceptual field in the moving identification 
of recognition, without built-up memorial repetition" (Hua 15, 604). While I do not specifically discuss the elements of this method, many of the phenomena under examination in this dissertation have only become phenomenologically accessible for Husserl through it.

3. Monadology. The concept of monad is intimately related to the problems of genesis and communication in Husserl. The monad is the ego understood in its temporal unity. The ego as a monad is a concretely constituted subject. For this reason, the monad is essentially in development. It has history. Furthermore, unlike Leibniz's monads, Husserl's monads have windows: they can enter into various types of connections by coexisting in common habitualities and by affecting each other. Empathy is notably only one of the types of intermonadic connection. Unlike empathy, the communicative connection, as mentioned above, is a developmental one. For this reason, it is present throughout different stages of development. What is crucial to note in this regard is that monads are also in potential communication with each other. This potentiality is revealed precisely by reconstruction. In a passage that could easily be considered one of the guidelines for the present study, Husserl describes the communicative development of the community of monads starting from their purely unconscious instinctual state:

1) The totality of monads in original instinctive communication, each continually living in its individual life, and consequently each with a sedimented life, with a concealed history, which equally implies the "universal" history; sleeping monads.

2) Development of monadic history as world-constituting; awakening monads, monads and development in wakefulness with a background of sleeping monads as constant foundation.

3) Development of human monads as world-constituting, as that wherein the universe of monads in oriented form pushes through to self-objectification, monads come to rational self- and human-consciousness and to world-understanding etc. (Hua 15, 609) 
We can instantly notice the relevance of this developmental picture to the psychiatric therapeutic case discussed above. Matsuo's patient had to be gradually driven back to (1), in order to then recover to (3).

In Chapter 1 I explain the three levels in Husserl's complex phenomenology of internal time-consciousness: the transcendent temporal objects, the stream of immanent experiences, and the primal living flow. Through the explication of his "radical reduction to the living present" and the irreducibility of the primal flow to immanent temporality, I demonstrate how Husserl's mature reflections on time are committed to a pre-affective and pre-intentional notion of the primal flow. I argue that the processes of "associative fusion" inherent to the flow reveal a dimension genetically preceding subjective time and affectively instituting its temporal modalities. This dimension is indicated as a passive ground for a communicative Ineinander.

Chapter 2 analyses Husserl's major theories of empathy and intersubjectivity in order to trace the various ways the concept of communication is embedded in them. It defines the original characteristics and scope of this concept in view of its central function in his genetic phenomenology. I develop an interpretation of key genetic moments in empathy and intersubjectivity and reveal the decisive role of style in the experience of others. On this ground I draw a clear distinction between those moments and the notion of communication, and explain their correlation.

Chapter 3 occupies a central place in the advancement of the argument. It traces the actual emergence of the concept of "communication proper" in Husserl's social ontology and, by revealing the tacit operation of another, instinctual and unconscious communicative structure it outlines an alternative account of his theory of 
communication. It thus defines explicitly the generative constitution of communicative structures in contradistinction with the notion of empathy and follows the stages of social constitutive accomplishment up to the sphere of cultural objectivations.

Chapter 4 develops a comparative analysis between Levinas' and Husserl's notions of communal time, sensibility and subjectivity and explores implications of the distinction between infinite (Levinas) and generative (Husserl) temporality for the relation between ethics and communication. While Levinas's unparalleled insight into the transcendence of the other and its ethical signification receives a due recognition, it is found inadequate to ground a notion of communication that derives sense not only from the face-to-face relationship but also from the connection with anonymous and absent others. A more practicable alternative is sought in Husserl's concept of "primal institution.” 


\section{CHAPTER 1}

\section{Immanent Temporality and Primal Flow: Foundations of Husserl's Theory of Communication Proper}

When in 1905 Husserl ventured to fathom the inherent temporal form of absolute subjectivity and then seemingly backtracked sighing that "for all this, we lack names" (Hua 10,75/79), he wasn't simply admitting to the inadequacy of the current philosophical vocabulary. Nor was he, in a prophetic vein, realizing what Derrida would later see as the "phenomenological "silence" [...] of the "self-relation" and describe as "the hiatus of indicative communication and even of signification in general." ${ }^{, 7}$ Rather, and in a most rigorous fashion, Husserl was drawing a critical phenomenological distinction, one that has apparently escaped the attention of many well-versed readers. He was referring to the difference between the immanent stream of lived experiences (Erlebnisse) and that what constitutes it, the absolute flow of "primal living" (Urleben). Eight years later in Ideas I, after he has systematically isolated through the phenomenological reductions the sphere of lived experiences, Husserl declares that this sphere as the region of pure consciousness is "in truth not what is ultimate; [and that] it [...] has its primal source in what is ultimately and truly absolute" (Hua 3, 162/193). What is ultimately and truly absolute is the inner time-consciousness in its absolute flow or as Husserl often calls it, the "living present" (lebendige Gegenwart). ${ }^{8}$ The latter is in 
fact what constitutes the immanent stream of lived experiences by providing "the necessary form combining lived experience with lived experience" (Hua 3, 163/194, translation modified). This distinct level of subjectivity, Husserl announces, represents "a delimited sphere of problems and one of exceptional difficulty" (Hua 3, 162/193).

This chapter attempts to redefine the distinction between the stream of lived experiences and the absolute flow in view of our engagement with other subjects. It advances a twofold claim. 1) It shows that, drawing on Husserl's later analyses of time, we can in fact conceptualize Urleben ${ }^{9}$ aside from the intentional acts it constitutes (actintentionality unavoidably confronts us with the inadequacy of expressive language). It is possible to provide a developmental reconstruction of the absolute flow in its preaffective set-up, the set-up prior to the ego's turning to the stimuli that awaken its conscious activity. In the C-manuscripts Husserl describes the structure of this original configuration as "pre-association" or "associative fusion" (Vor-assziation; assoziative Verschmelzung, Hua Mat 8, 309). 2) The processes of primal associative fusion reveal the potentiality of the absolute time-constituting flow as a form or a hyletic substratum affectively motivating and assembling not only the subject's lived experiences, but also, in a distinct, pre-temporal way, those lived experiences with the lived experiences of others, what Husserl refers to as Ineinander.

Husserl's investigations of temporality, regardless of their significant evolution from 1905 to the early 1930s, presuppose in a necessary way a moment of transcendence proceeding from the event of transcendental genesis. This is a specific form of material exteriority irreducible to the transcendence of the intended object or the ego's awareness of its own immanent processes. Because of its irreducibility, it latently involves the 
primal institution of the concrete sense of other subjects as a potential taking over (Übernehmen) of their own Erlebnisse. In the subsequent chapters I attempt to demonstrate how Husserl's reflections on the problems of intersubjectivity and empathy are increasingly informed by this notion of transcendence. This dimension is conclusively brought to the fore through the emerging generative account of intermonadic instinctual communication.

The present chapter proceeds by first laying out Husserl's systematic account of the tripartite structure of temporalizing consciousness (section 1). Section 2 deals with the specific reductions that reveal each of the levels that pertain to this structure. In section 3 , I address the paradoxes related to the inherent forms of transcendence implied in the constitution of lived experiences. Section 4 gives an account of Husserl's notion of the abiding form of inner time-consciousness as underlying the transcendence of lived experiences. Finally, the origin of this form and the structure of the primal flowing are discussed in section 5 and some implications for an understanding of the latent dimension of a communicative Ineinander are drawn.

\section{The Tripartite Structure of Consciousness}

Whenever he considers the constitution of objects or the unity of experience in a temporal context, Husserl consistently invokes the transcendental implication of a hierarchical constitution, Thus we have

1) The internal consciousness, the experiencing (Erleb e $n$ ),

2) The experience (Erleb $n$ is),

3) The intentional object of experience (der intentionale Ge gen st and des Erlebnisses, Hua 23, 326/397). 
The apprehension of the past and future horizons of an actually present perception constitutes the object. It implies the intended core of the object in its transcendence to consciousness and the object's possible (but currently absent) sides (level 3). However, experiences (Erlebnisse) themselves of temporal objects are also temporally constituted. They are given in the stream of consciousness as immanent temporal unities formed by appresentive extensions: back to elapsed and forth to awaited moments of experience (level 2). ${ }^{10}$ Finally, at level 1 , the very living-through of those experiences subsists as distinct from them. Such a living-through is, in this sense, a standing living present running throughout the progression of experiences. It constitutes at once the experiences in their continuum and itself as a primal flow. Since it gratns the experiences their unity and individuality, this living present constitutes and transcendentally underlies the immanent temporal stream. For this reason, Husserl also characterizes it as a pre-time (eine Vor-Zeit, Hua 34, 179).

Despite the numerous modifications he made to this structure throughout his longlasting reflections on time, Husserl remained committed to it. What supports this consistency is the notion of the constitutive relationship between the levels of temporalization. Although, occasionally and in different contexts, Husserl would describe them in a somewhat ambiguous fashion, typically, he presents the three levels as hierarchically arranged and ontologically distinct from each other. Level 2 is constitutive of level 3 and level 1, of level 2. At the same time, their ontological makeup and modes of constitution are strictly disparate. The major characteristic of the region of objects is that it is not a real part of consciousness and that its transcendence is nonetheless still intended in consciousness. Intentionality and immanent sensory contents (with their 
respective functions of apprehension and perception) characterize the sphere of lived experiences. Lived experiences comprise all intentional acts with the components that are immanent to them. The deepest level, the living present, which underlies this sphere, is for its part the experiencing of those lived experiences. This experiencing, however, is strictly differentiated from what it experiences. About the former Husserl often says that it is the form that concatenates the concrete data of the immanent stream. The living present provides the "universal, formal framework [...] in which all other possible syntheses must participate" (Hua 11, 125/171). Nevertheless, Husserl also —and quite frequently—describes the first level as a "primal flowing life" or a "primal flowing being" (urströmend Sein, Hua 34, 165). With respect to this fundamental characteristic, the time-form of the stream is grasped only as its invariant (Hua Mat 8, 148).

Given the fact that, besides being merely a formal framework, the first level is also characterized as a flow, it would seem confusing at first sight that Husserl conceives both level 1 and level 2 in terms of temporal "streaming." If both the stream of experiences (Erlebnisstrom) and the primal flow (Urström) are continuous and constantly running formations, why don't they run in one single flux? How can the flow be constitutive of the stream? Completely aware of this ambivalence, Husserl draws the distinction between the stream and the flow with a noticeable rigour. The most important $\operatorname{trait}^{11}$ distinguishing the primal flow from the stream of experiences, a trait that Husserl singled out in his later analyses, is that the flow is pre-intentional. The flow is in fact what constitutes intentionality in its entirety. Thus,

[o]ne sees the difference between [on the one hand] that pre-intentionality [VorIntentionalität], in which the flow of the stream of lived experiences [das Strömen des Erlebnisstroms] is constituted and which constitutes itself therein in the flowing life 
[strömenden Leben]: present, past, future, and [on the other hand] that intentionalityevery proper intention, every proper act-, in which on the basis of the flowing life (of consciousness and its consciousness-unities in the first sense), act-consciousness as egoconsciousness of something results, and therein beings [Seiendes] and time as form of beings, are constituted with the noetic act-modes of temporalization and with the present as present of beings, and past and future of beings. (Hua 34, 180) ${ }^{12}$

The flow of the stream of experiences is necessarily distinct from the stream of experiences. The necessity of this differentiation comes from fact that intentionality is a constitutive characteristic of lived experiences. In order for them to be presented as unities, as actual streaming and not merely grasped in an objectifying reflection, their constitutive basis must of necessity be pre-intentional. We have, in a certain sense, two currents. But they are not of the same order and exhibit an irreducible difference. This difference is at the root of their constitutive relationship. The stream of experiences comprises a manifold of individual intentional acts in "act-consciousness as egoconsciousness." In order for this manifold to be given, it has to appear in the connections of coexistence and succession. These connections can be supplied neither by the acts themselves nor by their multiplicity as such, since the latter would have to first be given in a conjoining experience. Such experience needs instead to be conditioned by one continuous and indiscrete flow, a flow that would unfold the modalities of present, past and future. This unfolding is the constitution of immanent time in a continuum, which while withstanding a temporal succession, does not itself have a consecutive articulation. The pre-intentionality of the primal flow is, in this sense, maintained as an indiscrete continuum.

This flowing living present is not what we already indicated in a different way as a transcendental-phenomenological stream of consciousness [Bewusstseinsstrom] or stream of lived experience. It is not a "stream" as we would imagine it, i.e. a proper temporal (or 
even temporal-spatial) whole, which, in the unity of a temporal extension has a continuously successive individual existence (individuated in its distinct sections and phases by the time-forms). The flowing living present is a "continuous" flowing being [Sein] and not a separateness [Außereinandersein], not a being in spatio-temporal (worldlyspatial), in "immanent-temporal" extension (so it is not in apart-from-one-another [Außereinander], it is not a separateness, not an afterness in the sense of points set apart in what is properly called time). (Hua 34,187 )

The pre-intentionality of the primal flow is defined by the non-separateness of its continuum. Thus the constitution of lived experiences amounts to the temporal individuation of this continuum. The flow is the flow of the stream. But it cannot be reduced to the stream. It is in fact this irreducible difference that articulates the form of immanent time as a form that does not, properly speaking, belong to it but is instead the abiding invariant structure of the flowing living present.

Explicating pre-intentionality, non-separateness, and time-form as three main aspects distinguishing the primal flow from the stream suffices to assert here that beneath the continuity of Erlebnisse, transcendentally lies the continuity of Erleben. This status of Erleben is determined by its passive temporalization. It grants consciousness its immanent temporal unity.

These are the systematic parameters of Husserl's account of the tripartite structure of consciousness. The fact that, time and again, he reaffirms its hierarchical order insisting on its apodictic necessity (Hua Mat 8,97 ) suggests its centrality to his account of inner time-consciousness. It provides us, therefore, with a guiding clue for our further discussion:

Double or triple meaning of the flow: 1) the experiencing flow, the pre-temporal; 2) the stream of immanent "lived experiences" as hyletic unities and as acts [...]; 3) the world time in which everything real "flows".... (Hua 34,180 n. 1) 
For Husserl, the primal flow is not an aspect immanent to consciousness. The exclusive right to immanence is reserved for lived experiences and their contents. Hence here it remains to be established what the status of the flowing present is as a primal phenomenon and with respect to the perspectives of immanence and transcendence. This is a befitting task for the phenomenological reduction. The different scopes and focuses of the various reductions would first demarcate the distinctions between the three levels of consciousness.

\section{Four Reductions}

The notion of the phenomenological reduction Husserl first developed in Ideas I (1913) has become almost commonplace in the traditional philosophical discourse. It is well known how this methodological technique- "the entrance-gate of phenomenology" as Husserl calls it (Hua 3, 52/56) — opens up and secures the access to the sphere of pure consciousness. Throughout his subsequent endeavors and until his last work, The Crisis of European Sciences and Transcendental Philosophy, however, Husserl continued incessantly to refine, redefine, and refocus the execution of the reduction. Thus already in Ideas I he refers not to one but to multiple reductions. ${ }^{13}$ Under consideration here are only the different modifications and stages of the transcendental-phenomenological reduction insofar as they disclose the gradation of temporal constitution. Viewed in this perspective, the reductions articulate the transcendental differentiation between the constitutions of temporal objects, the immanent temporality of intentional acts, and the living present. Their stages lead progressively to a reduction, which Husserl deems to be 
"the most radical" one, the "reduction to the living present" (Hua 34, 185; Hua Mat 8, 40).

What originally prompted Husserl to expand his reflections on timeconsciousness beyond the sphere of lived experiences was the phenomenological reduction introduced in Ideas $I$. It is instrumental to map out its structural moments within the perspective of the layers of temporalization. Above all, the phenomenological reduction is an alteration of the ordinary mode in which we experience the transcendence of the world. This mode, which Husserl designates as the "natural attitude," takes for granted the factual existence of the world and everything that might be experienced on the basis of its direct assumptions. The main characteristic of this "general positing" is the presentation of the total unity of the world as actual within experience. The world is always, in a more or less implicit way, factually present for us, and such factuality involves my own existence as well as the existence of other human beings (Hua 3, 53/57). In our everyday experience therefore, transcendence - be it the transcendence of objects, that of other subjects, or of my own subjective life-is essentially obscured. It lies undifferentiated within the thesis of "real" existence. Husserl singles out the structural characteristic of such "presentification" by pointing out that in the natural attitude the world, others, and the I are always "there" $(d a)$ and "at-hand" (vorhanden). ${ }^{14}$ It is this moment of factual interpretation of transcendence that is first subjected to a reduction.

The phenomenological reduction thus consists in the redirection of our attention from the naïve general intention, which accepts objects without being aware of its own activity, to the very act of intending in which objects are given as merely intended in a 
strict way. The result of this procedure is that the general thesis of the existence of the world is suspended, "put out of action," and the reflective sphere of transcendental consciousness is rigorously defined as the pure field of phenomenological description. Such "parenthesizing" of all judgments based on the immediate ontic acceptance of reality, however, does not mean that the world's existence is ruled out. Husserl is especially insistent that the phenomenological reduction is not a rejection of the natural attitude. Its peculiarity lies in the specific way in which the world and objects are left theoretically intact. The transcendental epoché is therefore a "modification" only of our intentional activity by virtue of which — while we retain the positing in itself - we cease to make use of it and thus enter a reflective type of attention directed exclusively to the mode of intentional givenness. In this mode, the world already appears simply as a "correlate of consciousness" and its transcendence, together with the transcendence of other subjects transpires a "transcendence in immanence." The modification performed by the phenomenological reduction is therefore at the same time an articulation of the schema of transcendence within the structure of intentionality.

What surfaces when we consider the result of the transcendental reduction in a temporal perspective is first and foremost the field of objects as temporally given in the stream of experiences. As such they have strictly differentiated immanent and transcendent sides. Although the objects are lived-through in consciousness, they are nonetheless constituted in intentional acts precisely as "the things of empirical experience in objective time" (Hua 10,73/77). Taken in this double way, objects amount to the third level ${ }^{15}$ in the temporal constitution of consciousness. What distinguishes the temporality of the individual object "whether immanent or transcendent, constituted in the stream" is 
duration (Dauer). The object "necessarily endures" and throughout its duration, it is constituted as continuous and identical within the process itself. In other words, the objectivity of the object's time as given in my experience lies in the experienced necessity that the change and the unity of what undergoes this change belong together. Importantly, this temporal determination is intentionally given. It defines the time structure of the object precisely as a correlate of consciousness as what Husserl calls noema. The time of the noema is the time on the third level of consciousness. But this time is constituted in the stream of lived experiences, which has its own temporal structure.

The series of reductions performed in Ideas I does not result in the disclosure of the time of lived experiences. ${ }^{16}$ Hence it does not mark the ultimate scope of the epoché. Within the corpus of Husserl's work, there are at least two examples—one quite early and the other later — of reductions that go further than the reduction of Ideas I: the "reduction of objective time," which prepares Husserl's analyses of internal timeconsciousness, and the "primordial reduction" to the "sphere of ownness" (Eigenheitssphäre), which introduces the consideration of the "other" in the Fifth Cartesian Meditation. These reductions isolate strictly the temporality of immanent lived experiences. A parallel examination of the two would help us explain how subjective and objective time relate phenomenologically.

The introduction to the lecture course on time-consciousness of 1904-05 is early evidence of Husserl's attempts to secure a primordial realm for immanent experience. Husserl's aim is to shift theoretical attention from the objective time of experiences to the domain of their immanent unities and contents. In this operation, the factual existence of 
world-time as well as everything that might be experienced on the basis of its direct assumption is suspended. The procedure involves two moments. First, we "abstract from every interpretation that goes beyond what is given" (Hua 10,5/5). Second, within the sphere of what is given we "reduce the perceptual appearance to the given primary contents" (ibid.). Through these two stages, we suspend the aspect of apprehension and retain the sensual contents of the temporal field. What remains after the two moments of the procedure are carried out is an original quasi-temporal field that has no relation to objective time. The demarcation of this field is the outcome of the "complete exclusion of every assumption, stipulation, and conviction with respect to objective time" (Hua 10, 4/4). Importantly, this disengagement does not concerns only what is naïvely pregiven in the natural attitude. It also rules out the noematic perspective of time, which refers to temporal object as intended.

When I observe a flying bird above the roof across the street, the experience of the continuity of its flight as an object of my observation depends on me having posited as a correlate of my experiences certain constancy and identity throughout the phases of the flight. By contrast, the original quasi-temporal field is structured entirely as a temporal modification of act-contents whose identity does not depend on the apprehension of a transcendent object. There is no objectifying intention running through the multiplicity of adumbrations (Abschatungen) that would render them present in second-order unities. Husserl indicates the moments of this result by distinguishing them from those of the objective perspective:

Here we have contents separated in time; we even see, phenomenologically, a separation or division in time. But there is no division as far as the object is concerned: it is the same. In the object there is duration; in the phenomenon, alteration. Thus we can also sense, 
subjectively, a temporal succession where, objectively, we must confirm a coexistence. (Hua 10, 7/8, emphasis mine)

At the time of his lectures on time-consciousness, Husserl had not developed the concept of transcendental reduction in the form we know it from Ideas I. But this is exactly what makes it significant. Husserl does not conceive of the intentional grasp of a transcendent object as an immanent intentional content. All that figures in the domain of subjective temporality is the phenomenological datum, the real (reell) contents that are immanent to the act itself. What he later formulated as irreal (irreell) immanent content and then termed noema is not taken into account. This circumstance points to a feature of even greater significance: the reduction of objective time does not have as its result the explication of the intentional correlation. It is a reduction to mere immanent senseintentions and modified in them immanent hyletic data. In other words, it is a reduction to the noetic side of the intentional correlation, to the "concretely complete intentive lived experience" (Hua 3, 199/233). Put in the language of Husserl's more mature timeanalyses, the reduction of objective time delineates the subjective stream of temporal unities as it is carried out through the retentional and protentional modifications of the primal impressional presentations. In this sense, the field this early epoché isolates is concentrated around the original presentation of the "now." Yet this is not the now of a cause whose effect a thing undergoes. The endurance of the thing does not retain the past of an already absent cause. Subjective time is precisely a constant "alteration." It is a stream in which what has elapsed is still lived on and what is to come is looked for.

The "primordial reduction" Husserl carried out in the Fifth Cartesian Meditation proceeds from a different methodological urgency. The prospect of solipsism he faces in the previous Meditations compels him to submit to a reduction what has appeared to be in 
question, that is, what has not been presented with apodictic validity. In the first place, this is the sense of "other subjects." But as far as for Husserl the possibility of an objective world is grounded in the world's being for everyone, the world is also to be excluded. The result of such total suspension is that the ego is reduced to its "sphere of ownness” (Eigenheitssphäre), viz., to its “transcendental concrete I-myself” (Hua 1, 125/93). The sphere of ownness obviously includes neither the noematic component of the transcendence of the object nor the sense of "otherness" with respect to other subjects. What Husserl hopes to gain by this procedure is not a renewed intersubjective transcendental perspective. The reduction aims to suspend precisely the transcendental possibility (and not simply the actuality) of "others". What he expects to reveal in this way is rather the non-intentional transcendent presence of otherness within the sphere of ownness, viz., "the manner in which the ego constitutes within himself the distinction between ego and other ego" (Ibid). Upon a further examination, this concrete difference appears in one single form: my own singular body passively experiencing itself:

I then find my animate organism [meinen Leib] as uniquely singled out—namely as the only one of them that is not just a body but precisely an animate organism: the sole Object within my abstract world-stratum to which, in accordance with experience, I ascribe fields of sensation. (Hua 1, 128/97)

Emerging in this way, the inner temporal self-experience of my body, taking place through constant self-differentiation and unification, seems to constitute the very core of my sphere of ownness. Husserl goes further to specify the inherent form of this dynamic:

$[\mathrm{O}]$ ne of the first things I run into is my immanent temporality and, with it, my existence in the form of an open infiniteness, that of a stream of subjective processes, and in the form of all these "ownnesses" of mine that are somehow included in the stream-one of which is my explicating. (Hua 1, 132/102) 
We can already establish, therefore, that the abstraction from the experience of others as encountered in the objective world and, along with that, the suspension of the element of the world ensuing from common constitution yield results very similar to those of the reduction of objective time.${ }^{17}$ What Husserl arrives at is nothing else but the concrete stream of immanent experiences considered apart from the temporal objects they constitute. More importantly, the fact that the results of the two reductions overlap to such an extent allows us to conclude that, when taken in transcendental regard, the sphere of lived experiences can in fact be scrutinized in distinction from the noetic field. The second level in the constitutive hierarchy of consciousness can thus be thought as necessarily distinct from the third one. To be sure, this is not to say that lived experiences are independent of the objects they constitute. We can rather affirm that, while intentional objects are the enabling condition for the immanent stream, they are not its constitutive trait. ${ }^{18}$ But can we claim the same about the relation of the immanent stream to the flowing living present?

Among the several accounts Husserl gives of the radical reduction to the living present one would be of special interest here as it takes its point of departure in what is supposed to be the main accomplishment of the Fifth Meditation: the notions of empathy and intersubjective constitution.

Husserl opens his exposition with a consideration of the psychophysical recognition of other subjects in spatiotemporality. Other people are given in my surrounding world in their physical bodiliness (körperlichen Leiblichkeit). By virtue of this givenness, their psychic life and their spatiotemporal extension exist in a unity. In this unity, the two are coextensive. By virtue of this coextension, I grasp at once both the objective and the 
immanent times of the other. I am able to do this because the same type of coextension is originally embedded in my own self-givenness. The obvious difference between the givenness of the other and my own is that in my self-experience I do not mediate from my own immanent temporality to that of the other. In either case, however, there is a continuity and unity of the concrete stream of experiences in the framework of a common world where each of us has parallel and unified temporal coextensions. Because of these coextensions my lived experiences have a concrete objective temporal position and I have a "potentiality of an I-can-actually-return-to-a-once-well-known" (Ich-kann-aktuell-aufAltbekanntes-Zurückkommen, Hua 34, 186). Each of my immanent experiences comes with a concrete reference point in the order of objective time and retains its positionality as it occupies a definite location in the sequential spatiotemporal arrangement of my past. This is indeed what articulates the individuation of experiences and enables them to validate new occurrences. Thus I can understand the other's experiences because I can put myself in her situation through a reference to my habitual validities. I refer back to a concrete past moment in my stream when I have possibly been located in the spatiotemporal position the other currently occupies.

Notwithstanding its consistency with the presentation of the sphere of ownness and empathy in the Fifth Meditation, Husserl does not commit to this model. Apparently, the outcome of the primordial reduction does not satisfy him and he only uses it as springboard to move further. Spatiotemporal referentiality indicates a mundane residue to the stream of consciousness and hence leaves its full transcendental constitution unaccounted for. What we have accomplished so far is only "an execution of the phenomenological epoché in terms of the world and in anyway in terms of all validities 
existing for us in advance (forming prejudice)" (Hua 34, 186). What is more, this epoché sets a "'restriction"” ("Einschränkung“, Ibid.) to the living present insofar as, through it, transcendental life is elucidated in terms of "real time," that is in terms of separateness and succession. The flowing living present, however, is "not a transcendentalphenomenological stream of consciousness or stream of experience." It is a “"continuously' streaming being [Sein] and not a being in [...] a spatiotemporal (worldlyspatial), or an 'immanent-temporal' extension” (Hua 34, 187). For this reason, we need to execute another, radical reduction that would suspend the objectively-immanent time of the stream and reveal "the primal ground and primal source of all actual validities of being" (Hua 34, 186). Husserl's statement has an almost performative overtone:

The reduction to the living present is the most radical reduction to subjectivity in all of my validities that take place originally, in all sense of being that has meaning for me and, experientially and consciously, a valid meaning. It is the reduction to the sphere of primal temporalization, in which the first and primally original sense of time occurs - time just as living flowing present. All other temporality, whether subjective or objective-whatever meaning might these words assume-will receive from it its sense of being and validity. (Hua 34, 186)

As we can see from this quote, the radical reduction marks a limit of incommensurability, a limit that differentiates the proper field of phenomenology — the lived experiencesfrom that what lies transcendentally prior to it, the pre-temporalizing flow of the living present. By accomplishing this, the radical reduction does not explicate yet another stratum of the immanent stream where lived experiences, instead of being anchored in objective time, are intentionally given to themselves. It is not an unwarranted trespass into a field of "naïve metaphysics." On the contrary, it is a first step into the execution of a transcendental "self-critique," a task motivated by "the tremendous wealth of problems 
belonging to the first stage of phenomenology — a stage which [...] is itself still infected with a certain naïveté" (Hua 1, 178/152). This radical "critique of phenomenological evidence $^{\text {(19 }}$ arises from within the very architecture of phenomenology. But, as Klaus Held observes, "whether this critique will prove apodictic in the discussion of the standing and the flowing of the living present remains as questionable as whether the unity of the standing and the flowing in the last functioning ego will turn out to be a "givenness" of a very special kind." 20 This question will be at stake in the following sections.

\section{Transcendence and the Paradoxes of Lived Experience}

As became clear from the above considerations the distinctive systematic domain of the phenomenological project is the sphere of lived experience (Erlebnis). By "lived experience" Husserl ordinarily understands the unified realm of intentional consciousness with its immanent and transcendent sides. Insofar as the immanent side involves a certain form of self-experience as an animation of immanent contents, it also contains a nonintentional element. And yet, since intentional consciousness consists essentially of acts constituting objects (real as well as ideal), the temporal unities in the inner stream are inseparable from objective being.

By virtue of this inseparability, the methodological recognition of the fact that our experience is always experience of something distinct from it redirects our attention from the natural belief in the existence of the world to that primordial region (Urregion) of consciousness within which objects are present as modes of givenness. What defines the unconditional character of this methodological orientation is that, while actually existing 
in the world, the "contents" of experience are taken as moments of the subjective intentional correlation. Husserl rejects the demarcation of the sphere of lived experiences on the basis of the psychological qualities of the acts. As the Logical Investigations first demonstrated and Ideas I made conclusively clear, traditional psychologism, both in its empirical (Hume) and its transcendental (Kant) forms, is incapable of grasping the primordial structures of the life of consciousness. Transcendental subjectivity can by no means be conceived as a being that unifies or produces the reality of its own "a posteriori" states. Any one-sided recourse, be it intuitive occurrences or pure forms of intuition would, according to Husserl, end up in solipsism. Indeed, what makes the notion of intentionality unique is the fact that, by virtue of its self-transcending structure, consciousness is an "absolute concretum." Its transcendental nature lies in the structure where our direct perception of the object (or ourselves) is necessarily accompanied by an indirect apperception. What is immediately present always indicates an appresentational horizon of other possible presentations drawn by the implicit intentional tendency toward the object as a whole and toward its background of surrounding objects and meanings. Whether Husserl explores it through static or genetic analysis, whether he identifies it at the level of active constitution or explicates its passive forms of temporalization, or even when he in his latest work extends it to the generation of the life-world, the transcendental frame set by this correlation remains the first apodictic condition for the phenomenological project. It is remarkable however, that for Husserl the apodicticity of intentionality did by no means preclude its problematicity. ${ }^{21}$ Quite the contrary, from the time of the Logical Investigations, until the Crisis intentionality remained the focal point of what can be considered his main question: What is the nature of the relation by virtue 
of which the transcendence of the world is articulated within the immanence of lived experience? As he states explicitly in the Crisis, this problem demonstrates the very "paradox of human subjectivity: being a subject for the world and at the same time being an object in the world." (Hua 6, 181/178)

Lived experience demarcates the proper region of Husserl's transcendental phenomenology. But how does he reconcile its primordiality with its "paradoxicality" and what is the function of temporalization in this reconciliation? With respect to intentional consciousness these questions amount to a single, specifically structural one: What is the capacity of the primordial structure (Urstruktur) of intentionality to incorporate a mode of transcendence irreducible to the constitutive presentation and selfevidence of consciousness? In order to address this question we need first to analyze the modes of givenness inherent to Husserl's categorial (or static) concept of intentionality. For if it is possible for him to explicate the modes of experience of transcendent objects in their necessary relation to consciousness, the schema of transcendence operative at the categorial level must already involve at the core of the immanent stream a reference pointing beyond the sphere of all lived experience.

Admittedly, Husserl has always identified the development of the concept of intentionality with the design of the structure of transcendence. But how did he frame the modes of transcendence within the necessary static sense-structure of constitutive consciousness? One point of departure for his detailed account of intentionality in the Logical Investigations is the "critique of the doctrine of the "immanent" objects of acts." ${ }^{, 2}$ According to this critique "[w]e must realize that a transcendent object is not present to consciousness merely because a content rather similar to it simply somehow $i s$ 
in consciousness $[\ldots]$ but that all relation to an object is part and parcel of the phenomenological essence of consciousness, and can in principle be found in nothing else, even when such a relation points to some "transcendent" matter." ${ }^{23} \mathrm{My}$ consciousness does not attribute a new real (real) predicate to the object, a predicate that exists in reality as distinct from and related to this object. By virtue of its pre-predicative directedness, consciousness is always a consciousness "of" objects without them having to be real (real) part of it. Thus, the phenomenological description concerns not only the modes of perceptual apprehensions and their objective correlates but also the "matter" of intentional acts, their "determinate objective reference." ${ }^{24}$ The scope of this critical inference gives Husserl grounds to postulate that, as far as they are actually experienced, "intentional objects" (traditionally conceived as "merely immanent") are the same as "actual objects" (traditionally taken as transcendent). ${ }^{25}$

On this basis Husserl is able to articulate a further form of transcendence, one emerging from a distinction operating within consciousness. Within the structure of intentional acts he differentiates between their real (reell) and their intentional (or irreal, irreell) contents. ${ }^{26}$ By real contents he understands the experiential (concrete or abstract) components of the act that are immanent to the act itself. In other words, real contents include characteristics of the intention such as its mode and quality (act-matter and actquality) of presentation, characteristics which constitute the act as such. As real contents exhibit concrete experiences in consciousness, Husserl also defines them as the purely descriptive psychological moments of the act. By contrast, although intentional contents are also moments of the act, they generally refer to the intentional object toward which the act is directed. Intentional contents therefore indicate the transcendent aspect of 
intentional activity, its movement through the present mode of givenness and beyond it toward an indirect, non-psychological, and objectively unifying dimension of consciousness.

The distinction between real (reell) and intentional contents allows Husserl for the first time to transfigure the naïve notion of transcendence typical of the natural attitude. The fact that the schema of transcendence becomes an essential characteristic of consciousness does not exclude it from phenomenological consideration. Quite the contrary, by inverting the relation, the concept of intentionality reveals the primordial openness of subjectivity as concretely situated in the world and at the same time as unfolding the horizons of its objectivity. The turning point of this shift, however, is neither of the kinds of contents taken as isolated source of experience. It is rather the internal unifying relation between experience and its object that makes possible the object's simple presentation as distinct from consciousness. In order to understand more accurately the modes in which the core concept of intentionality involves the transcendence of objects, we need to focus more closely on Husserl's first analyses of the transcendent component of this relation.

Although Husserl warns us that the notion of intentional content remains terminologically ambiguous, he makes further distinctions under this general rubric. He lays out three concepts of intentional content: "the intentional object of the act, its intentional material (as opposed to its intentional quality) and [...] its intentional essence." 27 While the quality/matter division is initially ascribed only to the real (reell) content of the act, at this point Husserl considers its parallel function with respect to the transcendence of the object. The content-element of the "intentional object" indicates the 
particular as-structure of the intended object. It is the presentation of the object insofar as it is given in the subject's particular intention and which has sense only as intended in the particular act. Put more formally, intentional content as the intentional object configures the identity of the object structured through the intentional act: this object is intended as this intended object. What is worth noting here is that the object is considered with respect to the particular kind of the intending act and not with respect to the particularity of the object itself. The intentional object concerns "the act-character, which stamps an act as merely presentative, judgmental, emotional, desiderative etc. ${ }^{, 28}$ In other words, it determines the quality of the act. The matter of the act, on the other hand, defines the mode in which the object appears. It "fixes the object meant in a general way [and] also the precise way in which it is meant. ${ }^{, 29}$ By matter or material of the act therefore Husserl understands precisely the manner in which this particular object appears as this object and not other. Clearly, each of these two aspects of intentional content functions as a variable with respect to the other. Regardless of the ways in which my consciousness is directed toward this particular coffee cup, whether it is present now as I am drinking from it, or I remember it from this morning when I had coffee, or I desire it because I am tired of writing and I need a warm refreshing drink, it is this particular cup that I am intending and not other. The matter of my act, viz., my coffee cup and the mode in which it appears, viz., in my drinking from it, remain the same. On the other hand, I might desire other objects in the way I have desired this particular cup. I might, for example, be hungry and think of a dinner plate. In this case, the desiderative quality of my act will be the same, while its matter will vary. In either of these cases however, or rather in the possibility of each, we notice a characteristic inherent to the intentional relation itself. 
This characteristic is the indication of transcendence. This is precisely what Husserl designates by "intentional essence," the third element of the intentional object. The element which remains constant endures not by virtue of the immanent necessity of consciousness, of the real (reell) existence of its "psychic nature," but by virtue of the object's own self(Selbst $)^{30}$ as it is for me. While Husserl does not explicitly discuss this specific mechanism, it is evident-especially from his notes to the second edition of the Logical Investigations (1913) - that the notion of transcendence in his first account of intentionality already involves a shift from real (reell) to intentional content. The most obvious corroboration of this argument is the fact that the material and qualitative determinations of the act are not only typical of the subjective sphere but — through the articulation of their variability —already become moments characterizing the non-present aspects of the object. The matter and the quality of the act constitute the distinct link of transcendence that allows Husserl to claim that the intended object is not merely an image or an immanent real (reell) element but the object itself as it is intended:

The transcendent object would not be the object of this presentation, if it was not $i t s$ intentional object. This is plainly a merely analytical proposition. The object of the presentation, of the "intention", is and means what is presented, the intentional object. If I present God to myself, or an angel, or an intelligible thing-in-itself, or a physical thing or a round square etc., I mean the transcendent object named in each case, in other words my intentional object: it makes no difference whether this object exists or is imaginary or absurd. "The object is merely intentional" does not, of course, mean that it exists, but only in an intention, of which it is real (reelles) part, or that some shadow of it exists. It means rather that the intention, the reference to an object so qualified, exists, but not that the object does. If the intentional object exists, the intention, the reference, does not exist alone, but the thing referred to exists also. ${ }^{31}$

The key implication of this conclusive remark to Chapter II of the Fifth Investigation is, as I take it, the inherently diachronic constitution of the intentional essence. What Husserl 
terms "intentional essence" seems to refer precisely to the connection between what is immediately present and what is appresented in the intentional act. Although Husserl does not elaborate on their temporal structure, it is clear that the former indicates the immanent determinations of the act, viz., the mode and the kind inherent to its instantaneous present; whereas the latter points to a sphere which is not simultaneous to that of the subject, prior or following its now-phases and thus transcending its psychological actuality. Intentional essence is hence the form by virtue of which the immediately present "profile" of the object implies the profiles that are not present but may possibly be presented. Through its function, what Husserl calls "real content" (reellen inhalt) and attributes to the subjective aspect of the correlation already contains the intentional or transcendent aspect of the object.

Arguably, as the structural analysis reveals, Husserl's notion of "intentional essence" indicates the specific form of transcendence operative in the Logical Investigations. However, along with such strong interpretation, we must emphasize that this early account of the structure of intentionality is in many respects problematic. For the purpose of the present exposition it suffices to point out that while Husserl's argument for the inclusion of the transcendent object within the intentional content (as both actual and possible fullness) serves quite agreeably the overcoming of the Cartesian duality, it obliterates the very differentiation of transcendence. The problem, as it seems, proceeds from the very procedure that establishes the correlation. When he explains the connection between the different parts of the act Husserl tells us that their manifold is "summed up in one total act, whose total achievement lies in the unity of its reference." 32 And although he specifies that such unity is "not set up alongside of the partial acts,",33 he 
cannot avoid the ambiguous possibility of ontological grounding. The unity of the intentional essence, therefore, can be regarded as both a pure articulation of the descriptive principle of evidence and a general synthetic frame, which brings us back to either a solipsistic regress or the naïve thesis of the existence of the world. At this point the need for an outlining of a more critical method and a more radical concept of transcendence become necessary.

After the introduction of the phenomenological reduction in Ideas I Husserl has already acquired the method that would allow him to describe the immanent experiences of transcendence as intentional contents without the ambiguities of solipsistic regress or natural presuppositions. What in the Logical Investigations was formulated as a correlation between real and irreal contents now takes the form of the noesis-noema correlation. As Husserl's account of this correlation is familiar to many, I will only touch on its main structural characteristics in relation to the problems of transcendence and intersubjectivity.

Husserl states that the theoretical point of departure of the phenomenological analysis is the understanding of the intentional structure as an articulation of the relation in which "the transcendent stands with respects to the consciousness which is a consciousness of it." (Hua 3, 64/73) Accordingly, he proceeds to define the two sides of this relation. The noetic side-which Husserl also identifies as the subjective or psychical side-includes those characteristics of the intentional stream, which are inherent to the act itself. The noesis makes up "what is specific to nous in the broadest sense of the word; it refers us back, according to all its actional life-forms, to cogitationes and then to any intentive lived experiences whatsoever..." (Hua 3, 174/205) It is therefore the 
moment of intentionality that gives sense to and is distinct from the sensation-contents of consciousness. More precisely, the noesis is the determination of the act precisely as a sense-giving (Sinngebung) which animates the primary intuitive contents of experience. By virtue of its animating directedness the noesis is essentially correlated with the noema. By "noema" Husserl understands generally the intentional object of consciousness insofar as it is given in the intentional acts. Although the noema is "not really inherent" (Hua 3, 182/214) in the lived experiences, it indicates the presentation of the object as intended. However, Husserl will retain a non-intentional element in the notion of noema and will suggest that it functions also as a sense-determination. Thus he will initially define the noema entirely in terms of the relation to a material content which is yet different from the material content of the noesis: "Corresponding in every case to the multiplicity of data pertaining to the really inherent noetic content, there is a multiplicity of data demonstrable in actual pure intuition, in a correlative noematic content." (ibid.) Subsequently however, he will tell us that the noema articulates the sense or the modality of the intention:

Perception, for example, has its noema, most basically its perceptual sense, i.e., the perceived as perceived. Similarly, the current case of remembering has its remembered as remembered, just as its "remembered," precisely as it is "meant," "intended to" in "the remembering"; again, the judging has the judged as judged, [...] and so forth. In every case the noematic correlate, which is called "sense" here [...] is to be taken precisely as it inheres "immanently" in the lived experience [...]. (ibid.)

It is clear even from this initial account of the components of the intentional correlation that in Ideas I Husserl conceives transcendence in two quite distinct ways. And this differentiated treatment entails an attempt of a peculiar dynamic explanation 
which is embedded within the generally static frame of the analysis and which is not without serious ambiguities.

First, most obviously, Husserl associates transcendence with the objectivity of the object. The latter is understood, however, essentially as experiential and therefore exclusively within the noematic moment of the correlation. Husserl emphasizes recurrently this schema by pointing out that in the phenomenological attitude the intended object is never fully given to consciousness but is always presented in adumbrations with respect to its intended meaning. "It can already be seen universally," he sates, "that no matter what its genus may be, any real being of something transcendent can become perceptually given to an ego only through appearances" (Hua 3, 81/95). The object thus remains transcendent to consciousness because its sides, aspects, and contexts can never be fully experienced. This is why Husserl will point out that the concrete mode of givenness in the noema constitutes a finite "closed lived experience." (Hua 3, 298/343) But precisely in this notion of noema there arises a problem unsolvable within the static method of Ideas I. The main cause for this problem is the fact that Husserl could not give a consistent account of the noema simply on the basis of its sense-presentative and perceptual function. Since the noema is defined precisely as the objective correlate of consciousness, he found himself compelled to introduce another element in it, namely the object itself which is intended, more precisely the core of the object as an eidos separate from the simple sense of experience. Husserl will also call this element a determinable $X$ and will claim that it pre-designs the givenness of the object as "idea in the Kantian sense'. Such idea "inheres precisely in the infinity of the noematic correlate" (Hua 3, 
297/432). This third moment within the structure of the noema turns out indeed to be the "true" representation of transcendence:

When the presentive intuition is one of something transcendent to it, then something objective cannot be adequately given; only the idea of that something objective can be given, or else of its sense and its "epistemic essence," and consequently there can be given an a priori rule for law-conforming infinities of inadequate experiences. (Hua 3, 298/343)

Such recourse to a last, purely ideal, notion of the noema however leads us to a paradox within the shape of transcendence which cannot be solved merely by means of the immanent-transcendent structure of the correlation. Based on this structure, Husserl would not be able to answer the unavoidable question: How is it possible that the notion of transcendence - a notion which refers to what lies precisely beyond the immanent sphere of lived experience_-be understood as a "peculiar type of intellectual seeing"? (ibid.)

This single question - or rather the possibility of its answering - brings us to the second sense of transcendence operative in Husserl's categorial analysis. To be sure, this second sense is not explicitly elaborated at this stage. Yet it gives us perhaps the most important clue to Husserl's transition from "the first stage of phenomenology" to genetic analyses and moreover to his essential treatment of the issues of passivity, alterity and intersubjectivity. When he analyzes the different stages of the reduction, he encounters the zero-point of its application, a point where the reduction itself seems to proceed from transcendence. This however turns out to be not the transcendence of the noema but rather the transcendence of the very source-point of the noesis:

If we retain a pure ego as a residuum after our phenomenological exclusion of the world and of the empirical subjectivity included in it [...], then there is presented in the case of 
that ego a transcendence of a peculiar kind — one which is not constituted-a transcendence within immanency. Because of the immediately essential role played by this transcendence in the case of any cognition, we must not undertake its exclusion...(Hua $3,110 / 133)$

It is precisely this second kind of transcendence, a transcendence that is not constituted but is rather itself constituting that points to the solution to the paradox of intentionality. Such solution can be sought only in the possible modes of apodicticity inherent to the flowing living present. And it must also rigorously avoid a hypostasis of the flow as a substratum of consciousness. This is precisely what the flow is not. It must be understood instead in terms of drawing of limits and of necessary critique and self-correction of the proper domain of phenomenology. Although the categorial analysis is by definition not concerned with this kind of transcendence, Husserl's reference to it in Ideas I demonstrates the fundamental role inner temporality plays at the very core of the phenomenological project. And if, for the purpose of the rigorous description of the structures of constitution, Husserl proceeds to "leave out of account the enigma of timeconsciousness" (Hua 3, 163/193-194), he is at the same time completely aware that the temporal transcendence inherent in the very essence of the ego and, accordingly, the ego's own alteration with respect to other egos, is the most fundamental one and is accessible only through an analysis of lived time itself:

[T]ime is a name for a completely delimited sphere of problems and one of exceptional difficulty. It will be shown that in order to avoid confusion our previous presentation has remained silent to a certain extent, and must of necessity remain silent about what first of all is alone visible in the phenomenological attitude and which, disregarding the new dimension, makes up a closed domain of investigation. The transcendentally "absolute" which we have brought about by the reductions is, in truth, not what is ultimate; it [...] has its primal source in what is ultimately and truly absolute. (Hua 3, 162/193) 
The ego's transcendence in immanence thus demarcates precisely that sphere of problems that can be addressed only by a phenomenology of the internal time-consciousness and a reconstruction of its transcendental source. And while Husserl notes that concerning this ultimate enigma his efforts "were brought to a conclusion in 1905" (Hua 3, 163/194f) as many of his later works show, time-consciousness and its radical transcendence remained his ultimate theme.

\section{The Silhouette of Immanent Time}

The initial question of the lectures On the Phenomenology of the Internal TimeConsciousness concerns the possibility of the perception of temporal objects. How are we conscious of the continuity between the present moment in the duration of a thing and the moments that have passed or are still to come? Husserl's answer is that our consciousness has the intentional capacity to transcend the immediate now-phase of perception by apprehending the contents that are no longer and not yet actual. Consciousness is thus an extended field, which always involves all three modes of streaming.

What is important to emphasize here is that the intentional apprehensions that run back and forth are in fact not distinct from the present perception. They are themselves parts of the extended continuous present of the consciousness of enduring objects. If, for example, I perceive a train approaching the platform at the station where I am waiting, my experience of the just passed position of the train is still present in the flow of my consciousness of its movement. Yet, while my intuition of the elapsed moment of the previous position of the train is present, I perceive that position itself as precisely past. This is the observation that allows Husserl to explain how we grasp the past as past and 
not as a present image. In the earlier analyses of time-consciousness Husserl uses the schema apprehension — apprehension-content (Auffassung-Auffassungsinhalt) originally developed in Logical Investigations to describe this relation. There this schema is essentially structured as a hylemorphic relation. Husserl conceives apprehension as the conscious act of grasping a certain experience. The various sensory data presented in the act are then the apprehension-content of the apprehension. In the same period, he calls the present perception of immediate past "fresh" or "primary memory" (Hua 10, 169/170-1). Applied to the field of internal time-consciousness, however, the schema apprehensionapprehension-content turns out to be inefficient for the elimination of the problem of the consciousness of time being itself of a temporal nature. Husserl attempts to address the issue by reworking Meinong's observation that "the duration of perception is not the perception of duration" (Hua 10, 64/66-72). If the temporal succession of sensory contents is apprehended in consciousness, then this apprehension itself must be in time. This would entail that the apprehension also involves a temporal content that requires another apprehension. Husserl realizes that this chain runs ad infinitum and that it proceeds precisely from the structure of the schema. The mode in which temporal objects are given in consciousness, that is the form of constitution on the third level in its tripartite structure cannot be accounted for through an act-synthesis of independently considered matter and form. Any approach based on abstract components ends up in an infinite regress. As long as apprehensions are conceived in an Aristotelian vein as matterforming intentions, the problem will persist.

The difficulty of infinite regress surfacing in the earlier lectures on timeconsciousness leads Husserl to abandon the apprehension - apprehension-content schema 
and to introduce a different model and terminology. He will call the original perceptional "now-point" primal impression (Urimpression) and the intentions toward past and future respectively, retention and protention. Primal impression taken in itself, Husserl underlines repeatedly, is an indication for an ideal moment. Without retention and protention it would have no perceptual extension and a constitutive function altogether:

The primal impression is what is absolutely unmodified, the primitive source for all further consciousness and being [...]. The moment of the primal impression in time is naturally nothing in its own right. Individuation is not something apart from what has individuation. The whole nowpoint, then, the content of the whole originary impression, undergoes the past-modification, and only by it have we exhausted the entire now-concept, insofar as it is relative and points to a "past", as "past" to the "now". (Hua 24, 268/265)

"In its own right," primal impression is consciousness in the original sense. Yet in terms of "real" (reel) immanent content it presents itself as always already modified. This is why Husserl will also define it as "ideal individuation." For the same reason he would call retention and protention "original modifications" (Hua 10, 300/311). It is precisely this "equiprimordiality" of the three temporal modes that forms the immanent temporal stream of experiences. Structured in this way, the stream also necessarily articulates and sustains the strict difference between the three modes. The articulation of the stream, according to Husserl, constitutes a constant and unalterable formal structure. This formal structure hinges on the double role of primal impression. The primal impression is both a ceaselessly generating source-point of the stream and a limit of conscious temporal experience. It is a source-point because through it enters every possible sensory stimulus and, in this way, it inaugurates the process of living-through extended experiences. It is a limit because it can never be grasped as such and its infinite shortness is registered only 
on the basis of an idealization similar to the mathematical abstraction of approximation.

As Klaus Held captures it:

$[T]$ he streaming present in the extension of the field of presence owes the full brightness of its co-floating core-phase to the ever-renewing primal impression, the unifying form of the "now." [...] Although, seen phenomenologically, there is no infinitely short momentperception, it cannot be dispensed with and remains as a limiting concept whose sense characterizes the self-fluxing limit of utmost consciousness. ${ }^{34}$

The key point with respect to this new model is that Husserl does no longer conceive the temporal appearance of transcendent objects as endlessly demanding ever-new apprehensions, apprehensions of previously enacted apprehensions. Instead, Husserl understands temporal appearance as a unified, original self-temporalizing stream of experiences. Since it does not separate its form from its content, this stream does not need a further, deeper, layer of intentionality or a hypostasis of an absolute consciousness that would end the regress. ${ }^{35}$ An intentional regard that is separate from its content would imply a temporal distance from what is intended and in the stream we do not have such intervals. Because they are moments inherent to the unity of the streaming experiences, retention and protention are in fact immediate presentations (Gegenwärtigungen) of temporal transcendence. This characteristic distinguishes them from memory and anticipation. The latter, Husserl tells us, are presentifications (re-presentations, Vergegenwärtigungen), which involve a separate intentional act and, as a consequence, constitute temporal objectivities.

We $[\ldots]$ have to distinguish the retentions and protentions from the recollections and expectations, which are not numbered among the phases constituting the immanent content but instead re-present [vergegenwärtigen] past or future immanent contents. (Ibid.) 
While retention and protention are immediately present in the temporal stream, memory (recollection) and anticipation (expectation) are precisely re-presentations. When a distant and long-sedimented past experience is reproduced through an active synthesis and is made present again we are not immediately immersed in the perception of the temporal unity of a "now" and a "just passed." Rather, by directing an intentional regard back to that past, we reconstruct the original experience in the present moment as a separate intentional object. This distinction allows us to say that there is a transcendence articulating temporal consciousness, which is not the transcendence of the world, but rather a transcendence proper to subjectivity. How exactly does this transcendence occur in the self-temporalizing primal consciousness?

After renouncing the apprehension-content schema, Husserl develops an analysis of the temporal structure of subjectivity that can be characterized as pre-noetic. In this analysis, he is concerned not so much with the constitution of enduring objects but with the modes in which immanent temporality is constituted as a stream of immanent contents. This stream demarcates a dimension transcendentally prior to the constitution of the intentional object, a pre-reflective synthesis of lived experiences understood as temporal unities. Put more systematically, while the apprehension-content model was designed to explain the constitution of temporal objects of experience (level 3 in the structure of consciousness discussed above), the pre-noetic analysis focuses on the temporal constitution of lived experiences themselves.

Time-consciousness is an "original temporal field," a continuum of original modifications in which the actual experience of primal impression merges with its modifications. In order for the immediate event of presentation to take place, retention 
must connect the experience of what has just "faded away" with the actual experience of what occurs "now." Thus, Husserl's basic argument about the structure of the stream is that the occurrence of primal impression is in fact concurrent with its intentional passage:

[W] hen the consciousness of the tone-now, the primal impression, passes over into retention, this retention itself is a now in turn, something actually existing. While it is actually present itself [...], it is retention of the tone that has been. A ray of meaning can be directed towards the now: towards the retention; but it can also be directed towards what is retentionally intended: towards the past tone. Every actually present now of consciousness, however, is subject to the law of modification. It changes into retention of retention and does so continuously. (Hua 10, 29/30-31)

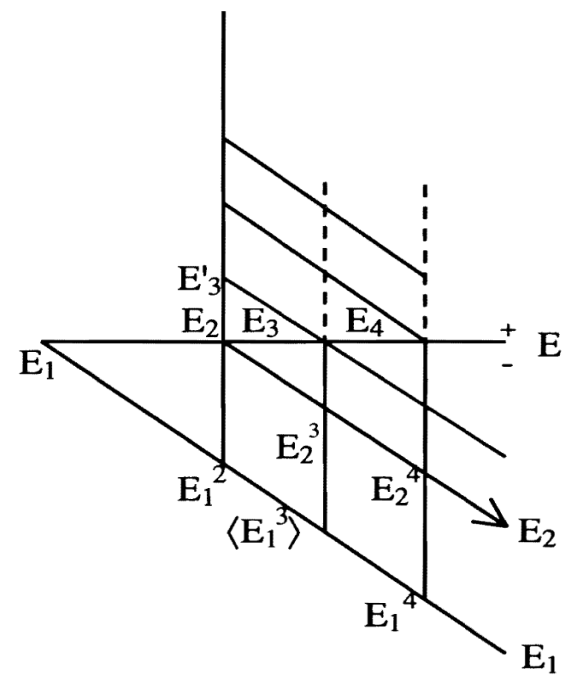

Fig.1 (Hua 33, 22)

As the original impression $\mathrm{E}_{1}$ in the diagram above ${ }^{36}$ elapses into the following original impression $E_{2}$, the retention $E_{1}^{2}$ of $E_{1}$ is itself actually present along with the newly emerged $\mathrm{E}_{2}$. In the current moment, therefore, we have a primal impressional experience $E_{2}$, a retention $E_{1}^{2}$ of $E_{1}$ seized in the intentional ray $E_{2}-E_{1}^{2}$, and a retentional intention $E_{1}^{2}-E_{1}$ hanging directly onto the expired impression $E_{1}$. The first thing then the diagram illustrates is how the streaming is not a simple succession of events in objective time. The connection between $\mathrm{E}_{1}$ and $\mathrm{E}_{2}$ is established not in terms of an external process 
presenting them in consecutive positions one after the other, but by virtue of the retention in consciousness actually working as part of a thicker present. Yet the diagram also shows how the stream is enabled by the configuration of transcendence within immanence. As an immanent content of consciousness, the impressional now-point would be impossible if it did not originally and necessarily imply the transcendence of falling behind and running ahead. While I constantly experience the immanence of primal impression, I am also constantly outside that presence. My consciousness is thus, by virtue of its primordial structure, always already transcended.

Although the function of protention is not symmetrical to that of retention, it is also an original modification of the present experiences and thus it is also a structural moment in the articulation of transcendence. $\mathrm{E}_{3}$ in the diagram above represents the protention to a future moment $\mathrm{E}_{3}$ in the current moment $\mathrm{E}_{2}$. While $\mathrm{E}_{3}$ exists in the "now" of consciousness and is intentionally grasped in $E_{2}-E_{3}{ }_{3}$, the vector $E_{3}{ }_{3}-E_{3}$ indicates the foreshadowing of the forthcoming $\mathrm{E}_{3}$ in the present $\mathrm{E}_{2}$. Without the immediate projection of my actual experience ahead towards what is to come - regardless of whether in this projection I am directed towards something particularly determined or my consciousness points emptily forward - the perception, which is at the bottom my extended temporal experience, would not be possible. My present consciousness is therefore at the same time an appresenting consciousness, an immediate transcending towards a dimension of "to come."

It is essential to recall that Husserl's account of time-consciousness presupposes a phenomenological reduction of objective time. We suspend the "empirical" thesis of objectively existent events, which is coexistent with the subjective temporal stream in 
order to be able to trace the "origin of time" back to its "material a priori" in the subjective stream (Hua 10,9/9). Thus when Husserl speaks of retention, protention and primal impression he does not refer to the empirically taken for granted concepts of past and future. He refers to the primal and abiding form that first makes time and the stream of consciousness possible. This form "supports the consciousness of constant change, which is a primal fact" (Hua 10,114/118). It remains invariable throughout the emerging and submerging lived experiences. Taken in its proper structure, this form is the invariant gestalt of the stream and thus remains inherently indeterminate:

In each primal phase that originally constitutes the immanent content we have retentions of the preceding phases and protentions of the coming phases of precisely this content, and these protentions are fulfilled just as long as this content endures. These

"determinate" retentions and protentions have an obscure horizon; in flowing away, they turn into indeterminate retentions and protentions related to the past and future course of the stream. It is through the indeterminate retentions and protentions that the actually present content is inserted into the unity of the stream. (Hua 10,84/89, emphasis mine)

We have demonstrated that the integral figure of retention, protention and primal impression sets up the apodictic standing form of transcendence that constitutes every immanent perceptual present regardless of its concrete content. Being precisely an apodictic form, the silhouette of inner time does not hinge on the concrete contents of affective life. It remains immutable as a standing living present.

\section{The Stream and the Flow}

The question that guided us in the previous section concerned the temporal constitution of the immanent stream of lived experiences. We arrived at the realization that what constitutes the unity of the stream is the shape of its own limits, the standing form of the 
time-modalities. This realization, however, leaves the question open of how these limits are set: whether there is an outlying dimension that provides their form or this form belongs to the immanent stream and maintains its differentiation from it as a standing invariant. If there is such a dimension, a further question arises: Is the flow an indiscrete and centered in itself continuity that belongs to the conscious live of the ego or is it an unconscious, pre-egoic and passive flow that can only be reconstructed by asking back from within the stream?

Husserl himself seems to remain undecided between the two main alternatives above. There is plenty of evidence in his work to support each of them. Here I try to defend the second one and propose that the temporal limit-form of subjective time can be conceived as a primal institution proceeding from a pre-affective (voraffektiv) flow of primal association. This pre-affective flow precedes phenomenal consciousness in a transcendental-genetic sense. While the relationship between the flow and the stream is one of affective awakening that unfolds the temporal modalities, the flow itself preserves its pre-conscious (vorbewusst) status as associative life. This particular hypothesis is not systematically developed in Husserl's corpus. Nonetheless, it acquires a compelling prominence in his latest works, mainly in the C-Manuscripts and-in a quite different context - in the Crisis. I advance it here not only because it conforms better with the critical tenet of his most mature thought, but above all, because I find it more cogent with respect to the explanation of the structure of the flow itself.

One aspect about which Husserl is consistent when analyzing the stream of experiences is that it is distinct from and yet constituted in the flow. He maintains this view regardless of his particular grasp of their relation. Why does he persist with this 
position while remaining unsettled about other important aspects? Besides the conspicuous results of the radical reduction, the reason lies in the very form of the temporal modalities.

In the diagram above (Fig. 1), the ordinate $\mathrm{E}_{1}{ }^{3}-\mathrm{E}_{3}$ indicates the tendency of retentional modifications $\mathrm{E}_{2}{ }^{3}$ and $\mathrm{E}_{1}{ }^{3}$ in the moment of impressional datum $\mathrm{E}_{3}$. Thus while $\mathrm{E}_{2}{ }^{3}$ is the retention of impression $\mathrm{E}_{2}, \mathrm{E}_{1}{ }^{3}$ is the retention of retention $\mathrm{E}_{1}{ }^{2}$, which is a retention of the original impression $E_{1}$. Now while the intentional vector $E_{1}{ }^{3}-E_{3}$ (or $E_{3}$ $E_{1}^{3}$ ) exemplifies the consciousness of immanent contents (here $\left.E_{3}\right), E_{1}^{2}-E_{1}^{3}$ illustrates the self-continuation (self-retention) of the stream within itself. Thus the entire experience of intention $E_{1}{ }^{2}-E_{2}$ merges horizontally into intention $E_{1}{ }^{3}-E_{2}{ }^{3}$. The stream persists on its own while retentions sink into deeper (darker) layers of consciousness. Moreover, by continuing itself in this way, it supports the succession of actual data along the abscisse $\mathrm{E}_{1}-\mathrm{E}_{2}-\mathrm{E}_{3}-\mathrm{E}_{4}$. This double structure outlines Husserl's theory of the double intentionality of retention, its so-called transverse (Quer-) and length intentionality (Längsintentionalität). According to this theory, the retention does not only retain the elapsed primal impression of the temporal object, for instance, the tone that had just resounded (transverse intentionality). It also retains the retention of the initial impressional moment (length intentionality), the immediate sense of the tone that just expired. In other words, time-consciousness does not only unify the temporal successions of enduring objects. By affecting itself along the stream of lived experiences it unfolds (retains) its own temporal phases and thus temporalizes itself. Husserl introduces the distinction as follows:

Every adumbration of consciousness of the species "retention" possesses a double intentionality: one serves for the constitution of the immanent object, of the tone; it is this 
intentionality that we call "primary memory" of the (just sensed) tone, or more precisely, just retention of the tone. The other intentionality is constitutive of the unity of this primary memory in the flux $[F l u \beta]$; namely retention, because it is a still-being-conscious, a consciousness that holds back-because it is precisely retention-is also retention of the elapsed retention [...]; it is continuous retention of the continuous preceding phase. (Hua $10,80 / 84-85$, translation modified)

The "one" and "unique" streaming constitutes the unity of its object and of itself. In other words, this one stream is at the same time objective and subjective, reified and animated, pertaining to the outer and to the inner attitude, hetero- and auto-affective.

Now the reason why Husserl abides by the distinction between the stream and the flow is rooted in this notion of double intentionality. To be sure, the former does not equal but rather leads the to the latter. The double structure of retention belongs to the “one, unique flux $[F l u \beta]$ of consciousness" (Ibid.) In it, we do not have a consciousness that is distinct from and constituted by a deeper layer. Through it "the flux of consciousness constitutes its own unity" (Ibid.). Sill, by singling out the horizontal dimension of intentionality, Husserl detects an internal, entirely continuous with itself and passing throughout the life of the subject stream, a stream that does not follow the structure of succession of objective events.

One trait of the flux, however, compels Husserl to look for a dimension beyond $\mathrm{it}^{37}$ : the retention that carries out the self-temporalization of the flux is itself an intentional act. While he has overcome the infinite regress proceeding from the apprehension-content schema and lived experiences are not any more conceived as internal objects, the problem would still reappear as long as the temporal unities within the flux constitute themselves through an internal length-intentionality. In order for a retention to be constituted, another retention would be required, which for its part would need a further retention, in a series 
continuing ad infinitum. Thus "[o]ne sees that if the standing flow had actual intentionality in itself as a flow, we would come to an infinite regress." (Hua 34, 180)

Husserl identifies two more specific reasons for this new kind of infinite regress: 1) the retention is a separate act distinct from what is retained in it and 2) the retention is not engendered by immanent data but proceeds rather from the activity of the ego. Husserl aims to overcome both these aspects by interpreting the process of selftemporalization in terms of the function of affection. By affection he understands "the allure [Reiz] given to consciousness, the peculiar pull that an object given to consciousness exercises on the ego" (Hua 11, 148/196). Importantly, affection does not necessarily derive from objects. "The most original affection is to be seen as the affection generated in the impressional present" (Hua 11, 149/197) and whether this present is affectively extended into an experience of an object depends on the specific configuration of the series of affections and on the activity of the ego motivated by it. Specifically in this sense, affection precedes intentionality. It is the very awakening of an intention as "a pull that is relaxed when the ego turns toward it attentively, and progresses from here, striving toward self-giving intuition" (Hua 11, 148/196). In order to avoid the moments of separation of the retentional act and the activity of the ego in self-temporalization, Husserl explains self-temporalization as self-affection. The latter is prior to the active response of the ego, a response which itself introduces a separate event in consciousness. Thus the stream of immanent experiences reveals itself as a pre-reflective, immediate, latent and passive continuity of affections. In the C-Manuscripts, Husserl explicitly discriminates between the affections which stimulate intentional constitution of objects and those which remain within the stream: "The affection [can be] noetic and noematic. 
The ego-acts and the functioning in them ego are always and necessarily affected. So [there is] the necessity of self-affection.” (Hua Mat 8, 260)

If, conforming to the explanation based on self-affection, we presume that the temporal stream, constitutes itself in a passive pre-intentional self-givenness and this selfconstitution is a necessary presupposition for the acts of the ego. The obvious inference from this presumption would be that by "living present" or "primal standing flow" Husserl means nothing else but the aspect of the lived experiences in which they are affectively given to themselves and that this affective self-givenness necessarily underlies and accompanies every intentional act. The flow, in this sense, remains constant throughout the acts of consciousness and, because of its constancy, it can be distinguished from them.

\section{In Self-Awareness and Alterity and several subsequent articles ${ }^{38}$ Dan Zahavi}

follows the same line of reasoning and claims that "the notion of "self-affection" is in fact appropriate as a description of pre-reflective self-awareness." ${ }^{39}$ Zahavi's argument is that "the pre-reflective self-awareness of the act and the non-objectifying selfmanifestation of the absolute flow are one and the same. ${ }^{40} \mathrm{He}$ openly disputes the view that there are two different kinds of self-awareness, one pertaining to the lived experiences and the other to a substratum of self-manifestation. Subsequently he clarifies this position by emphasizing that "to make this point is not to deny that there are good reasons for insisting upon the difference between our singular and transitory acts and the abiding dimension of experiencing, between die Erlebnisse and das Erleben." 41 The reason for this clarification is obvious. Our self-awareness accompanies all our intentional acts while it remains constant. I am aware of being the same subject of my 
experiences from yesterday as well as today. The living present hence stays "strictly singular" while the experiences are plural in their continual change.

However solid this argument might seem, I don't find it entirely plausible. My main suspicion comes from Zahavi's recourse to the notion of self-affection. Affections and actions in the fluctuating life of the ego are inseverable. Husserl, even abundantly, refers the ego as a pole of affections and actions. Affections and actions always emerge and function together in interplay (Zusammenspiel): the affection calls upon the ego to respond and turn attentively toward what is affecting it, to take a grasp of it and proceed in its intentional striving to further accomplishments. The reactive response is therefore nothing but an action. Let us quote Husserl on that:

Affection and action may not split so far apart. Is not affection a mere pre-modus of action, the modus of awakening of the action? The ego is awoken, "called" to act. a) The ego, which has acted and therefore has acquisitions, a persisting in it validity as a modification of the original actions, is awoken for reactivation. b) The ego apperceived. In it is awoken the potentiality to react, that is, to modify previous real action, but [by] a different modification, the one through apperceptive analogy. (Hua Mat 8, 350)

Accordingly, if we accept Zahavi's view, we would also have to picture the experiencing side in the stream of experiences as being constantly ceased and blocked, interrupted and punctured by emerging acts stimulated by inner retentive affections. The ego, actively responding to its own phases, would recurrently separate one retention from another. Instead of experiencing the enjoyable easeful warmth of the spring sun in the park, for example, I would have confusion-like instantaneous episodes of pleasure interrupted by by introspective grasps of my enjoyment giving way then to another portion of sun and momentary pleasure. The continuous flow of self-awareness underlying my experience would thus be impossible. There cannot be an indiscrete continuity of self-affections. 
Self-affections can only appear in a disjoined manner and what holds them together must be of different character and lie somewhere else.

Husserl himself timely arrived at a similar realization and, using his own analytical apparatus, familiarly, uncovered a possible infinite regress in the very notion of continuous self-affective stream:

That I have cold feet, now comes into my attention, but [in fact] this cold has lasted through a long stretch of time, it has repeatedly pressed forward and has been detected, and in between, it remained continuously undetected [...] but in this, it did not come to affection; for affective tendencies (the pull, the attraction to the ego to react in turning towards, I grasp as self-noticeable in the reflection, it is not a mere façon de parler) the question is if they necessarily belong to the background. But in this case would not the tendencies (as noticeable things) lead back to tendencies of a new level and with it yet the same again, and so on in infinitum? This remains a standing problem here. (Hua 33, 285, second emphasis mine)

Husserl sees in affection exclusively a "pre-modus" of action. And as such, affection cannot belong to the flowing living present. This, furthermore, means for him that affection is only a motivation for the ego to cast a reflective regard back on the flow, to thematize what has actually affected it, and not to be the immediate retentive reverberation that articulates it. In this sense, affection is not entirely pre-reflective. It is the very initiation of reflection. Then, after having discovered this, what alternative does Husserl explore?

Apparently, he has had the solution at hand lurking as early as in his lectures on passive synthesis where he describes affective tendencies that precede affection. Nevertheless, he actually turned his attention to it only in the C-Manuscricpts where he writes: "Egoic activity is preceded by passivity — egoic passivity — and both presuppose 
association and pre-consciousness [Vorbewusstsein] in the form of ultimate hyletic underground.” (Hua Mat 8, 53)

In the transcendental history the ego's becoming, this associative hyletic underground precedes the ego's affections and actions. With respect to it, the ego is not yet awoken and is indeed only the potentiality of its coming to consciousness. Therefore, self-affection does not the event that first bring the ego about. Prior to or in between the ego's reflective glances, in its pre-affective, non-operative states, the ego is passive and anonymous. It is a "sleeping ego" (Hua Mat 8, 98). What is significant in this notion of pre-affective life is that, for Husserl, acts and experiences are not original but “derivative" (abkünftig). They are derived from affection but do not strictly speaking originate in it: "what is thematized [as a response to affection] is straightforwardly derivative, namely, it derives from affection and this affection derives from the preaffective mode of the pre-"consciousness" of that what exerts the affection (Hua Mat 8, 190-191). The radicality of this insight can hardly be overstated. The associative hyletic substratum is distinct from and antecedent to the ego's lived experiences. It is what first awakens the ego for its conscious life and thus what institutes its immanent temporal form. This form is not a result of the self-manifestation of lived experiences but is instead derived from the pre-conscious and pre-temporal "primal associative fusions" [urassoziative Verschmelzungen, Hua Mat 8, 298] in the substratum. This realization already permits us to see how Husserl's question implies the answer:

Primally flowing and primally constituting non-ego $[N i c h t-I c h]$-is that the hyletic universum that has always been constituting and always already constituted, a temporalizing-temporal primal event (Urgeschehen), which is not from the sources of the ego, and thus "does permit ego involvement"? 
Yes, we can say that the associative hyletic substratum is in fact what Husserl called the primal flow.

\section{Conclusion}

Husserl begins a manuscript of 1932 called "Phenomenology of Communication Community" by asking: "How do I experience others when I accomplish empathy?" In a manner that would appear odd to those familiar with his account of intersubjectivity only from the Fifth Cartesian Meditation, he proceeds immediately to sketching out the general principles of experience: "experience can be experience in any interest, and so does the empathic experience" (Hua 15, 461). "Interest" here is taken in the context of his notion of affection, according to which the immediate response of the ego to an appeal exercised on it first announces itself as interest in what has emanated this appeal. Husserl then distinguishes two types of experience. One is thematic and comprises "[a]11 that belongs to the actualization of the interest" motivated by the affective call (Ibid). The other is non-thematic and involves the state in which the affective tendency doesn't reach the ego and, accordingly, the ego "experiences without this answering look and listening taking place, without making the transition to the interested activity occur" (Ibid.)

What I tried to present in this chapter was precisely the temporal basis for the nonthematic experience of the other, an experience that does not convert into an interested activity but remains implicit, abiding and flowing, and thus underies all affective and active interactions with other people. Once we have already assumed this background, Husserl assirts, any emerging appresentation "consists in a responding to and in the other person in a quasi with her life: [with] her experiencing, her thinking, her values, her 
actions in a presentifying appresentation, and this insofar as they are in each case particular [bestimmte]. I live "as it were" with." (Hua 15,462) Towards the end of the manuscript Husserl expands this insight and designates this relationship as das Ineinandersein and das In-Deckung-sein. These concepts of "being-in-one-another" and "being-layered-in" I had in mind when in the introduction to this dissertation I refered to Dr. Matsuo's case of silent recovery. On these concepts I hope to shed some light in the following chapters. 


\section{CHAPTER 2}

\section{Empathy, Intersubjectivity, and Intermonadic Communication}

The present chapter analyses Husserl's major theories of empathy and intersubjectivity in order to trace the various ways the concept of communication (Mitteilung,

Kommunikation) is embedded in them. Its purpose is to define the original characteristics and scope of this concept in view of its central function in his genetic phenomenology. In Husserl's later work, this concept appears as closely connected and often overlapping with the categories of empathy and intersubjectivity. I draw a clear distinction between these two categories and communication and explain its complex correlations with them.

Husserl's abundant and long-lasting reflections on intersubjectivity incorporate numerous expositions often branching out into diverse strains of thought and competing hypotheses. The scholarship, nonetheless, commonly adopts certain systematic divisions in terms of the stages, the methodological and thematic range of his work. Among those, the distinction between static, genetic and generative analyses has proven fairly productive both because it maintains the rigorous boundaries between the different constitutional domains and because, methodically explored, these domains turn out to

complement each other. ${ }^{42}$ While I navigate my exposition toward Husserl's genetic and 
generative accounts of communication, for the purpose of this chapter, I adopt the distinction between constituted and constituting intersubjectivity. ${ }^{43}$ This distinction, which in a certain way traverses the above one, would in my view provide a clearer guideline for the explanation of the key role of the notion of communication in Husserl's phenomenology.

Husserl's differentiated approach with respect to the constituted and the constituting intersubjectivity can be seen on two planes: 1) the constitutive theory of the "experience of the alien" (Fremderfahrung, cf., Hua 15,4) examines the modes of access to other subjects starting from the embodied direct face-to-face encounter. ${ }^{44} 2$ ) The theory of the intersubjective constitution of the "experience of the world" (Welterfahrung) analyzes this experience as involving "others not only as worldly objects, but constantly (in ontological co-validity) as co-subjects, as co-constituting, and both as intertwined." (Hua Mat 8,394 ) This intertwinement reveals a priori an open horizon of unknown others as always functionally implied in the constitution of objects.

This chapter does not aspire to provide a systematic presentation of either of these dimensions. Both are already well-known to the scholarship. Nor does it venture into a survey of the ample critical literature on them. I try instead to trace within both Fremderfahrung and Welterfahrung the developmental stages of the communicative relationship. With a main reference to Husserl's monadological account of the subject, I argue that intermonadic communication ${ }^{45}$ conceived in terms of mutual temporalization provides a key coordinative link between the embodied and the open intersubjectivity. Thus I attempt to show that communication has a validating function in Husserl's theory of intersubjectivity as a whole. Such an argument, I suggest, might supply a productive 
model for addressing some controversial issues in contemporary social cognition research such as the relationship between embodied interaction and "mindreading," and the structure of joint attention.

The majority of Husserl's reflections on intersubjectivity describe the communicative relationship as an intersubjective constitution of a higher order. Communicative performances define a distinct category of intersubjectivity, namely, social community (sozialen Gemeinschaft). They make up the original "social acts" in a process which Husserl calls "communalization" (Vergemeinschaftung). In this process are built the "objectively existent social communities of different levels" including what Husserl calls "personalities of a higher order" (Hua 1, 160/132; Hua 15, 19), collective unities bearing the characteristics of individual subjectivities. Nonetheless, in order for all these layers of communicative constitution to be accomplished, a basic grasp of other subjects must already be secured. In other words, communication presupposes empathy. How are the primary forms of communialization such as prelinguistic face-to-face interaction different from direct empathic experience? If empathy functions as an enabling condition for social acts, what are the specific constitutive elements that it provides to interpersonal communication?

\section{Reduction and Primal Institution}

Above all, Husserl's explication of social acts has a transcendental character in the same sense the analysis of empathy does. For this reason, it presupposes the same methodological steps. 
Within the natural attitude we usually communicate without fundamental problems. Even when we stumble upon major misunderstandings we still interpret ourselves as members of a community where we take for granted the intersubjective meaning horizons of the world with which the different strata of sociality are already established. For Husserl however, to found a theory of intersubjectivity on such a "selfgiven experience" (selbstgebende Erfahrung) would amount to "a bad nativism [and ...] a sensualistic inability to understand the truly phenomenological method of immanent analysis of the intentional structures of empathy" (Hua 14, 335).

Thus in the Fifth Cartesian Meditation Husserl delimits the transcendental ground of empathy as the sphere of ownness (Eigenheit). In order to gain a strictly phenomenological access to the "intentional structures of empathy," we have to return to the realm of our experience where they are given in their pure transcendental validity. For Husserl, this is to be accomplished through two distinct reduction procedures. The first one is that of the general phenomenological epoché. This reduction introduces the phenomenological attitude by suspending our belief in the existence of objects; it opens to reflection the sphere of conscious experience where the transcendence of objects and other subjects are given as its intentional correlates (cf. Hua 3, 102-110/108-117). However, Husserl's purpose is specifically to explicate "how I can constitute in myself another Ego" (Hua 1 154/126, emphasis mine). Therefore, the transcendental sense "another ego" cannot be found in the "straightforward consciousness" of the world, even though after the first reduction, others are already given as noematic correlates. This would amount to an explanatory circle where we presuppose exactly what we want to explain. In order to gain a primordial access to this sense therefore, we need to execute 
another, "peculiar" (eigentümlich) epoché. This epoché abstracts us precisely from the immediate "noematic-ontic mode of givenness" of others, that is, from a kind of naïve intersubjective intentionality. What is more, since any experience of the world entails others since it is a world that is "there for everyone," this reduction must also exclude all possible mediate intersubjective meaning and thus objectivity as a constitutional product. (Hua 1,153/124).

The primordially reduced sphere exists as concrete temporal unity. Husserl names this unity after Leibnitz's concept of monad. The monad is itself the self-temporalizing streaming life of the ego (Hua 15, 121, 355-356). It includes a manifold of sensory data, intentionalities and habitualities as well as the world constituted in it. As such it posits the experiential sense of one's own body. Thus it includes two strata of transcendence: the primordial transcendence which is immanent to the sphere of embodied experiences and the transcendence of the objective world. But how do monads constitute in themselves the sense "another monad"? Is there a transcendence of a third kind characterizing the mode of experience of the other?

The self-temporalization of the monad is a primal passive-synthetic process. In it, the ego becomes affected by primary sensory impulses, what Husserl calls primal hyle (Urhyle). Affective intentionalities are at the same time modifications of the sensory inputs exercising affective force on it. By intending its past hyletic experiences as past together with the present ones the ego appresents itself and thus sustains its unity and continuity. The senses of this kinaesthetic appresentation accompany all my movements and perceptions. They provide the implicit self-awareness that constitutes the "living present" (lebendige Gegenwart) or one's experience of one's living body. They also form 
individual proprioceptive habitualities, or what today we would call "embodied expertise." ${ }^{46}$ These are often latent and "unconscious."

To Husserl, the monadic self-appresentation of one's own bodily unity has the character of an original experience. Original experiences, be they of oneself or of objects, according to him, are events of "primal institution" (Urstiftung). In primal institution a certain (noematic) sense becomes initiated. Thus every time we have an experience of a similar kind the same sense becomes affectively awakened (cf. Hua 11, 172/221). Now, in empathy, it precisely such process that takes place:

You are associatively awakened by the appearance of the alien living-body-thing [Leibding]. That initially indicates my own originally given living body [Leib] and my co-connected psychic sphere [Seelisch], in my corresponding self-having and self-doing insofar as it is related to the appearance-regularity of my living body and is parallelized with it. (Hua 14, 164)

Whenever in the primordial sphere a physical body (Körper) of another subject presents itself, a kinaesthetic process of transfer of the sense "living body" ("animate organism," Leib) occurs, from the experience of my own body to the perceived other body. Put in psychological terms, we have a cross-modal transmission from proprioceptive to exteroceptive sensory perception. The transmission conveys the awareness of the "primally instituted" unity of my own body over to the transcendental object-unity that appears to be similar to it within my ownness. This transmission is a passive-associative accomplishment that is articulated in the inner temporal stream. It refers to our bodily capacity for automatic, fast, and unconscious responses ${ }^{47}$ in social encounters. The associative transmission is stimulated by the index of similarity between the primal experience of my own and the perception of the other's living body. The outcome of this 
process is what Husserl describes as pairing (Paarung): the appresentation of the other as co-present (mitgegenwärtig).

Various problems with this notoriously "Cartesian" account have been pointed out by numerous critics. ${ }^{48}$ The central one has been that Husserl unduly anchors the understanding of the other within the primordial sphere. My body cannot be a "motivational basis" (Hua 1, 140/111) for the experience of another's body. I experience my body in a fundamentally different way than those of others. More specifically, the association between the hyletic data of my living present and those of the other's body is unwarranted because a relation of similarity cannot obtain between the intentional modes of self-awareness and the awareness of perceived objects.

\section{Intersubjective Style}

Yet commentators typically fail to notice that Husserl himself - although not always consistently — addressed the issue of the other's unique mode of givenness (Hua 1, 143/113; Hua 15, 15-16). ${ }^{49}$ In the Fifth Mediation he asks: "what makes this living body another's, rather than a second living body of my own?" (Hua 1, 143/113) His answer is given in a strictly temporal-genetic context. The difference is drawn on the basis of the special "style of verification" (Bewährungsstil) carried out by the experience of the other. From the perspective of its style this experience is seen as developing through the emergence of series of "new appresentations that proceed in a synthetically harmonious fashion" (Hua 1, 144/114). The other manifests herself as someone else through the distinct character of dynamic concordance generated throughout her behaviour. This is the other's temporally unfolding unique style of alteration (style of othering, 
Änderungsstil, Hua 15, 87). It is this style that constitutes a "unitary transcending experience" (Hua 1, 144/114). Key to note here is that the apperception of the other is accomplished in dynamic terms and not on the basis of mere perception. This is a point of crucial importance since in numerous manuscripts succeeding the Fifth Meditation Husserl shows a genetically motivated tendency to construe the intersubjective relationship in developmental terms. The meaning of "behaviour" (Gebaren) however is clearly not to be taken in a behaviourist sense. The understanding of other people is not found simply on observations of their physical bodies (Körper) and their movements. Their behaviour opens a dynamic intentional horizon. The core of Husserl's insight is that this intentional horizon can never be presented in intuition. The other's subject's transcendence is necessarily unfulfillable. But what is given in intuition is this very unfulfillability. The accomplishment of such givenness is what precisely determines the style of experience of another living body. It secures the transcendence of the other by providing "accessibility of what is not originally accessible" (ibid.). The notion of style thus seems to acquire a central function in Husserl's account of intersubjectivity. This function is twofold: 1) it enables the "unity of similarity" that carries out the associative pairing on the level of dynamic of accomplishments which is based on expression and behaviour (Husserl's later work corroborates this); 2) it validates the difference between self-experience and experience of the other by providing a verification of her/its unverifiability. For the purpose of the present exposition, the second moment requires further explanation.

Obviously, the notion of style is key to Husserl's argument in the Fifth Meditation. This rather "operative concept" ${ }^{, 50}$ also marks a number of other, earlier and later, 
analyses. Broadly, it refers to the abiding character of a certain experience as it unfolds in time. ${ }^{51}$ Throughout a developing experience every intentional act can be confirmed or conflicted in various ways and degrees by subsequent, fulfilling (positive or negative), intentional acts. This happens in continuous synthetic processes that unfold across a manifold of intuitions retaining or altering the identity of the intended object. The dynamics, course, concordance, or discordance of intentional fulfillment define the object's style of experience (Erfahrungsstil). ${ }^{52}$ This meaning of the concept of style is closely related to the notion of primal institution. Primal institution, as mentioned above, concerns the original experience of an object. When I encounter an object of a certain type for the first time, its noematic sense is instituted. Once this sense is acquired, it has a validity that points to other possible experiences of objects with the same sense (of the same type). Each such new experience when it actually occurs would refer back to the primal institution of its sense (the original experience of an object of this type). Thus the style of a given experience is determined by the kind and degree of vivacity and fullness of such reference back to the primal institution. Importantly, this reference is not a conscious representation. It is a passive-synthetic process of associative awakening. ${ }^{53}$

Now, in the intentional appresentation of the other as someone else, the moment of association has an exceptional structure. This structure determines the distinct style of fulfillment in intersubjective experiences. To be sure, the associative awakening motivated by the presence of the other's body refers back not to the primal institution in an original experience of another's body but to my own kinaesthesis. My living body is itself the primal institution that engenders the sense "living body." The latter becomes valid for possible embodied experiences of others. What is passively awoken in each of 
those is the sense of my own kinaesthetic unity. In this precise sense, I associate the other body I experience with my own body on the basis their similarity in style (moment [1] above). We can call this notion of style kinaesthetic style emphasizing that the continuous fulfillments in both experiences involve a reference to the primal institution of the subject's proprioceptive and motor organization.

Along with the similarity, however, there is an irreducible difference between the two experiences. This difference is also a difference in style. Yet it announces itself not in the primally instituted sense (which in both cases derives from my somatic experience) but in the precise mode of reference back to it. Different kinds of associative awakening occur when I experience myself and when I experience the other. In the Fifth Meditation Husserl provides only a static description of this difference while the genetic explanation is only hinted at through the concept of style. ${ }^{54}$ Possible genetic lines of elaboration of the latter however may be discerned in his earlier lectures on passive synthesis and his later notes on intersubjectivity.

In the Fifth Meditation Husserl writes that the appresentation of the other subjectivity is a "mediate intentionality." It consists in a necessarily non-originary making-present (Vergegenwärtigung) of the other's subjectivity. Importantly however, this "non-originary making-present can do it only in combination with an originary presentation (Gegenwärtigung)" (Hua 1, 139/109). What we have here is a specific kind of combination (Verflechtung) of mediate and immediate syntheses. It is the same kind of combination that we find in Husserl's discussion of the relationship between immediate and mediate associative awakening in the lectures on Passive Synthesis: 
If an $a$ that is given to consciousness reminds us of a $b$, then the associative awakening is either immediate or mediate, and immediate and mediate associations are always intertwined (verflochten) with one another, even if it is only the mediate one that is able to obtrude for itself upon us. For example, in a conversation we are having, a thought is expressed that reminds us of a friend. The thought belongs to the unity of the present conversation: the conversation reminds us immediately of a previous conversation with the friend in which the same thought was expressed. The association between $a$ and $b$, thought and friend, is a mediate one. What is immediately connected is $a$ with $a^{\prime}$ and $a^{\prime}$ with $b$, i.e., the immediate awakening goes from something that is identical, uniform, or especially similar to something that is similar to it: that is, the bridging member, we say, connects the present consciousness with the previous one. (Hua 11, 284/419-419)

In the case of embodied intersubjectivity, obviously, $\boldsymbol{a}$ is the direct perception of the other. However, while it is clear by inference that $\boldsymbol{a}^{\prime}$ must be the kinaesthetic selfawareness of the experiencing subject, and $\boldsymbol{b}$ the appresentation (apperception) of the other, what remains puzzling is how exactly $\boldsymbol{a}^{\prime}$ plays its mediating role and how $\boldsymbol{b}$ is accomplished through it. The answer we find in some of Husserl's final remarks on intersubjectivity. As I will give those their deserved attention in a subsequent chapter, it would suffice here to indicate the functioning of two constitutive components: what Husserl terms zero-kinaesthesis and reconstruction.

When another person's behavioural styles associatively awaken my sense of my own behaviour what is it that becomes motivated? Clearly, I do not get confused to presume that it is I who behaves right now over there in this or that way. Nor do I automatically repeat or simulate the actions or recreate the circumstances of the other. Properly speaking, my kinaesthetic system is not motivated for any intentional or active processes. Rather, the influence is applied to its latent pre-intentional level which, nonetheless, according to Husserl, "is not nothing." This kinaesthetic level is 
characterized by "nil vivacity" in the gradation of intentionality and consciousness and for this reason is what in the proper phenomenological sense should be called "unconscious." Now, Husserl doesn't use the expression "zero-kinaesthesis" (Nullkinästhesie) very often. ${ }^{55}$ But it seems to be most relevant to grasping the mode of reference to the primally instituted body of the experiencing subject within the intersubjective relationship. The zero-kinaesthesis is precisely the mediating $\boldsymbol{a}^{\prime}$ in the appresentation of the alter ego. The following example Husserl gives in the 1935 manuscript "Das Kind" clearly illustrates this:

The child expresses noises involuntarily in involuntary kinaestheses, it produces repeatedly the same [noises] voluntarily, learns to repeat all its (generally used in community) noises willingly and produces them voluntarily. To these noises belong enabling kinaestheses. But the mother in turn expresses similar noises, initially, imitations of those of the child. The child hears them, has them, but without its associated kinaestheses, which [would be] associatively awakened, but are not; instead zero-kinaestheses arise from this [the mother's] production. (Hua 15, 606, emphasis mine)

Zero-kinaesthesis lies beneath all constitutional activities and accomplishments of the ego. It designates the living body's ultimate passivity. However, Husserl is instant that zero-kinaesthesis is "in no way nothing." It could be conceived as nothing "only with respect to affective force and therefore with respect to those accomplishments that presuppose precisely a positively valued affectivity (above the zero-point)" (Hua 11, 167/216). It is delimited in this way by a "zero-awakening" (Hua 11, 155/202) as the unities that initiate it come from outside the subject and for this reason the subject is conscious of them. Put somewhat in the language of the Fifth Meditation, I cannot access 
the other in its originality but this inaccessibility is itself evidently verified in and by my primordiality. The latter is understood here as the "unconscious" (Hua 11, 154/201).

Given that empathic experience stimulates unconscious affective processes, how do we proceed from this point to a conscious appresentation of another subject (from $\boldsymbol{a}^{\prime}$ to b)? This step undoubtedly bears upon what Husserl identifies as generative constitution. In the Fifth Meditation he indicates the deficiency of an account of such constitution and foresees the "tremendous labour of explication pertaining to the lower spheres" (Hua 1, 169/142). He only broaches the issue by presenting the apperception as a result of an intention in the mode of "as if" simultaneous with perceptual experience. The association in this case is based on the "style-form" analogy between the experiences of "here" and a kinaesthetically possible but not actual "there" (§ 54).

Despite these nuclear indications, it is only in his later elaborations that Husserl takes up a generative approach to the intersubjective analogical apperception. ${ }^{56}$ In those, he often suggests that the regressive questioning back (Rückfragen) of genetic phenomenology can be extended beneath the sphere of phenomenal constitution to a sphere that can only be (re)constructed. The latter inquiry would carry back to layers "prior" to the living present by following its modifications as pure possibilities of what cannot be presented in it. The minds of others would thus be grasped on the basis of what is experienceable precisely as non-experienceable. This liminal experience relates to generativity in its strict sense. From within the limits of the lived-through temporality it approaches whatever lies beyond itself in an articulation similar to the one through which we experience birth and death. The following passages dating from the early 1930's illustrate the course of Husserl's advancing into this problematic field. 
Every conceivable transcendental ego is conceivable for me, it is to be constructed from my actuality and my capacity [Vermöglichkeit]. (Hua 15, 383 n.)

But now the pauses in my own being, i.e. in what is experienceable in its self-hood, are properly constituted and constituting. Is the worldly whole, the entirety of possible experience-everything? The unconscious, the sedimented underground of consciousness, the dreamless sleep, the birth-Gestalt of subjectivity, that is to say, the problematic being of birth, death, and of the "after death." [...]

This whole sphere of being is one of reconstruction - namely of the patent going back to the latent, of inquiring into its modification. But there is reconstruction of such things as consciousness, which is in a way experience of an experiencing subjectivity that is not actively experienced, and which enables an actual communication and designation of being, and which is fundamental. This is the case with the psychic life of the primal child. (Hua 15, 608)

With this, the style of experience of the other described in the Fifth Meditation becomes analytically clearer. The sphere of the other's subjectivity is accessible in its inaccessibility as a temporally extended behaviour that motivates me in my passive kinaestheses which, for their part, motivate a phenomenological construction. As Husserl repeats in the lectures on passive synthesis, these three elements are intertwined and operate simultaneously.

\section{Reciprocity}

Most of Husserl's descriptions of the communicative relationship from the 1920's, including the brief related discussion in the Fifth Meditation, can be subsumed under two interconnected characteristics: reciprocity (Wechselseitigkeit) and overlaying (Deckung). The former is an enabling condition arising from but not essential to empathy. The latter is a constitutive element of the communicative process per se. 
The consideration of the notion of style was necessary in order to demonstrate how the pairing between the other's body and mine provides at the same time a constitutive difference between their two modes of appearance. The transcendence of the other is radically different from the transcendence within the ego's primordiality. But does this difference preclude reciprocity? If this is not the case, is reciprocity a necessary or possible feature of empathy and what is its genesis within the empathic relationship?

In its basic form, intersubjective experience affords a grasp of the other's embodied subjective states in face-to-face situations. Yet, the mere experience of the other as a living body does not necessarily entail the singularity of a particular other in a particular situation. Such singularity is accomplished exclusively in communicative contexts. It is quite different from the concreteness of the other's body as a living body. On Husserl's accounts from the 1920's, communication seems to be a subcategory of intersubjectivity. Empathy and communication are not two kinds of intersubjective settings. Every communicative situation presupposes empathy but not every empathic experience entails communication. In order for the empathic experience to be at the same time a communicative one, it must be reciprocal and situated in a concrete embodied framework. This condition would, furthermore, enable the mutual awareness of the communicators so that each of them attends to the other in a singular and situated manner. The subject necessarily expresses her communicative intention and the other person is necessarily aware of it regardless of whether she understands the particular communicative content. This is what stricto sensu constitutes the empathizer as an "I" and the empathized other as a "you." In other words, communication must involve what contemporary psychologists define as "social contingency." Social contingency delimits 
the communicative situation as an autonomous sphere of dynamic intersubjective coregulation that is itself accomplished through reciprocal awareness. Already in Ideas II Husserl noticed in these precise terms the constitutive connection and distinction between empathy and communication:

The acts of mutual relation (Wechselbeziehung) in society are [...] especially pre-eminent amid the acts of one-sided empathetic understanding of the life of the other Ego. It is not sufficient that the others are understood as persons and that the one who understands comports himself unilaterally toward the others [...]; mutuality of understanding (Einverstandnis) would not be needed for that. But this is precisely what is at stake here. Sociality is constituted by specifically social, communicative acts, acts in which the Ego turns to others and in which the Ego is conscious of these others as ones toward which it is turning... (Hua 4, 194/204; fist and second emphases are mine)

To be sure, reciprocity here does not imply symmetry. The communicative relationship is phenomenologically captured in terms of first and second person perspectives. It is the relationship between I and Thou (Hua 1 159/132; Hua 14, 171; Hua 15, 476).

Furthermore, Husserl follows the constitutive function of the abiding habitualities that are layered down through the I-Thou connection. He defines the accomplished thereby formation as the transcendental "we." The "we" is, according to him, a higher order individual unity whose correlate is the objective world (Hua 1, 137/108; Hua 15, 476).

In the majority of his discussions Husserl claims that the dynamic communicative space develops from the empathic experience. What are the specific mechanisms by virtue of which empathy enables communication? In the Fifth Meditation Husserl introduces communication in the context of his discussion of the communalization of monads and the correlated to it constitution of objectivity. The axis of this whole 
exposition is the living body of the other. The latter is the substratum for the constitution of both the "lowest level" of community and objective nature. Husserl highlights this core function by stating that “[ $\mathrm{t}]$ he other's animate bodily organism (fremden Leibkörper) [...] is the intrinsically first object, just as the other man is constitutionally the first man" (Hua $1,151 / 123)$. The other's body as constituted in the ego's primordial sphere implies from the very outset the correlation by virtue of which it is at the same time the body of someone else. Thus the other's body is co-perceived as identical for both ego and alter ego. This is possible because the appresentation that pertains to this body necessarily contains the component that the other ego is constitutive in this body (ibid.). The result is that the immanent content of an experience belonging to the primordial sphere is simultaneously transcended by the representation of another constituting subject. By extension, every natural object experienced in the primordial sphere "receives an appresentational stratum [...] united in an identifying synthesis with the stratum given to me" (Hua 1, 153/125). Still revolving around the common perception of the other's body, Husserl's next step is to show how the same identifying synthesis applies to the temporal stream of the living present itself:

[T] he coexistence of my ego and the other ego, of my whole concrete ego and his, my intentional life and his, my "realities" and his, in short, a common time-form is primally instituted; and thus every primordial temporality automatically acquires the significance of being merely an original mode of appearance of objective temporality to a particular subject. (Hua 1, 156/128)

The coordination between the concrete temporal streams of the egos, that is between the egos as monads, constitutes an intermonadic temporality. The latter belongs to the "first and lowest" level of intersubjective constitution. Communication proper, in the Fifth 
Meditation, emerges at a higher level: after an open community of monads is explicated as constitution "purely within me" as "constituted in every other monad" (Hua 1, $158 / 130)$. It is on this basis only, according to this text, that a communicative praxis becomes possible:

On the basis $[\ldots]$ of [intermonadic] community [...] it is easy to understand the possibility of acts of the Ego that reach into the other Ego [...], the possibility of specifically personal acts of the Ego that have the character of acts of mine directed to you, the character of social acts, by means of which all human personal communication is established. (Hua 1, 159/132)

Obviously, the advancement of the intersubjective world-constitution, starting from the perceptual core of the other's body and continuing through the primal institution of intermonadic time and community to a full-blown social world, requires a reciprocal relation. The body presented in my primordiality must at the same time bear equally the sense "someone else's living body." This however reveals an apparent ambiguity in Husserl's account. If we presume, as he establishes in Ideas II, that empathy is not constitutionally reciprocal, how can we account for the foundational role of reciprocity? If communalization and the constitution of objectivity presuppose reciprocity, then the original associative pairing must be mutual. Both Husserlian scholars and opponents to Husserl's tradition have addressed this ambiguity (Schutz, Theunissen, Waldensfels, Yamaguchi, Zahavi). I will show below how Husserl remains faithful to his account of Ideas II and introduces reciprocity only at the level communalization. This however will grant a certain privilege to the phylogenetic developmental dynamics of communicative praxis which will suggest a possible clarification of the ambiguity.

We can certainly identify a possibility of reciprocity lying within the pairing relationship. This however is by no means a necessary moment. Empathy, on Husserl's 
account, is not inherently two-sided. Husserl draws this modal distinction, albeit somewhat subtly, in the analysis of pairing in the Fifth Meditation. What is also noteworthy here is that the mutuality within pairing is genetically accomplished:

[W]e find essentially present here [in the associative pairing of passive synthesis] an intentional overreaching (Übergreifen), coming about genetically (and by essential necessity) as soon as the data that undergo pairing have become prominent and simultaneously (zugleich) intended; we find, more particularly, a living mutual selfawakening (wechselseitige Sich-wecken) and self-overlaying (Sich-überdecken) of each with the objective sense of the other. This overlayering (Deckung) can be total or partial; it has respectively its gradation, with the limit case of sameness (Gleichheit). As the result of this overlaying, there takes place in the paired data a mutual transfer of sense that is to say: an apperception of each according to the sense of the other... (Hua 1,142/113; emphases mine; translation modified)

The constitutional logic here is clearly that of passive synthesis. In terms of the genetic development of intersubjectivity it is crucial to observe how pairing is not conceived as reciprocal per se. It rather becomes reciprocal. Mutual awakening or bidirectional transfer of sense takes place only "as soon as" both fields of data acquire prominence and are intended in simultaneity. We know, however, from Husserl's analyses of passive association (not necessarily related to intersubjectivity) that pairing occurs not only in simultaneous dyadic prominence. It might as well take place in successive singular prominence. This distinction is definitively drawn in the Passive Synthesis lectures:

Syntheses, like those of coexistence in an original present and those of succession in an original sequence, in streaming. The synthesis of coexistence is not one that generates; it does not later form a connection out of an entity prior to the synthesis; it does not first have one entity and then another one that links it up to the first and through this generates a whole. The successive synthesis constitutes succession, but it links up impression and retention. We can say here that it essentially conceals what has just occurred (belonging 
to the previous Now) by the occurrence of the current entity, the previous Now is causally modified by the new Now. (Hua 11,397/494; emphases mine)

To be even more to the point, the relation of coexistence (simultaneity) is directly invoked in reference to the process of reciprocal transference:

Conditions of the possibility of intention and affection that are carried over [...] from something that is relatively most similar to something that is most similar to it, and together with the one-sided or mutual transference or awakening for consciousness have a connective force that links the special affections (Hua 11, 285/419-420; emphasis mine)

These passages apply directly to Husserl's introduction of reciprocity into intersubjective pairing. Hence primary intersubjective experiences can be either one-sided or reciprocal. The constitutive characteristic of the modality of reciprocity in it is: simultaneous dyadic prominence.

Prominence must be understood in the context of Husserl's account of affection. All hyletic data are experienced as stimuli that exercise an affective allure (Reiz) or calling (Rufen) upon the ego. Not all of them, however, come into relief in actual affection. Some remain non-thematic and lie dormant in the background. These are what Husserl describes as pre-affective contents. Those which actually affect the ego acquire conspicuity as the ego turns intentionally toward them. In reciprocal pairing I am affectively directed simultaneously to two phase-contents since both have affectively attracted the ego. If they exhibit a degree of similarity, they form a pair by each motivating the ego to attend to the other one.

Simultaneous dyadic prominence is neither sufficient nor necessary condition for the constitution intersubjective pairing. Similarity is. The association of similarity, 
Husserl underlines, takes place in an a priori fashion. It is not based on cohesiveness or contiguity within the stream of consciousness. ${ }^{57}$ In this sense, simultaneity and dual prominence only supplement a certain modality to the relationship of similarity. Importantly, as I hope to have shown in the previous section, the similarity motivating the intersubjective pairing is not a correlation between isolated hyletic phase-contents. It is a similarity between general styles of behaviour and expression. Yet, this doesn't change the structure of the relation of similarity. On the contrary, it validates it with respect to the irreducible difference between the experience of my body in proprioception and the other's body in exteroception. As Husserl's time manuscripts make clear, the retentional modifications, "primal presentation," and protentional modifications are indivisible and this determines the habitual styles of temporal experiences. ${ }^{58}$

\section{Overlaying}

While the moment of reciprocity is not constitutive of rudimentary intersubjective understanding, it is essential when it comes to communalization and the constitution of objectivity. As pointed out however, in Husserl's work of the 1920's, communalization (Vergemeinschaftung) can hardly amount to communication (Mitteilung, Kommunikation). The latter defines specifically the realm of the social. In terms of genetic gradation, "social acts" are phenomena of a higher order. They comprise the different modalities of connection between monads once the intersubjective constitution of the world has been accomplished. In this sense, Mitteilung presupposes Vergemeinschaftung. Despite this clear-cut stratification, there is a transcendentaldevelopmental link between the two. This link is articulated by the operation of 
overlaying (Deckung). Overlaying makes the transition between these constitutional stages possible.

Overlaying is one of the fundamental constructs of passive synthesis. The "unity of overlaying" (Deckungseinheit) designates the manner in which an empty (indeterminate) intention becomes fulfilled (determined) by an intuitive intention wherein the inherent concordance of a line of experience is accomplished (Hua 11, 6/43). In this sense, overlaying plays a key role in every experience of objects. In the context of intersubjectivity, this very same constitutional logic is employed, although in a distinctly modified way. What accounts for the possibility of experience in this case is not the egoic but the intersubjective constitution. Nonetheless, as Husserl's mature work reveals, the egoic constitution of the world transcendentally presupposes the intersubjective one which, for this very reason, is genetically uncovered at a later stage. Thus intersubjective overlaying is not derivative from but only analogous to the subjective one. Hence, from a transcendental-genetic perspective, the experience of the other as a mere physical body (Körper) is always secondary and grounded in intersubjective experience. The proper overlaying with the other is primarily intersubjective. And it has a significantly different constitution. What is its particular function?

First, intersubjective overlaying necessarily involves reciprocity and reciprocity requires simultaneous dyadic prominence. In order for overlaying to emerge, it does not suffice that I phenomenologically construct the sphere of the other's lived experiences. It would not be adequate even if her subsequent behavior and expressions harmoniously verify my initial appresentation. Let us say I am on a hiking trip and I notice unusual movements along the bushy cliffs across a river. The directed purposeful shape of the 
movements, their spherical range as if they embrace a center, their familiar rhythm, etc. make me immediately assume that this is another (human) living body. I follow the movements up the steam along the river when the riverside across opens into a lowgrassed ridge. I see then that this has been another hiker like me making her way through the bushes. My original appresentation is being continuously verified. Nonetheless, no intersubjective overlaying has occurred. With intersubjective overlaying, Husserl states, there "takes place an association at a higher level" (Hua 1, 147/118). ${ }^{59}$

Husserl often uses the analogy between temporal and intersubjective overlaying. In associative remembering the similarity between a present and a past experience awakens a memorial representation in an associative synthesis. By virtue of the established dynamic correlation the contents of the memorial and the perceptual intentions overlay each other: the awakened memory opens up new horizonal fields which begin to function as anticipations and in turn awaken further experiences; the new experiences once again remind of something in the past, and so on. A temporal overlaying of past and present experience, past and present self takes place. Importantly, memorial intentional acts and perceptual intentional acts remain qualitatively different. When I grasp a past experience I grasp nothing present. I intend the past precisely as past. This is defined by the characteristic of the act itself. Had it been otherwise, I wouldn't be able to distinguish the memorial from the present moments of perception (or imagination). Memorial representation (Vergegenwärtigung) and actual presentation (Gegenwärtigung) remain strictly separate.

In intersubjective overlaying we have a somewhat parallel structure. Having transferred the awakened in my primordial sphere sense of my Leibkörper over to the 
perceived Körper by virtue of their similarity, I have already appresented the other Körper as a Leibkörper. This condition enables a representation of a higher order: the same Körper given in my perception as another Leibkörper is simultaneously given to the other person as her "internal sense" (inneren Sinn) of her own Leiblichkeit. Thus her inward-outward perceptual field correlates with mine through my apperception of it. On the ground of this "co-indication" (Mitindizierung), along with the data originally part of my primordial sphere are given data with the index of belonging to someone else's primordial sphere. Thus my perceptual field and the perceptual field of the other overlay each other. Obviously, this overlaying resembles the temporal one where the aspect of remembering corresponds to the subject's corporeity and the one of anticipation, to the other's corporeity. However, Husserl does not remain with the mere analogy. He makes a clear distinction between the two. Unlike the temporal overlaying - he repeatedly points out - the intersubjective one is based on "compresent givennesses." (Hua 14, 530). He explains quite clearly the implications of this co-presence for the constitution of objectivity in a manuscript of 1921 :

The coexistence of a plurality of subjects implies initially "simultaneity," even if we know nothing yet of a common world: co-there-being with (Mitdasein mit) a subject, the being of the two is equivalent to the possibility of a "perception" that both perceive and then we have simultaneity and relationship to an objective world, a world in a presence, present in both subjects, and thereto the horizon of objective past and future. (Hua 14, 103)

My experience and that of the other occur and layer into each other simultaneously. And this is what makes the intersubjective overlaying experiences constitutive of a world. Needless to say, Husserl's point is not that the self's and the other's experiences become identical at this point. It is the very overlaying that generates identity and this is the 
identity of the object. The "functional community" among the experiences of different polar subjects of various aspects of the object (originally, the other's body) constitutes the world. What distinguishes the subjects themselves, according to Husserl's account of the 1920 's, is the different loci of intending. This is why Husserl terms this overlaying an "overlaying in distance" (Deckung in Distanz, Hua 14, 531) ${ }^{60}$ This account is based on kinaesthetic positionality and capacities for movement. By virtue of the given to the body potentialities in the form of "I can" and past experiences of movement, while I am "here" in my absolute presence, I can remember how I have found myself in other places and the orientational transformations of the system of perceptions this involves. Thus I can fantasize "as if" I am absolutely present over there where I perceive this other body and experience the surrounding world from the position of this other orientational center. However, since I occupy my actual "here" and simultaneously perceive this body over there and I cannot be "here" and "there" at the same time, to my imagined "as if I was there" is affixed the modifier "someone else." Thus the simultaneity itself in the phenomenon of intersubjective overlaying guarantees the absolute difference between the subjects involved.

Many scholars have found this spatially based constitution objectionable. Among them we can include Husserl himself whose pondering on "the paradox of subjectivity" in the Crisis (§54) clearly extends to spatiality and kinaesthetic potentiality in intersubjective overlaying. How is it possible, he asks there, that transcendental subjects accomplish a universal constitution of the world and are at the same time human beings as components within this world? From the transcendental-constitutive perspective of the reduced consciousness all anthropological and personal features are merely as 
phenomena, i.e. as constitutive products. (Hua 6, 185/183) More specifically, in order for the embodied overlaying between different subjects to take place on the basis of the herethere correlation, the constitution of a common surrounding world must have already been brought about. The predecessor of this paradox we find in Fink's famous essay of 1933 "The Phenomenological Philosophy of Edmund Husserl and Contemporary Criticism," which Husserl endorses in his short preface ${ }^{61}$ There, in order to establish a common framework within which to answer certain non-phenomenological critiques of Husserl, ${ }^{62}$ Fink formulates the paradox strictly in terms of the problem of communication. If the meaning accessible within the transcendentally reduced sphere were to be communicated to others both in the sense of persons within the natural attitude and egos of other meditating philosophers, we would be faced with an unsolvable problem. In order to share the transcendental sense of constitution, the "phenomenologist" has to precisely step out of the transcendental sphere and address the "dogmatist" within the natural attitude since this attitude is the only "basis shared by both. ${ }^{\text {“63 }}$ Further, the phenomenologist has to resort to a common language and concepts available and conceded upon within the natural world. Finally, she has to employ a logic, through which to identify the two aspects of her subjectivity: herself (or more accurately, itself) as a meditating monad and herself as a human being in a common world. Fink concludes by solving none of the three moments of the paradox. Instead, he suggests further work that would make the adaptation of the paradox possible so that the transcendental sense becomes communicable. ${ }^{64}$ Thus the paradox of intersubjective overlaying entails directly the paradox of the possibility and the constitutional level of communication. This paradox, let us note, remains effective even if we presume that transcendental 
intersubjectivity at its primary level were completely validated. As Kozlowski notes in his insightfully critical work, if Husserl had to take recourse to the theme of communication at all, it was because he realized that the mere appresentation of "the existence of the other's stream of consciousness, does not create a mutual relationship between the monads $[\ldots]$ The monads may indeed mirror each other in empathy but they still remain 'silent'., ${ }^{65}$

We can describe the implications of this paradoxical situation by indicating three incompatible possibilities. 1) Either we abandon the transcendental attitude altogether and account for intersubjective overlaying as mundane community in a pregiven common world. In this case we would have to equate primary intersubjectivity with everyday communicative praxis. 2) Or, as Fink hints at one point, we try to "insert the reduction within the natural attitude in an "unmotivated" and "false" way" and then clarify it gradually using the already given space, time, and language. This would assign the phenomenologist the rather hermeneutic task of indefinitely interpreting herself. 3) Or we account for an intersubjective overlaying that is accomplished on a passive, pre-objective and thus concretely temporal level. Then we would have to demonstrate genetically, i.e. by a reconstructive questioning back, the developmental accomplishment of intersubjectivity starting from the unconscious, pre-egoic, purely streaming interaction of monads and showing every ego as possibly transcendental.

Three years after Fink published his essay, in the Crisis, Husserl—probably responding to his assistant's urging - attempted to point at a solution to the paradox. This solution clearly takes up the last possibility. ${ }^{66}$ Husserl does this in two main steps: a) he makes a "correction" to the (static) notion of the reduction and now presents it in 
connection to a regressive questioning back starting from the pregiven world of the natural attitude and moving to the "depths of the functioning" of the primal ego (Ur-Ich) and the very constitution of intersubjectivity in it. The natural attitude is thus seen not as "excluded" from consideration but rather as what provides us with a guiding thread for a genetic investigation of prior stages of constitution; b) he employs solely the temporal structure of the living present to point at the constitution of "another I" in its primordiality. Key to this step is that he interprets the elapsed and forthcoming phases of the flux, the immediate "past" and "future" as the "self-alienation" (Ent-Fremdung) of the "primal presence" (Urpräasenz, Hua 6, 187/185). This self-alienation seems to guarantee both the validity of the other in my temporal stream and my selfmundanization. But do not past and future, considered in this way, remain within the scope of the reduced consciousness? How does one differentiate between the otherness of "depresentation" and that of the object and the other subject?

One of the "immanent" critics to raise this problem precisely in the contexts of the paradox and its connection to communication is Alfred Schütz. After singling out central inconsistencies in Husserl's second-order constitutive analysis related to the paradox (the capacity of the here-there correlation, the appresentation of the other as a concrete monad, the constitution of objective nature, etc.), ${ }^{67}$ Schütz interrogates whether the institution of the world presupposes a we-relationship and if it is founded upon the possibility of communication. ${ }^{68}$ His almost immediate conclusion (drawing, to be sure, on Ideas II rather than the Fifth Meditation or later works) is that the common surrounding world and sociality cannot be accomplished through communication since "reciprocal 
understanding and communication already presuppose a community of knowledge, even a common surrounding world (and social relationships), and not the reverse."

Schütz then examines Husserl's presentation of the solution the paradox in the Crisis (§ 54) discovering in it "the core of the problem of transcendental intersubjectivity." Yet he demotes even this account pointing out that Husserl still allots the absolute singularity of the ego a privileged place in all constitution. ${ }^{69}$ Schütz concludes that communicative intersubjectivity cannot be constituted in the purely transcendental sphere "since all communication requires events in the natural world and [...] already presupposes intersubjectivity viz., the We-relationship.. ${ }^{, 70}$ Is this openly axiomatic statement correct? Is the natural attitude a necessary condition for the accomplishment of intersubjective overlaying and communication? Does the communicative "we-relationship" presuppose a constitution of intersubjectivity? Or is it possible that communication is accomplished in a genetic-temporal way, which is transcendentally prior to the constitution of objective nature and thus coincides with overlaying? Husserl's transcendental account of mundane communicative constitution might provide the key to answering these questions. 


\section{CHAPTER 3}

\section{The Emergence of the Generative Concept of Communication}

Absolute consciousness is not created, but it occurs with another absolute consciousness in communication, and indeed in conscious communication. Then it must be said, a certain communication is always present.

Husserl (1909) $)^{71}$

This chapter explores the emergence of the theory of "communication proper" in Husserl's transcendental phenomenology of intersubjectivity. It attempts to explicitly define its meaning and function in contradistinction with the notion of empathy and, in this way, to demonstrate its generative constitution. To this end, the chapter locates a number of ambiguities in Husserl's attempts to draw a clear differentiation between communication as a relationship constituted through conscious social acts and communication as a form of interaction based on instincts and drives.

The key argument advanced is that, when considered from the perspective of generative phenomenology, the concept of Mitteilung or Kommunikation becomes a central element to Husserl's social ontology. I claim that this concept has the capacity to cancel the opposition between social acts and instinctive intersubjectivity and thus to frame a non-deterministic teleological theory of sociality. When Husserl takes on a 
developmental account of intersubjectivity, the constitutive role of the concept of empathy begins to decline and gives way to the work of embodied communication. I support this argument through a systematic presentation of Husserl's working out of the constitutive connection between sociality and what he sums up as "drives and instincts" (Triebe und Instinkte, Hua 42, 93 ff.)

At the center of my examination are the two parts of the manuscript of 1920/1922 titled Gemeingeist. I also consider the second volume of Husserl's Ideen as well as texts from 1918 and 1919 published in Husserliana 13 and a number of relevant manuscripts from the mid-to-late 1920s, notably, the group of texts related to the second part of Husserl's lectures "Introduction to Phenomenology" of the winter semester of 1926/1927 (Husserliana 14). Various manuscripts from the mid- and late1930s are also consulted (Husserliana 15).

\section{Systematic Considerations}

The first part of Gemeingeist (Communal Spirit, Hua 14, 165-235) written in 1921-1922 constitutes Husserl's first systematic exposition of a theory of communication. ${ }^{72}$ To be sure, in Logical Investigations the notion of communication has already been notably discussed. This discussion, however, conceived of communication exclusively in terms of language. In it, the concept of communication was strictly derived from the grammatical forms of expression and indication (Ausdruck and Anzeige). ${ }^{73}$

With the later development of Husserl's theory of temporality and the idea of intermonadic temporalization, the concept of communication evolved significantly to include a number of prelinguistic elements related to intercorporeal communication. 
Nevertheless, partly because Gemeingeist I articulates some of Husserl's initial reflections on communication proper, it remains in many respects ambiguous.

Taking into account the rich theoretical context of Husserl's analyses of intersubjectivity by invoking a number of surrounding texts produced during the period 1920-1927, we can systematically reconstruct the emergence of the specific notion of Kommunikation (or occasionally, Mitteilung) and establish its relative place in the broader framework of Husserl's phenomenology of intersubjectivity. A major motivation for this task is the observation that when Husserl uses the concept of communication, he does not always refer to processes occurring as social acts. Often, he would also imply the non-explicit operation of behaviours determined by instincts and drives. Such an observation seems to overturn the predominant, though itself still undeveloped, scholarly view of Husserl's notion of communication. According to this view, communication belongs to the higher level of intersubjective constitution, which Husserl calls "communalization" (Vergemeinschaftung). This is a stage, which succeeds the primary grasp of others, and at which the constitution of the social world is accomplished. Considered on this level of Husserl's social ontology, communication would necessarily have to presuppose the empathic relationship. ${ }^{74}$

However, a strong alternative to this view emerges as soon as we take into account the thematic and methodological complexity of Husserl's approach. Social communication seems to require empathy for the constitution of sociality only when it is laid out in the framework of the static analysis of intersubjectivity. The purpose of the static analysis is to explicate the intentional structures that provide the transcendental subjective foundation for the validity of intersubjectivity. Yet in the early 1920s', as a 
result of his deepened studies of temporality and passive syntheses ${ }^{75}$ as well as of the development of the problematic of embodiment, Husserl became interested in the genetic constitution of intersubjectivity. He began to outline a method for the reconstruction of the concrete temporal becoming (or "primal institution," Urstiftung) of empathetic appresentations and the generated through their accumulation, systems of habitualities.

Considered in this context, the one-sided relation of foundation obtaining between empathy and communication in static phenomenology gives way to the "reciprocal" relations of genesis and generation. What is generated in the horizon of primal institution and the accumulated habitualities reveals itself as what in turn modifies, reshapes, and generates these habitualities themselves. Thus empathy and communication appear to be in a correlation of mutual foundation. This brings to the fore the possibility of a nonfoundational account of communication. ${ }^{76}$

The static-genetic branching out of Husserl's investigations leads to a considerable ambiguity deeply embedded in his accounts of intersubjectivity and sociality, ambiguity that probably persisted until his latest writings. One of the grounding assumptions of the present work is that this ambiguity can not only be located but also resolved when the notion of communication is taken as its fulcrum. It is precisely for this purpose that we need an account of the emergence of this concept within the development of Husserl's phenomenology of intersubjectivity. 


\section{Negative Definition of Communicative Acts}

The focus of Husserl's discussion in the first part of the Gemeingeist manuscript is social acts as performances of the active ego constituting concrete interpersonal unities. ${ }^{77}$ The fundamental social acts are the communicative acts (mitteilenden Akte). The latter constitute social realities.

Husserl introduces communicative acts by distinguishing them from instinctive behaviour. Communicative acts are not constitutive products of "drive-intentionality" (Triebintentionalität). ${ }^{78}$ They are the necessary accomplishments of "communicating stivings" (kommunizierende Streben). They are carried out not by "instinctual subjects" (triebhafte Subjekte) but by “communal subjects” (Gemeinschaftssubjekte).

It is remarkable, however, that from the very outset of this important text Husserl implicitly uses this distinction not to differentiate the egoic ${ }^{79}$ from the communal, the non-social from the social realms, but to separate two kinds of intersubjective relationship. He distinguishes here a relationship that is "prior" to empathy and one that comes "after" empathy. What does this puzzling duality amount to? Husserl clearly demarcates two kinds of social relationship each emerging accordingly "before and after empathy" (vor und nach der Einfühlung). The former he identifies as "instinctual" (triebhafte), the later as "conscious" (bewusst). The first is categorized as "primally social" (ursoziale), the second as "properly social" (eigentlich soziale).

While this way of stratifying sociality remains ambiguous throughout both parts of the Gemeingeist manuscript, what is clear is that "before and after" do not designate positions in the factual sequence of objective time. They are rather different stages or 
moments of communal lived experience. In a certain way, we already experience other subjects "before empathy." According to Husserl, however, such experiences are not authentic (eigentlich) communicative experiences. When, for example, the young child is impulsively motivated to imitate the caregiver or when an adult is urged to help a child we do not have authentic social acts. ${ }^{80}$ The parental love and especially the mother-child love, familial relationships, "instinctual care" (triebhafte Fürsorge), and sexual love $(\text { Geschlechtsliebe })^{81}$ are all instances of instinctive relationship and do not constitute communicative interactions. In them, we do not stricto sensu experience co-pleasure (Mitfreude) or co-pain (Mitleid) with others. We are not pleased or displeased by something together with them. Instead, we are entirely determined by others and feel "pleasure because they are pleased, sadness [because] they are sad" (Hua 14, 166, my emphasis). Since we take upon ourselves their lived experiences and do not actually coordinate ours with them, we do not perform authentic social acts. Quite conceivably, the inverse motivation does not lead us to authentic social acts either: when I love someone, my acts proceed from my own interest, that of nourishing her pleasure and happiness. When I hate someone, my acts derive from my interest in "harming" and "annihilating" the other. Even when I act on the ground of "reason" by taking the liberty of contemplating on my drives, I still do not perform communicative acts. I am still blindly motivated by spontaneous interests, which are instinctual and rational at the same time. Regardless of their particular source, the acts that have a pre-empathic motivation "are not social acts and not acts of authentic social love [or other motivation]" (ibid.). Authentic communication involves a conscious "consideration of other subjects as targets of the action [and] as subjects who could do us 'good' or 'harm"' (ibid.). Therefore, 
it necessarily presupposes empathy. Empathy is required because through it one recognizes the other as a living body and as a subject of that body and its surrounding world. This implies a consciousness of what Husserl calls the "I can," the capacity to comport to this surrounding world and to interact with it, to be determined and determine. In communicative acts we are necessarily involved as self-conscious subjects acting upon others in order to determine them to do or understand this or that. In instinctual behaviour this explicit purposive turning to the other is missing. The other is not consciously addressed and apprehended. In this kind of social relations I merely "simulate a subject" (fingieren wir ein Subjekt). But what do the communicative acts properly consist in?

\section{Positive Definition of Communicative Acts}

Social acts, Husserl tells us, involve 1) doing something with the specific intention that the other person takes note of it and an expression of this very intention as well as an expectation that she behaves "so and so" in response; 2) the other person's understanding of my act as so intended; the addressee must be able to grasp my intention as specifically communicative and addressed specifically to her as well as to comprehend my expectations of a certain response.

A communicative social act is thus for Husserl not given if I am not conscious of my particularly communicative intention. Nor does it take place if I therefore omit to bring my intention to expression so the other takes it into account and acts.

It is important to point out that, for Husserl, this structure is not necessarily a linguistic one. It rather originates in preverbal interaction: visual, haptic, auditory, and kinaesthetic. Most of his examples testify to this origin: he speaks of different facial 
expressions and different kinds of touch; he describes how his friend silently throws a piece of wood in the fireplace in sign of understanding, he often refers to the way gypsies lay crossed branches on crossroads to let their fellows know which path to take; and he mentions how his wife leaves an apple on his hat in the morning so he does not forget to eat before he leaves. The examples do not necessarily need to involve a physical copresence to convince us that, for Husserl, the primary form of communication is the faceto-face interaction. The structure, upon which all types of communication are modeled, involves embodied interactants, which perceive each other, can touch or hear each other and look each other in the eye. Therefore, primary communication necessarily involves a concrete other, aware of and present in front of me. This structure is instituted, according to Husserl, in the original connection between I and You (the I-Thou relationship, die Ich-Du-Beziehung):

[An] immediate communication, or better touch (Berührung), original connection between I and You taking shape in the originally experienced empathy: we have the original experience of the standing-over-against-one-another (Einander-gegenüberstehen), and I "say" something to her, I "express myself," I perform an expressive movement or a phonetic expression or make an externally obvious, noticeable move or gesture suitable to awaken in the other the consciousness that I intend to express something to her... (Hua 14, 167, my emphasis in italics)

Obviously, not only speech but the whole multimodal array of sensorimotor competences is fit to draw the attention of the other and motivate her to interpret my embodied behaviour as means to address her and direct her interest to a particular (physical or ideal) object. The latter becomes the object of the I-Thou-intentionality. As an embodied interaction in "standing-over-against-each-other" (Einander-gegenüberstehen), the I- 
Thou-relationship provides the constitutive form of every communication. What exactly are the elements of this form?

Communication requires 1) "touching" (Berührung), that is to say, a mutual perception and a common presence; and 2) "turning" (Wendung), an actually performed address and sharing a fact that affects the addressee and requests a response. In order for an interaction to qualify as communicative, the very intention to communicate must first be communicated. This intention, for its part, must be grasped by the other. Touching and turning define, in this way, the formal structure of the communicative act.

Communicative acts also involve a determination of what is intended, expressed, and expected. This determination is displayed in formulations such as "this is so and so" and "you shall do" (ibid.). It is the communicated fact (Tatsache), about which the other is "called" to take note and respond. This is the indication of the content of the communicative act.

"A certain hand and finger movement, throwing a piece of wood in a particular direction etc. attracts the attention and interest of the addressee to the object of my own interest" (ibid.). As a result, we begin to intend the same thing together.

The "primary other" accomplished through and defining this formal structure is the concrete embodied other. My addressee is not merely "the Other" in general. She is a "you." She is present "within the framework of reciprocally and simultaneously completed [wechselseitig und gleichzeitig vollzogenen ...] 'touch"' (Hua 14, 168). Only in this framework can the two of us share a concrete context and can I indicate the particular content of my communicative acts. Grammatical form can reflect this structure only through context-dependent pronouns ("I" and "You"). We recall here Husserl's 
distinction from the second volume of Logical Investigations between subjective and objective expressions (19/2 553). The meaning of subjective (indexical) expressions is entirely contingent on singular contexts of embodiment and embededdness: temporal, spatial, social, cultural, etc. Unlike objective expressions such as the mathematical ones, the sense of subjective expressions can never be fully grasped outside of this situatedness. The same applies to the indexicals "this," "that," "here," "there," "up," "down," etc. Thus, one can satisfy ad fundum the formal requirements for a communicative act only in a face-to-face situation. Only then can I motivate this singular other to grasp exactly "this" particular object or meaning, or to perform exactly "this" action. Only then can we achieve joint attention and action.

Given this unequivocal prioritization of embodied interaction, one may find surprising Husserl's claim that the communication with absent others can also have an IThou structure. An absent addressee can also be "You" and also be "touched." This is, he points out, where Berührung must function also as a simile (Gleichnis)

Husserl makes use of the ambivalence of the German Berührung which, much like the English "touch," fluctuates between the meanings of "tactile sensation" and "distance communication." Berührung in its haptic sense, however, remains for him the original form of communicative encounter. When I am in contact with absent others I reach over a temporal distance. In the communicative act my present communicative will concerns a future understanding of the sense I have articulated in "materially lasting communicative expressions" (Hua 14, 168). The same applies to my grasp of senses articulated in past expressions. Of course, in all these cases, "I" and "You" do not literally "touch" each other. They are separated by a "stretch of time." The subject of the 
communicative act, however, preserves her will and her appresentations by an institution (Stiftung) of a sense that becomes part of intersubjective sedimentary habitualities. In the latter, the appresented ideal meaning acquires a signifying function outside the individual living present. Such a function, of course, includes all forms of written word but also various non-linguistic types of cultural production such as artifacts of everyday life, architecture, lasting works of visual art or music. Husserl says of those collectively that they become "spiritual hands" (geistige Hände), ${ }^{82}$ by which a present ego and an absent alter ego "touch" one another. "Even the dead and the living spiritually shake hands [...] in this communication understood as directed by a past living person and received by a present living person" (Hua 14, 169). ${ }^{83}$

Husserl's consistent analogies to embodied intersubjective contact here stand for the ontological prioritization of the face-to-face engagement. The communicative connection with absent others is grounded in direct perception and intercorporeal synchrony. But how, given that the subjects of communication in temporal distance (Mitteilung in zeitlicher Distanz) are diachronically separated by a "stretch of time" (Zeitstrecke), can embodied synchronization become a condition of possibility for their connection? This question, of course, is closely related to the essentially socialphenomenological problems of history, culture, and tradition. A manuscript from around 1925 gives us a more systematic clue as to the original constitution of intersubjective habitualization, which lies at the root of diachronic communication:

According to the confirmation of the pure monadic (phenomenological) experience (selfand other-experience) underlying the reality of being - as an evident, as a necessarily "undoubtful" certainty out of every monad, every monad for itself and in itself is by its being, related to the other. This grounding relationship of being in being-for-one-another is evident as a relationship of coexisting in an intersubjective time. This is not objective, but 
immanent-intersubjective time of coexisting according to all subjective time-modes, followed by identifiable stretches of time [Zeitstrecken] and time positionings [Zeitstellen]. This grounding relationship is the foundation for any other intersubjective relationship, for an intersubjective and purely spiritual [geistige] cau sality [...]. (Hua 14, 360) ${ }^{84}$

The condition of possibility for intersubjective connectedness over a stretch of time is transcendentally prior to and holds despite objective time. The relationship of coexistence between the communicating subjects takes place in a mode entirely different from a parallel duration of objects. It is rather grounded in the direct coordination between the distinct temporal streams of a multiplicity of monads and is accomplished in the passiveassociative intercorporeality of "touch" (Hua 14, 371). It is formed at a stage of experience genetically prior to the constitution of objects. This genetic priority is evident even in the most common experiences of touching another person. When I tap my friend on the shoulder, the affective power of touch immediately opens a purely immanent side of a reciprocal and simultaneous intermonadic experience. This experience cancels the subject-object correlation. My friend is no longer a "he" but becomes "you." We have commenced a "space" of an immanent intersubjective time.

Now, it is precisely this "spiritual causality" of intermonadic temporalization and not the natural causality of objects that provides the ground for the communication across periods of time. Central to the touch-structure of this diachronic connection are the intersubjectively oriented habitualities.

Once absorbed in the continuous retentions of the monad, the intersubjectively shared temporal experiences become part of the living present. And, if they are not further reawakened by new impressions and associative syntheses, they progressively lose affective vivacity and sink into the "dark horizon" of the subject's sedimented past. 
This decline of intuitive fullness deepens to a degree of vanishing from the range of awareness and is already registered only in a "limit-mode of consciousness." This is according to Husserl the phenomenological analog of "the so called "unconscious", (Hua 17, 280/319), the zero-point of consciousness, where past experiences are deposited and held in a vague "distant retention" (Hua 11, 288/422). Now, this capacity of consciousness to forget and nonetheless retain in distance its past intersubjective experiences in the form of habitualities is instrumental for the possibility of what Husserl metaphorically indicates as "spiritual touch." It constitutes the temporal horizon of consciousness as an immanently “de-presentifying" $\operatorname{limit}^{85}$ and an implicit reference to an intersubjective horizon. It is because of this intersubjective habitualization that Husserl is able to say that "the institution of personal associations must be considered in mediate ways in which the persons remain 'unknown"' (Hua 14, 182). In other words, in the habituality of every monad there exists a layer of anonymity, which necessarily refers to a principal absence. It is this absence that makes a communicative address to an absent addressee possible. Through it, in the very medium of communication structurally is implied "an indefinitely open multiplicity of others as if I am not just "personal" in my turning $[\ldots]$ to the other" (Hua 14, 214). What is more, even if I know well the absent person, my address is conditioned by this anonymous, indefinite and impersonal plurality of other subjects. This understanding of the communication with absent others clearly points to the emerging generative themes in Husserl. ${ }^{86}$ The implicit non-personal horizon in this type of communication does not only concern contemporaries who are not currently present or known to me but obviously extends to the possible renewal (reinstitution) of meanings prior to my birth or subsequent to my death. ${ }^{87}$ 
This problematic becomes all the more important as soon as we consider it in practical and axiological terms. The communicative relationship is a relationship of "practical will-community" (praktische Willensgemeinschaft). Its practical determinations are expressed by the aspects of motivation and possible action. The communication of my will in the form of request is a type of contact (touch, Berührung) that implies the intention to determine the addressee's volitions and actions to follow this intention. Husserl illustrates this practical aspect of communicative acts through the case of master-servant relationship. In the latter, a habituality is instituted as a foundation for an enduring personal relationship. The fully accomplished Willensgemeinschaft, however, requires that the fulfillments of the addressor's and the addressee's intentions are bound together. In other words, it requires reciprocity.

\section{Personal Intersubjective Becoming: Empathy, Communication, or Instinct}

It is of central importance for us to understand that, for Husserl, "person" designates the ego-subject in its concrete communicative constitution. There are no persons outside of the socio-communicative relationship. Personality is a self-consciousness acquired "within the enabled by communication striving community and community of will" (Strebensgemeinschaft und Willensgemeinschaft, Hua 14, 171). Thus, the ego as a person entails a full system of volitional intentionalities in the forms of practical and axiological communalities with other egos. The ego becomes a person exclusively in communication.

Yet Husserl's account remains somewhat obscure regarding the exact features of this process of becoming as well as regarding the specific characteristics of the person as product of communicative development. To understand the inherent moments within this 
becoming better it might help to heuristically consider the question of "who" the communicating ego is as a member of the developing community of will. "Who" is the subject of the communicative constitution? From the outset, we can distinguish three possible answers: 1) either is it a concrete other experienced as distinct from everyone else and grasped in its specific characteristics as this "you," uniquely standing over against me; 2) or it is primarily another living body like mine and an alter ego grasped on the basis of its similarity with my kinaesthetic self-experiences; 3 ) or it is yet a source of passive affective motivations stimulating an implicit instinctive intentionality whose correlate remains largely undisclosed.

To be sure, Husserl's explicit answer in the first part of the Gemeingeist manuscript leans toward the first option. He explains that it is only in the I-Thou relationship that the subject acquires full concreteness and gains in this way personal "self-consciousness" (Hua 14, 171).

But was not the alter ego within the empathic experience per se a fully temporal monad, individuated in its concrete actualizations and localizations? In his references to intermonadic communalization Husserl reveals that while in empathy the I itself is already inherent as a subject of its life and its surrounding world and the alien I is given as "the other I," these are only present as poles of affection and action (Hua 14, 172). The I is "fictitiously" grasped as a source of the temporal flux. As such, it itself remains constant and enduring throughout its striving in a manifold of modalities. For this reason, in the context of the above question the alter ego as it is given in the empathic experience turns out to be entirely deprived of qualities. From a genetic developmental point of view, it is no one. The alter ego in the empathic relationship is anonymous. 
What is more, we can say that, understood as a pure transcendental I, the empathized ego is immutable. It can neither be born nor can it die. Husserl often emphasizes that, conceived in a strictly reduced sense, the transcendental I is immortal. From a mundane point of view, at the same time, this merely empathizing subject is nothing but the functional subject-pole of empathy. Husserl is explicit that the transcendental immortality of the ego does by no means designate an infinite journey of a psyche. The transcendental ego's immortality is completely compatible with the death of the psychological and empirical world-ego, with "its corporeal decomposition, and [...] the fact that it cannot be found in the objective spatio-temporal world, its non-existence" (Hua $11,378 / 467) .^{88}$

But does not the ego of the I-Thou relationship require precisely this mortality? Must not "the ego of affections and actions" be itself in development? In order for it to be able to motivate and to be motivated by another, must it not be primarily grasped from the perspective of its birth and death, its concrete temporal phases, loci, and habitualities? And would not this entail a move back to the natural sphere of the mundane human subjects? Indeed - to answer the last question first — in a strictly genetic key, Husserl remains faithful to the transcendental approach. But he also affirms that it is the communicative relationship itself that brings about the developmental subject in the concreteness of its habitualities. How is this last statement compatible with the transcendental view of the immutability of the ego? Now the genetic method of inquiry allows Husserl to think development precisely from the perspective of its transcendental accomplishments. In this sense, it starts from the moment of empathy where the ego seems to be defined by the static form of its temporal flow but moves forth to a new stage 
which, while preserving the constituted sense "another ego like me," institutes the sense of a concrete human ego within a social setting as a practical subject of volitions and actions. In communication, therefore the transcendental ego becomes a transcendental person; empathy becomes an individual encounter, the immutable ego becomes a born, developing, and mortal individual. This is precisely why Husserl articulates it in the following way: "[t]he origin of personality lies in empathy and in the further arising social acts.” (Hua 14, 175).

We need to take into account however, that the subject as an ego-pole and the subject as a person are two irreducible concepts of transcendental subjectivity. They cannot be ordered in a foundational hierarchy. Through them Husserl grasps two incomparable dimensions of constitution and communication that can by no means be derived from empathy. But does not this indicate a deeper contrast between them? If we consider statements like the following one, we would have to answer in the positive: "It is not sufficient for personality that the subject itself is held as a pole of her acts, it [personality] is constituted only through the subject that occurs in social relationship with other subjects, and it is already practically objective" (Hua 14, 354). I can encounter the other as "you" only in an already presupposed genetic context. In this sense, it is not empathy that grounds the I-Thou relationship. The latter must have a different and parallel origin that goes back in the transcendentally genetic communicational history. Only if I and the other are in development can we encounter each other as these particular ones.

In the I-Thou relationship the transcendental monad does not simply constitute itself in the constancy of the form of its unity throughout the flow of its lived experiences. 
It is a monad that becomes individuated through the specific determinations of embodiment and the sedimented habitualities of concrete experiences. The monad acquires a specific style and character. It becomes a personal subject. But this does cannot occur prior to the mutual experience in the I-Thou connection. The mutual determination wherein the specifics of the particular egos are accomplished seems to have a "primally social" (ursoziale) history independent of empathy. Needless to say, we should understand this genetic dynamics in a strictly developmental sense. Husserl describes it as follows:

As a subject of motivation I now step into the primally-social I-Thourelationship; I am not only beside the other as other, but I motivate him, he motivates me; and in the distinguished proportion that constitutes the I-Thou relationship produced by social acts there lies a unity of striving or specific volition encompassing both subjects in advance, in which both are reciprocally oriented to each other in the actual consciousness of each other as striving subjects to "act" reciprocally, that is, to determine each other in a directedness of striving to each other to an action or to a suffering [from each other]. In this community, not only each strives, but each one is herself also objectively as a striver; she is not only given as such to herself, but is also given objectively. (Hua 14, 171)

Only in the mutual determination between "I" and "you" can the I become fully identified as this particular I with this particular history and individuality. One can be a personal I and be conscious of this fact only in a practical relation to a "you." This also entails a communicative process of "mundainzation.” By recognizing each other's communicative intentions, motivating each other, and fulfilling each other's claims, the communicators mutually thematize and summon themselves into a common interactive surrounding world. This results in a structure of joint intentionality which institutes the objective, worldly side of the interaction. Thus the possibility of conflict between my claim and the other's way of taking over it refers me back to myself as a practically 
objective communicating person. I become conscious of myself as an objective subject, a person, and a social agent. The human subject is a life and striving not only as selfpreservation of its world of things (Sachenwelt) but also, equiprimordially, a life and striving as a communicating person in a personal world (Personenwelt).

Despite the apparent ambiguity of Husserl's statements regarding the autonomy of communicative acts, it is clear that he retains a primal level of sociality. It is also obvious that this level is not based on conscious social acts but is constituted through "unconscious" 89 instincts and drives. Its precedence means a priority in the generation of the different social connections. In Gemeingeist I Husserl does not give us a clear indication about the structural differences between these connections. A manuscript he wrote approximately at the same time, however, addresses precisely the question of the "different possibilities and ways of combining monads through combining their ego-subjects" (Hua 14, 270). Here we see precisely the parallel genetic communicative history he bypasses in Gemeingeist. We have a passive and an active connection where the passive underlies the active one and constitutes an absolute intermonadic reality:

The absolute reality is thus not merely a bunch of piled up monads [...] but a single connection, a totality of monads, each of which in originary (perceptual) way only living its own life, but each in passive causal and active operating connection with the other, a unity of working-into- and becoming-in-one-another [Ineinanderhineinwirkens undgewirktwerdens], which as inherently first, has its common product as nature [...] as a fixed lawful nature and physical and biological [nature]. (Hua 14, 270-271)

And he explains this ultimate transcendental horizon in a passage whose phenomenological and metaphysical significance can hardly be overstated: 
This whole monadic process is under universal laws of genesis, particularly under essential laws, the elaboration of which is the biggest task of phenomenology. Every monad has - thought alone — its own immanent developmental laws, and the essential laws are here such for every monad in and of itself. But the commecium of monads as such also has its fundamental essential laws of genesis, and a conscious commercium, a social community (translated into an absolute, the monadic) its history and its essential law of hist ory. The task is here to show that monads are only compossible as monadic through being developmental laws and these in accordance with a uniquely determined whole, a whole of community development, in which each phase is marked out [...] (Hua 14, 271, last emphasis mine).

It is the process of "communal development" of monads unfolding from the fundamental essential laws of genesis onto the concrete phases of the specific intermonadic connections that constitutes the genesis of the I-Thou relationship described in Gemeingeist I. To the question of "who" regarding the subject of intersubjective becoming, therefore, we have to answer by subscribing to the first (the concrete experience of the other) and the third (passive-affective instinctual community) options in their developmental connection. The specific structure of this connection is still to be expounded. For this purpose, concrete phenomena like personal love might prove productive.

\section{Personal Love}

Love is a key element in Husserl's social ontology and it occupies a befitting place in the exposition of Gemeingeist. Husserl sketches out a phenomenology of love in which he discusses various modalities of love: personal love, "ethical love," "parental love" as well as related phenomena such as "community of enjoyment" (Gemeinschaft des Genusses), “care" (Fürsorge) and family. 
Among those, personal love plays a crucial role in the process of developmental achievement of the communicative relationship. The reason for this is that it appears to be akin to both social acts and instinctive behaviour. As such, it not only separates but also ties together drive-intentionality and social experiences. Without reconciling these two, it maintains their mutual irreducibility in a non-foundational relationship. Because of its extraordinary position however, the constitution of personal love remains highly ambivalent. This ambivalence proves so impassable for Husserl, that it puts in question the very definition of social acts. Does not personal love allude to the possibility that sociality might have two independent sources? How are we to understand the crucial position of personal love with respect to the possibility of such a dual origin? Does this position demonstrate a critical deficiency in Husserl's account? Or is it rather an indication of an important insight into a primal form of intersubjectivity, one that might bring together different approaches, stages, and classes of problems in Husserl's phenomenology of sociality?

Personal love is for Husserl a continuous disposition, a practical habitus, and a constantly actualized pursuit. We can distinguish two constitutive elements in it: individual style $(S t i l)^{90}$ and intersubjective in-one-another (Ineinander). Husserl gives us the following initial definitions of each of those respectively:

1) An active pleasure [favour, Gefallen] in the personal individuality of the beloved, in her whole attitude, in her passive and active behaviour into her surrounding world, in the expression of her individuality in the living body, in the spiritualized bodiliness in general.

2) A striving, not only for the greatest possible pleasure [Freude], but for a personal "touch" ["Berührung"] with her and for a community in life and striving, in her life in my life, namely, her striving is included in my striving, insofar as my striving, my willing is realized itself in hers and in her realizing activity, like her own in mine. (Hua 14, 172) 
As a "pleasure in the personal individuality of the beloved," personal love prioritizes precisely those experiences of another ego that distinguish its singularity in a concrete connection with my own subjectivity. Expressions like "I love the way you walk, the way you speak and how you look at me; I love your sense of humour and the tenderness in your voice" single out this kind of experiences as motivational bases for personal love. For this reason we can say that personal love is the epitome of the grasp of the "Thou" in the communicative relationship.

This moment of singularity is also articulated at the level of community itself. The community between the lovers is an autonomous unity. The lovers institute it as a striving community for all possible intentions of the two and not just for this or that particular common enterprise. This means that the community of love (Liebesgemeinschaft) is not primarily a community of knowledge or action towards a common environment. Rather, it is a sphere where "in a universal way all striving of one enters in the striving of the other $[\ldots]$ and vice versa" (Hua 14, 173). This allencompassing intentional community, Husserl remarks, is the "actualized touch (Berührung) of the lovers" (ibid.). The structure of the moment of touch is that of

\section{Ineinander:}

Lovers do not live next-to-one-another (nebeneinander) nor with-one-another (miteinander), but in-one-another (ineinander), actually and potentially. Thus they also bear in common all responsibilities; they are connected in solidarity (sie sind solidarisch verbunden), even in sin and guilt. (Hua 14, 174) $)^{91}$

It is obvious that neither the pleasure in the style of the beloved nor the intersubjective Ineinander involves empathy. Empathic appresentation attributes the sense "another ego" to the body of the other as an already constituted object similar to my past self- 
experiences. Nothing reminds of such an appresentation in the experiences of the individual style and the in-one-another of the lovers. Nevertheless, even after his initial definition of personal love Husserl still insists that "the origin of personality lies in empathy and in the further arising social acts" (Hua 14, 175). Does this mean that personal love somehow, in a broad generality, requires empathy insofar as, in order to be able to love at all, we need to recognize in the beloved "another living body like mine"? Well, Husserl's account of "sexual enjoyment" (Geschlechtsgenuss) as one of personal love's conditions undermines this alternative. In sexual enjoyment, according to Husserl, we have a fluctuating typification of normality and abnormality and it is not my kinaesthesia that set up the experiential criterion of a normal body. After having examined the constituents of personal love and upon introducing the notion of "ethical love" Husserl writes: "The question is [...] if this [personal] love is not a borderline case, and if the concept of personal love always makes a good sense. The described [personal] love is perhaps a sinful love or includes all sinful love in itself" (Hua 14, 174). While the reference here is clearly to "sexuality" the reprehensive tone has a rather contextual function. It is raised only as preparation for the ensuing discussion of "ethical love" as a constitutive element of "Christian community." What is essential to consider in view of the sexual moments in personal love is that it remains irreducible and resistant to the empathic stratum in the I-Thou. This irreconcilability determines the necessary privilege of personal love as a "borderline case" of love. Its marginality does not recede back to a prior or resolve forth into a higher form of social relationship. Personal love remains a contradiction that permeates Husserl's phenomenology of communication. But precisely because of its contradictory character, through it we can ask about the specific structure 
of the connection between the passive-affective community and the concrete construction of social reality. Is this connection itself established in terms of social will or does it also require instinctual strivings? Which one of them dominates the correlation? In Gemeingeist I, personal love remains a problem-laden concept. Its problematic position however seems to be rooted in the broader systematic distinction between static and genetic phenomenology, a distinction that Husserl does not always carry out consistently. We see the duality partly relaxed — though by no means resolved—when Husserl establishes the developmental connection between personal love and "ethical love." These two modes of love pertain respectively to two consecutive stages in the constitution of sociality: "Prior to the ethical lie the personal attitudes which are subject to ethical review, approval and disapproval.” (Hua 14, 175, my emphasis). This priority obviously holds not by virtue of a founding sense-structure of an already constituted ethical relationship. The ethical is rather an outcome of the intersubjective development of the personal. While the former comes out of the latter, it is also an intersubjective validation of what precedes it genetically. But the connection does not follow by a necessity. The genesis of the ethical love is not a matter of a natural determination. It is rather a possibility for self-definition that must be made a subject of a practical demand and a normative necessity. Both these are strictly social formations and would emerge only on the ground of social encounters. They are established as a consciousness of social communicative telos. Thus what is reviewed, approved or disapproved at the level of the ethical is the other person in the sense of an "ideal ego carrying an "infinite task"” (ideales Ich als "unendliche Aufgabe"). If in the loving relationship I come to respect the beloved in terms of her "vocation" (Beruf), my feeling for her acquires an ethical 
definition. But is such definition in place when the vocation is still dormant in "a seed (ein Keim) that is [yet] to unfold in a self-enacting way"? If the "good purpose" is not yet explicit, it becomes evident from Husserl's account, the vocation in the other person does not get automatically recognized and thus an ethical attitude does not ensue by necessity (Hua 14, 174). But this is a condition that expresses the crucial peculiarity of Husserl's genetic teleological framework: it is a specifically communicative framework that has nothing to do with natural necessity.

The link between personal love and sexual enjoyment is explored in a section where Husserl also examines particular phenomena such as care, parent-child relationship, and meal sharing. This link is as far from natural causation as possible. Husserl's main concern here is the distinction between the normality and abnormality of sexual pleasure. More importantly, he asks, "is this an original or a derivative distinction? Can a dimming scientific and aesthetic intention establish a hierarchy of values?” (Hua 14, 178) Although his answer is in favour of the axiological option, he doesn't consider the distinction to be an original one: I can proceed against the body I am taking pleasure in. I can evaluate it purely as an object of physical pleasure (e.g. I can kill someone for sensual pleasure). By virtue of the fact that the subject is also given here with the body, I can also take pleasure in the other's subjectivity and thus in the consideration of her pleasure as well. The intentional form of this "unity of enjoying community" is articulated as "with-one-another" (miteinander) and "through-one-another" (durcheinander), that is, the pleasure would be constituted through the mutuality of determination and the commonality of fulfillment. What is noteworthy here is the derivative structure of the valuation: it is not because I originally know what normal and 
abnormal enjoyments consist in that I accomplish an enjoyment unity with the other. My notion of normality might vary significantly from that of my partner. It is because I recognize the personal individuality of the beloved. Again, the constitution of the relationship is a social one. But what is it precisely that Husserl means by "personal individuality"? How is it given in the specific intentionality of pleasure within the sphere of my own subjectivity?

\section{Individual Style and Intersubjective Ineinander}

In his accounts of personal love in Gemeingeist I Husserl does not develop sufficiently the constitutive moments of individual style and in-one-another. These moments, however, appear to be essential for the presentation of the genetic-phenomenological structure of social acts and communicative behaviour in general.

In Ideen II Husserl devotes special attention to the modes of experiencing the particular character of another ego. There he distinguishes "individual" and "general type of understanding persons" (Hua 4, 270/282). The general comprehension of others reveals lived experiences and motivations in universal terms. We experience another "human subject" and another living body in general. When, for example, we observe how "this man is $[\ldots]$ reaching for a cup because he wants to drink, and he wants to drink because he is thirsty" (ibid.), our grasp has nothing to do with him as an individual person. It belongs to the type "universally human." The individual type, in contrast, highlights the style distinguishing the peculiar "affection and action, with regard to the way she has of being motivated by such and such circumstances." (Hua 4, 270/283). If, for instance, the man suddenly changes his mind and gives the cup to a thirsty child, this 
would manifest his "good heart." The gesture would thus pertain to his individual personal style (ibid.).

The distinction Husserl carries out in this manner is crucial for the present argument. At first sight, he seems to differentiate between empathy and communication simply in terms of the couple general/particular. In doing so, he also departs from the presumed founding-founded relationship between them.

When I empathize, I apprehend the other in terms of the universal typicality of her corporeality. The other is grasped as an analogon of my own embodied self-experience. This relation takes place on the basis of similarity in general style. The latter is determined by my own embodied living present as the primal institution (Urstiftung) for this general typicality. Thus every future particular encounter with another embodied subject invariably refers back to my original kinaesthetic sense.

The grasp of the other's personal style exhibits a radically different structure. In a rare vein of exaltation Husserl depicts it as an instance of illumination sparked by "glances, positions, or expressions; when we, so to say, 'gaze into an abyss'; when the 'soul' of the [other] person suddenly 'opens itself up'; when we 'fathom wondrous depths"' (Hua 4, 273/286). This astonishment in the face of the other has nothing to do with empathizing. It proceeds from the exclusive circumstance that the appresented sense "this individual person" does not derive from my own kinaesthetic experiences but is instead given in the concrete manifestation of the other's actual singular character. The mode in which this manifestation takes place Husserl calls "intuitive flair." "Intuitive flair," he remarks, "is a term which very often signifies just the opposite of intuition [Anschauung]" (Hua 4, 273/286). ${ }^{92}$ Strictly speaking, its constitution does not involve a 
presentation of sensuous contents. "Intuitive flair" is an "empty intention" that institutes a connection between multiple experiences of the person. It proceeds from an anticipation of an experiential concordance among these experiences, a concordance that hasn't yet been intuitively presented in a full intention.

The relationship of associative coupling in empathy is, by contrast, instituted by my own embodied experiences. The understanding of the other is in this sense founded on the general style of my ego's self-apperception. The grasp of the individual style of another person does not involve such an appeal back to my own body. What we have instead is a leap forth "prior to the explication, prior to the actual subsequent establishment of the nexuses [...], a presentiment, a pre-seeing without seeing, an obscure, specifically symbolic, often ungraspably empty, premonition” (ibid.). We grasp the singularity of another person not by transferring our pregiven and implicit knowledge onto her. Rather, we discern a previously unfamiliar sense and grasp it in an empty intention and anticipation of the possible goals, tendencies, and directions in her behaviour. "To see a man," Husserl writes, "does not mean to already know him. To see a man is $[\ldots]$ different from seeing a material thing. Each thing is of a certain kind. If one knows the kind, the rest can be dispensed with. A man, however, has an individual kind, and each man has a different one" (ibid., my emphasis).

What Husserl means by "intuitive flair" is then the experience of the other person in purely developmental terms. It is a flair for a concrete experiential unity with its temporalizations and localizations, history and habitualities. Thus through "intuitive flair":

$[\mathrm{w}] \mathrm{e}$ capture the development of a person if we reconstruct the course of his life and make it intuitive in such a way that the entirety of his development as a man becomes 
comprehensible in an experiential way, especially with regard to his manner of letting himself be motivated as a subject, together with all the definite actions and passions proper to him. (Hua 4, 272/385, my emphasis)

Thus the intentional structure of "intuitive flair" can be regarded as inverse to empathy. Although Husserl does not arrive at such a statement explicitly, he is close to it when he highlights the impressional (imprinting, prägend) way in which a grasp of an individual type is instituted:

I enter into relationships with various Ego-subjects and come to know the typical moments of their pregivennesses, of their actions, etc., and I apprehend the latter according to these types, but it is not as though I first had the types in abstracto [...]; instead, the type becomes pronounced and gets impressed [imprinted, prägt] on us in multiple experiences, and it determines an apperceptive form and then a layer in actual apprehension that can be abstracted out. (Hua 4, 273/285)

It is not the similarity within the genus of a style implied in my embodied self-awareness "in abstracto" that motivates my apprehension of another person's individuality. It is the difference articulated in the process of "impression" (Prägung) that institutes the other's peculiar character. This is what in everyday life we usually call "first impression."

Thus the Thou within the I-Thou relationship is to be understood as what Husserl calls an "absolute concretum." "W3 We may also recall his analyses of passive synthesis where he considers the concrete subjective time flow through the phenomena of "affection and association." There he shows that the formal structure of temporality cannot by itself account for the specific affective force exercised upon the ego. This force is contingent on the prominence, similarity, and contrast, through which the lived experiences become configured as concrete Gestalten. This is precisely the synthetic structure of intuitive flair. The concrete other determines the ego to turn to a singular 
experience. Concrete stimuli influence and awaken the ego. The formation of this force, as we can see from the following passage, is a process of experiential overlaying and affective communication:

If we inquire into how such awakening takes place, the answer will run: Just as within coexistence an intuition becomes unified with an intuition, and initially within primordially impressional coexistence, an impression becomes unified with an impression, becomes unified not only in a continuous local juxtaposition, but also through a synthesis of overlaying in distance that takes place essentially, and [...] overlaying and affective communicating (Deckung und affektives Kommunizieren) are inseparably bound together [...] (Hua 11, 175/224, my emphasis).

The expressions "overlaying" and "affective communication" apply in this context broadly to any embodied experience engendered by stimulation of latent habitualities. In the same broad context, Husserl speaks of the passing over into-each-other (ineinander) as overlaying (Deckung). (Hua 11, 13/49-50) But these constructs also compose the "lawful regularities" functioning behind Husserl's accounts of personal love and communincation. ${ }^{94}$

Broadly understood, for Husserl, Ineinander articulates a moment in the passivesynthetic progress of fulfillment in the experience of objects. Its intersubjective sense however, refers to a specific mode of constitutive interconnectedness among monads. Husserl spells out its major characteristic by comparing it with Aufeinander (onto-oneanother), which is a constitutive element of the inner-worldly interaction.

In the world people exercise on each other "spiritual influences" [aufeinander "geistige Einwirkungen"], they enter spiritual connections, they interact [wirken aufeinander] from ego to ego, and to do so, I must know the other and determine her, and, for my part, "conform to her." But we also act into-one-another [wirken ineinander], I take over the will of the other in my will; I am in service to her. What I do, I do not just on my behalf, but also on her behalf, her will takes effect in my acts. In shared pain, shared pleasure, I 
am not in pain just as I, but the other lives in my pain or vice versa, I'm immersed in the other and live in her life [...]. (Hua 14, 268-269)

What does the distinction between Aufeinander and Ineinander imply? Ineinander involves a direct intertwining of my primordial sphere and that of the other, an experience that constitutes an immediate interconnection without the use of a third element. Aufeinander presupposes a natural world through and in which the interaction takes place. In Ineinander the distinct monadic temporal streams are not mediated through an object. The other's living present becomes the real (reell) content of my lived experiences and vice versa. But how is an event of an intertwining between two egoic surrounding worlds possible outside of a pregiven common world wherein only can a subject express itself and another grasp the meaning of this expression? Husserl draws a distinction that allows him to address this question:

Every ego-subject has its own experiences, but in the intentionality of its experiences [...] it recognized the other, in its selfhood [...], and the effects that it exerts on the other and experiences from it, [...] are $\mathrm{direct}$; although they presuppose that one sees the body of the other outside, they highlight inwardness... (Hua 14, 270, emphasis italics mine).

Ineinander, therefore, articulates the temporal intertwining between the different streams of consciousness not in some external to the objective world dimension. It refers rather to the transcendental genetic accomplishment of experiential commonality. In this sense, it is definitively pre-empathic. Husserl separates the relationship of empathic coupling from that of "life- with-one-another and in-one-another" (Miteinander- und Ineinanderleben):

I can combine with I (you), I touching, overlaying in a peculiar way with a counter-I, the activity of one and the activity of the other not merely separate parallel actions [...]. But this unifiedness can be very different. The empathized Other may be left out of me and without unity with me, I merely see him and understand him, I can think with him and 
feel myself touching him, and taking position with him, but I can also live in him in a piece of my willful life, willing in him as subjected to me [...] (Hua 14, 269, my emphasis)

The mutual intermonadic determination, Husserl often reminds us, requires that monads have windows. And it is empathy that opens up these windows. But these windows are not "doors" through which another subject can actually enter. What passes through them are "past own experiences through recollection" (Hua 14, 260).

\section{The Primal "We” and Personal Unities of a Higher Order}

In the second part of the Gemeingeist manuscript Husserl deals with what he calls “personal unities of a higher order.” Personalities of a higher order refer to social formations as conceived by analogy to individual subjectivities or personalities. We can mention here interest groups, clubs, institutions, political parties, states, nations, languages, religion, art, humanity, etc. Such a person-analogy, however, is for Husserl not a figure of speech. It is a "real" analogy. For example, about humanity (Menschheit) Husserl states that we "can and must really consider [it] as 'a human being in general"" (kann wirklich, und muss als "Mensch im grossen" betrachtet, Hua 27, 21) and we must attribute to it an ethical self-determination in the way we attribute it to individual persons.

With respect to their practical relevances, to the personalities of a higher order correspond as correlates of their activities certain ideas, values, beliefs and decisions. Although a personality of a higher order is composed of individual subjects, it is not reducible to an aggregate of those subjects but has rather a community-life (Gemeinschaftsleben) of its own, with its own community-self-consciousness (Gemeinschafts-Selbstbewusstsein), and community-acts (Gemeinschaftsakte). These levels of communal constitution have their relative autonomy through correlations to 
corresponding forms of ideal noematic unities, namely, the accompanying ideas, symbols, convictions, etc.

The analogy, however, is not as direct as it seems at first sight either. It implies the paradox that although I identify my ideas, values, and beliefs as mine, the majority of them are grounded in lived experiences of other subjects. In the same manner, my own experiences may institute a sense that can be appropriated by others. In either case, the production of sense is based on temporal dynamics of coordination and co-regulation among subjects that involves a "suprapersonal consciousness" (überpersonale Bewusstsein).

The production of enduring sense, concordant and sustained across different subjectivities belongs to the class of problems that Husserl later designates as generativity. Although this term is not itself employed there, in the second part of the Gemeingeist manuscript Husserl develops substantially its problematic.

Generativity can precisely be described on the basis of the analogy discussed above. It involves an analogical extension of the genetic problems outside the limits of the concrete temporal becoming of an individual consciousness. In other words, it refers to intersubjective genesis or, as we might also like to designate it (without any biological connotations), a phenomenological phylogenesis. ${ }^{95}$ In this context, we can understand the notion of "generation" in two main ways. First, it concerns the event of becoming as a process derived out of the limits of the streaming life of the individual ego. Central themes here would be those of birth and death. Second, it deals with forms and processes that take place over different communities and generations. These could be phenomena of 
cultural and historical renewal, structures of language, symbolic systems, and cultural artifacts.

Defined in this way, the thematic framework of generativity comprises phenomena with distinctly communicative characteristics. Yet, we can also and somewhat schematically point out that, unlike the interactive I-Thou layers of communicative constitution (discussed by Husserl in Gemeingeist I), the generative layers (mostly carried out Gemeingeist II) organize communicative praxis on the basis of "We-intentionality." To the extent to which the communal acts performed by this intentionality entail correlates as "spiritual objects", the very notion of Gemeingeist ${ }^{96}$ already delineates the generative framework.

Quite differently from the Hegelian meaning of this concept, in Husserl's use of Gemeingeist we identify two correlated components: "spiritual” objects ("geistige" Gegenstände) and social subjective unities (sozialen Subjekteinheiten). ${ }^{97}$ "Spiritual" objects are the objects that are derived exclusively from communal acts. They are not objects pregiven to human activity in the sense of an objectivity of nature. They can be understood in two ways: a) as intersubjectively constituted objects, correlates of "a given normal human community [and] shared [...] identifiable temporal reality" and b) as "reason-reality" (Vernunftwirklichkeit) which Husserl associates with human sciences "as sciences of spiritual objects in general." Social subjectivity, on the other hand, refers to the very subjects of communal actions and to the higher subjective unities attached to them (Hua 14, 192). In other words, they include the different levels of existence of the "we." What is particularly important to note here is that the concept of Gemeingeist does not transcend the difference between social subjectivity and social objectivity. Unlike 
Hegel for whom the components of Gemeingeist are necessarily sublated in the historical forms of objective spirit and absolute spirit, Husserl insists on the essential irreducibility of their difference. For Husserl, community consciousness (Gemeinschaftsbewusstsein) corresponds directly to individual consciousness (individuellen Bewusstsein) and the latter is conceived exclusively in transcendental terms. The axis of this correspondence is the immanent side of the constitutive correlation to the objective world. Spiritual objects in the sense of cultural accomplishments are the products of an intersubjective constitution. Within the correlation to these objects, a community has the status of a transcendental unity. Because of the constitutive character of the correlation, social subjectivity remains necessarily distinct from spiritual objects. Husserl expresses this necessity in the following way:

The constitution of an objectivity of the community of life in the communal subjectiveobjective time is related to the unity of the common for all given surrounding world. An inone-another of the outside world for "us humans" and the inner world: we humans appear in the unity of a life in this world, this world to which we ourselves and our consciousness belong. (Hua 14, 219)

What Husserl obviously suggests here, is that the constitutive relationship of Ineinander precisely requires the difference between a community and its objective accomplishments

The personal unities of a higher order are constituted in communal acts. The latter, however, are performances of unified community-subjectivities (Gemeinschaftssubjektivitäten). Community-subjectivities presuppose the shared intentionality of the "we" (or we-subjectivity, Wir-Subjektivität). Husserl tells us that "[t]he community-subjectivity is a many-headed subjectivity [vielköpfige Subjektivität]" (Hua 14, 218). What is the primal institution of this many-headed subjectivity? In 
connection with the previous discussion of the social and the instinctual dimensions of communication, several further questions arise. To what extent does community subjectivity involve an embodied face-to-face relationship? Is it based on individual streams of consciousness and can we say in this sense that it is a mere accomplishment of a plurality of participating subjects? Or is it instead some sort of autonomous formation?

If the latter is the case, is this autonomy not still an achievement of originally independent subjects? Or does it, on the contrary, grow out of an anonymous driveintentionality in whose primal streaming life the different egos are still indistinct? To begin answering these questions we must first clarify how Husserl understands the notion of the "we."

The "we," Husserl says, is "[t]he social personality $[\ldots]$ with the purposeful values, desires, will, action, according to the social purpose" (Hua 14, 213). This social personality is constituted in communication; it is a "communication-community" (Kommunikationsgemeinschaft). Importantly, the synthesis that carries out this constitution is a mediated one:

In communication I have not mere self-experience (as original), but self-experience that now includes apperception of the self-experience as it is experienceable for all others, in such a way that I and we all can hold identity by a mediate synthesis of our experiences. (Hua 9, 394)

What does "a mediated synthesis" imply here? Does it mean that the "we" does not require a direct face-to-face experience and does not involve empathy? Husserl's account in this respect is somewhat confusing. It appears to replicate on the level of communitysubjectivity the ambiguity of social acts. He would often make statements such as "It is through empathy that the personal connection is instituted wherein [...] 'a conviction is' 
alive, 'a valuation,' 'a will' with all its conditions for unity. And as correlates we have the unity of 'one' action, 'one' work, and [...] the unity of a State, a religion, a language, a literature, an art, etc.” (Hua 14, 194). At first sight, it seems that what Husserl suggests is that the whole constitutive gradation ascending to the community-consciousness starts with an empathic primal institution. In fact, this is not the case. A closer reading of this and other related texts reveals that empathy is only a vehicle for the acquisition of personal unities of a higher order.

Experiencing the other as another living body and grasping the other's particular lived experiences cannot by itself generate a we-subjectivity. Empathy implies neither shared intentionality nor possible common correlates. Had we accepted such an implication, we would lapse into "circular reasoning." In order to be able to empathize, we would have to presuppose an already existing community-consciousness. This community-consciousness, for its part, would only be possible on the basis of empathic appresentation. Empathy can be neither a constitutive element nor an enabling condition for the formation of the we-subjectivity.

When it comes to explaining the "we" Husserl is quite aware of the possibility of a vicious-circle. This is why he always insists that its first constitutive moment is what I cannot experience or understand of the other but somehow accept directly:

Each communalized ego has not only its own consciousness, but by looking into others and combining with others also a connection of universal consciousness (universalen Bewusstseinszusammenhang) with a many-headed subjectivity, but, of course, [in this] losing itself into the indeterminate. For each [ego] there is a remote horizon: the open indeterminate plurality of others, except for the ones I really understand and include [in my experience]; the indeterminate and un-traversed consciousness of others beyond what I really know or grasp of them [...] (Hua 14, 218, my emphasis) 
As it is "beyond what I really know or grasp of others" this indeterminate consciousness is clearly transcendent to every possible empathic experience. To substantiate this point we need to recall Husserl's copious definitions of empathy, according to which, empathy is exclusively grounded in the primordial sphere. (Hua 1, 131; Hua 15, 122). The egoic surrounding world (as he also calls it prior to the Cartesian Meditations) encompasses all original embodied experiences, among which also appears the experience of the other's body in the mode of another living body. ${ }^{98}$ Now, if Husserl tells us that the "we" necessarily involves an intending of "unknown personalities" and that empathy operates exclusively within the scope of embodied face-to-face experience, it is clear that empathy cannot in principle generate community consciousness.

Empathy and we-subjectivity are separated by the second epoché. In the second epoché I abstract from every aspect of phenomena, which I cannot experience immediately in the living present. We can conclude, therefore, that the we-intentionality does not require empathy or a face-to-face relationship.

The everyday sense of the world is a product of an intersubjective co-constitution. In it I encounter others without originally constituting their sense but rather receiving it as embedded in the very structure of my world experience. The primary medium for the synthesis of individual experiences of multiple subjects into a we-subjectivity is therefore the world itself:

In the normal experience of the world, which has from the outset the sense of an objective (intersubjective) experience of the world, everyone and thus I myself have the experienced object in an apperceptive consideration with respect to the open intersubjectivity. Even when I have no explicit notion of others, there is still the existence [Dasein] of others in a continuous co-validity and apperceptive function. The development of the perception-sense and the constitution of the world of objectivity, the 
thing, the human being, etc. lead to intersubjectivity with its associated constitutive structures [...]. (Hua 9, 394)

Insofar as the world is constituted as a world for everyone it is the primary medium for the motivation of a communication-community. To the extent to which everyone is oriented to a common surrounding world, I "know" everyone. This is the basic structure that constitutes the "we." With respect to a common experience, an individual understands herself primarily within the horizon of being "together" in a "mutual understanding consciousness" (Wechselverständigungsbewusstsein).

When the streams of consciousness of different subjects are directed to and constitute the same object field, they acquire an intentional commonality. The function of habituation plays a major role here. The passively constituted world of my apperceptions underlies my practical conduct and determines through its continuous uniformity the profile of my personality. We have a plurality of persons with their multiple streams of consciousness and capacities attached to the same fields of experience. By virtue of their habitual sedimentation every representation is modified by those of others and in "this wonderful way $[\ldots]$ consciousness is reflected in consciousness and this mirroring that is peculiar to consciousness finds and 'overlays' [deckt] itself with the mirrored image and thus has [acquires] the objectively identical" (Hua 14, 199). While this is primarily a mediated commonality, the subjects become "for-one-other" (füreinander) and "to-oneanother" (zueinander) through habituation.

Now, the for-one-other and to-one-another of habituation express the mutual modification of the streams of consciousness whose overlaying extends into an accomplishment of a common reality. ${ }^{99}$ This is a process grounded entirely in passive synthesis. Husserl is explicit that the world is always already there for us and we can 
intend an indeterminate horizon of anonymous co-constitutors only "through" it.

Nevertheless, the newly developed method of genetic analysis allows him to inquire into processes transcendentally and developmentally "prior" not only to objectivity but also to the lifetime of the ego itself. The following passage from Husserl's lectures on passive synthesis gives a good illustration:

My passivity stands in connection with the passivity of all others: One and the same thing-world is constituted for us, one and the same time [is constituted] as objective time such that through this, my Now and the Now of every other-and thus his life-present (with all immanences) and my life-present—are objectively "simultaneous." [...] That is, my life and the life of another do not merely exist, each for themselves; rather, one is "directed" toward the other. (Hua 11,343/632)

Taken by itself however, the analysis of the passive constitution of the primal community-consciousness and its correlative world and time cannot supply us with a full explanation of the dynamics of social formation. What is more, this analysis is short of resources to exhaustively address the questions generated within its own domain. Notably, the major one among those is the question about whether and to what extent the primal institution of the communal world is a concrete historico-cultural accomplishment. This question concerns directly the nature of communicative community since it reveals it in the light of two crucially contrasted alternatives: the possibility of a constitution based on intersubjective instincts and the possibility of institution based on social acts and cultural objectifications. Husserl, to be sure, was able to clearly detects the conflict between these two alternatives:

In contrast to the instituted by specific activity sociality stand the intersubjective, purely spiritual connections of dark and first displaying their sense only in the disclosure of their satisfaction, intersubjective instincts. (Hua 9, 486) 
Obviously, Husserl is aware of the danger of a certain "essentialist" understanding related to the concept of communicative instincts. If the co-constitution of objectivity and intersubjectivity were entirely dependent on the dark implicit work of driveintentionality, social relationships would be graspable either as an external natural facts, that is, in terms of "associative-inductive connection," or as "purely spiritual relationships" (ibid.)

The claim I advance here is that Husserl in fact manages to develop an alternative account. The key to the coordination between concrete social activity and indeterminate instinctual passivity seems to lie in the specific structure of accomplishment of personal unities of a higher order. Husserl explains this structure through the analogy between personal lifetime and socio-historical time, between individual and collective habituation. The constitution of individual personality, according to Husserl, takes place in the form of subjectively oriented time. (Hua 14,217) Individual personality is tied to continuous habituations and sedimentation of apperceptions through which the relative identity, the "typicality of orientation," and the uniformity of personal style are accomplished and maintained throughout a lifetime. ${ }^{100}$ In an analogous structure communities maintain their unity, "typicality," and style. "The individual consciousness corresponds to the community-consciousness, the individual acts, to the community acts, etc." (Hua 14, 218). A nation as a unity of a higher order has its "personal" character established in its concrete line of history as the typicalities of its orientations (past and future horizons) and enduring cultural formations passed down through generations (language, literature, folklore, etc.). 
Here we must indicate two crucial conditions for the possibility of this analogy: inner temporal concordance and noematic sense. These two conditions indicate structural moments in the constitution of individual personality and they are reproduced at the level of social unities. In this way they become constituents of the personalities of a higher order as well.

Only if the personal ego is conceptualized in terms of its concrete genetic development and not in terms of the static foundation for its validity is the correspondence with communal formations possible. It is with regard to the passive genetic regularities of inner self-temporalization that the analogy is drawn. Husserl specifically emphasizes this as an axis of the analogy:

With the specific community is constituted the community-time and the modes of subjective givenness of that time, of the community of subjective givenness. [...]

Time is seen from inside the form of intentional genesis. It is, therefore, the idea of this genesis as a community genesis, genesis of the community as a community, in its community-life in its community-acts and -affects, self constituting community performances, passive geneses of forms of community, community activities etc. (Hua $14,221)$

It is this subjective givenness, the inwardness of a living present and its concrete progress in experiential regularities (whether a lifetime or a historical time-period) that parallels individual and higher-order personalities. Husserl's concrete-case descriptions demonstrate cogently the point. He speculates about an extreme contrast between different social entities. He entertains an almost commonplace anthropological thought. He imagines entirely isolated, probably yet undiscovered, "wild tribes" (think of the recently found tribes in Brazil) who live on Earth without any contact with the global "interacting community" (Verkehrsgemeinschaft). The claim he advances is that such 
tribes would not form any kind of a "life-unity" (Lebenseinheit), at any scale, with the remaining world-community (no more than Martians would). The explanation to this claim would be that, despite the fact that we share a "planet," an atmosphere, possibly, flora and fauna, in terms of the socio-temporal interiority, we do not establish any concordant time-structure, any "interaction" (Verkehr) with them. Furthermore, we do not share cultural accomplishments or arrangements that would provide the "reinstitution" (Nachstiftung) of social "idealities." There are such commonalities between European nations and Patagonia, for example, and Husserl points at it: "faith." England and English colonies, Schwabia and Bavaria all share at one level or another certain normative, ideal, or material consistencies.

With this we also grasp the function of the social noematic sense. The latter articulates the objective accomplishments of a community-subjectivity. All products of communal consciousness and activities, i.e. institutions, material and non-material culture, belong under this category. To these processes is associated the "selfconsciousness" of the community. They bring about its objective representations and, unlike the socially subjective ones, are "permanent" unities. Besides articulating current norms (values, believes, everyday life uniformities, etc.), the latter also communicate "historical spirit" so that "[m]y life and that of Plato are one. I continue his life's work [...] his desire, his will, his Gestalten continue in mine $[\ldots]$ " (Hua 14, 198)

Framed in this manner, the two conditions for the analogy between individual and social unities, namely, temporal concordance and noematic sense, become essential for the elucidation of the above-raised question regarding the constitution of communication community. We discover that the temporal concordance of social habituation cannot but 
have a passive pre-intentional organization and that all cultural accomplishments require active constitution. Passive synthesis discloses objects only insofar as they affect us and it is only through active synthesis that a productive disclosure can be carried out. It becomes obvious, therefore, that temporal concordance and noematic sense are distinguishing characteristics of, respectively, intersubjective instincts and specific social acts. These two produce two distinct aspects of social reality. These are the aspects, which we explicate by, respectively, genetic and static analyses. Taken together, however, that is, by preserving the genetic primacy of the instinctual and yet carrying out in connection with it, a form of objective constitution, they make up the field of generative constitution. While being genetically founded on passive intersubjectivity, it also involves the supplement of speculative construction (or reconstruction). ${ }^{101} \mathrm{We}$ can say about this supplement that it extends passive genesis with an active one.

While the analysis of the specific structure of the passive/active correlation in the constitution of sociality has to be left for a future investigation, what is important to point out here is that, for Husserl, the passive and the active moments remain strictly differentiated. This is why Husserl insists that, unlike the we-subjectivities, cultural objectivations acquire "permanent validity” (bleibende Geltung; e.g. Egyptian hieroglyphs, Plato's dialogues, etc.). ${ }^{102}$ It is this distinction within the structure of the passive/active correlation that allows Husserl to speak in the Keizo articles of cultural renewal and intercultural communication.

What is of utmost importance, however, is that the unique structure of this "dynamic" correlation between instinctive intersubjectivity and communicative acts in Husserl's conception of personal unities of a higher order enables him to give an account 
of social generativity that is alternative to both the egoic conception of "open intersubjectivity" and the concrete experience of actual others.

\section{Conclusion}

We can conclude that, in the I-Thou relationship, there is always a singular "You" originally accompanying the general grasp of another subject as a living body. It is not that we first experience the other subject as "another living body like mine" and then we encounter her as a specific "You." We grasp immediately the other in the peculiar style of "her entire conduct, in her passive and active comportment toward her surrounding world, in the expression of her individuality." The other is originally as much "another

living body like mine" as she is this particular "You." Five years after Gemeingeist ${ }^{103}$ Husserl writes:

[S]ocial connectedness [...] can be produced not only by social acts. As individual subjects exert their activity on the basis of a dark, blind passivity, so the same applies to social activity. But already passivity, the instinctive drive-life (instinktive Triebleben) can produce intersubjective connection (intersubjektiven Zusammenhang).

Thus a sexual community is in its deepest ground already produced by the sexual instinctlife, it may first reveal itself in the fulfillment of its essential intersubjectivity. It should be noted that this passivity belongs in the framework of pure subjectivity and can be investigated as such in the phenomenological reduction. (Hua 14, 405)

This passage is crucial as it marks the actual explicit shift in Husserl's approach to sociality. No longer does he consider the constitution of community exclusively in terms of individual monadic development. Now he also takes up the question of phylogenetic 
processes concerning the original totality of the multiplicity of monads. This marks decisively Husserl's mature interest in problems of phenomenological construction and generativity. The key implications of this shift which has already tacitly guided the analysis in the Gemeingeist texts can be articulated as follows.

1) We move beyond the static-foundational notion of sociality, according to which the communalization begins in the subject as an isolated egoic act. We do not, however, rule this notion out. Social acts remain a theme of the properly descriptive inquiry wherein the genetic quest finds its leading clue.

2) We move into the lower strata of social temporality, beneath the genetic-foundational approach and into a sphere of generative reconstruction. This sphere is defined neither by social acts nor by empathy. It is a sphere of social potentialities and habitualities wherein "community is in its deepest ground already produced."

3) The investigation remains strictly transcendental. We can now identify it as a transcendental psychological explication of the constitution of the anthropological world. This explication is made possible by the inquiry into the sphere of personalities of a higher order which revealed the dimension of cultural objectivations: the symbolic order of practical, epistemological, and axiological formations. The questioning back into the temporal origins of communicative praxis and its world-constitution enables "selfmundainzation" of intersubjectivity. This question leads to the "transformation of the phenomenological reduction into the radical justification of transcendental conception of the world" (Hua 14, 408). Such justification opens phenomenology decisively to the domain of particular sciences and provides a phenomenological access to the regional 
problems of sociality treated by disciplines such as anthropology, social and developmental psychology, social neuroscience, dynamic systems theory, etc. 


\section{CHAPTER 4}

\section{Infinite and Generative Time: Levinas and Husserl on Communicative Temporality}

The previous chapter attempted a reading of Husserl's account of sociality in terms of the processes of generative development. This approach allowed us to bring to the fore the concrete interaction with singular others. The latter was revealed as a form of intersubjective connectedness distinct from both the general recognition of other living bodies in empathy and the implication of an open plurality of co-constituting subjects in the givenness of the object. The premise for such a demarcation was the unique status of the structure of Ineinander. Ineinander underlies the communication with other subjects in their concreteness. On the one hand, it is grounded in the transcendental-genetic function of intersubjective instincts and on the other, it is oriented towards the wesubjectivity and the personalities of a higher with their array of noematic accomplishments: objective forms of social time and rational cultural unities.

Importantly, the distinct status of Ineinander transpires exclusively upon a generative inquiry. It is only the latter that yields the sense-expressions of the other in a preobjective manner.

Nevertheless, while chapter 3 distinguished the original communicative dimension from empathy and from social acts (grasped in their static sense-structure), it did not afford a conclusive definition of Ineinander in its proper temporality. The 
difficulty in accomplishing this lies in the ambiguous status Husserl assigns to Ineinander. While being distinct from object-based relations to others, the temporality of Ineinander is phenomenologically inaccessible without them. The uncovering of the primal institution of the singular "you" necessarily involves the sense-structures of the object and of the other as another "lived body like mine." I cannot grasp the individual style of the other person in its irreducible singularity without considering her as another subject like me with its respective affections, actions, and surrounding world, and without assuming a common for us world-correlate with its involving common social formations. But herein also lies the danger of losing sight in favour of the object of the actual otherness of the other. Husserl thus will oftentimes find himself entangled in the pitfalls of the egological tendency to derive the communicative relationship from the objectanchored horizon of intersubjectivity. Understood as fundamental, such tendency conceals the proper temporal dimension of the communicative Ineinander.

The present chapter ventures to clarify this ambiguity by reconsidering Husserl's generative notion of communicative temporality in the light of Levinas's accounts of infinite time and substitution. It attempts to assess Husserl's views not only against the explicit critique Levinas levels at them, but above all by radicalizing the temporal aspect of Levinas's continuous and implicit debate with Husserl regarding the problem of intersubjectivity. The motive for such juxtaposition is that both thinkers face similar problems when they attempt to justify the passive notion of alterity at the level of active constitution. The discordance between these two levels reveals a similar skeptical urgency at the core of each of the two accounts of intersubjectivity as a tension between two times: singular and plural. In Husserl, this urgency takes the shape of a necessity to 
coordinate the singularity of Ineinander with the universality of empathy and to explicate the modality of the former into the sphere of personalities of a higher order, within the dimension of cultural objectivations. In Levinas, it comes from the need to secure the ethical responsibly for the other within the sphere of consciousness and thus on the plane of justice, reason, and history, a plane which is often referred to as the dimension of "the political." Put in phenomenological terms however, one and the same question can be applied to both accounts: How can a relation to the singular other be maintained as diachronically transcendent to the self-temporalizing flow of the ego and yet take place and acquire validity as a correlate to its abiding synchronic form, within the structures of social order and within the objectively mediated forms of communication? My claim is that Levinas's answer to this question stays at best with his skepticism, whereas Husserl's generative account of intermonadic temporalization suggests a more practicable response.

\section{The Sensible Constitution of Subjectivity in Totality and Infinity}

The central exposition of Totality and Infinity, the working out of the ethics of the face, brings to its terms Levinas's attempt to explicate the structural moments of what he calls "metaphysical exteriority." Approached as an implicit debate with phenomenology and thus as a problem of the alteration of transcendental subjectivity, such explication requires, as Levinas announces in the preface, the "fixing" of a new intentional structure. Its "general guideline," he states, is "the difference between objectivity and transcendence" (TI, 49). The major accomplishment of Totality and Infinity is hence the explication of the figure of the face-to-face as a signification and intentional structure 
arising from the articulation of this initial difference. The face introduces a meaning prior to the noematic sense, outside of the form in which the intentional object is constituted as a correlate of the ego's synthetic activity. Levinas will still employ intentional analysis and commence his description of the face in a quite phenomenological manner as a "presence in thought of an idea whose ideatum overflows the capacity of thought" (TI, 49, emphasis mine). Yet, although the idea of infinity is inscribed within consciousness, it introduces an event of excess that does not proceed from the spontaneity of the subject. Strictly speaking, the ethical relation does not take place within the egological phenomenal sphere. Its intentionality is anterior to what Husserl delineates as the general structure of lived experience (ego-cogitation-cogitatum). The infinity of the face-to-face relation is produced merely through the dismantling of this structure, a dismantling that occurs each time as prior to the living present. Irreducible in its alterity, the face transforms the structure of intentionality into a primary ethical relation, the relation of infinite responsibility to the other.

Taken in the context of his polemic with Husserl and hence with respect to the inversion of transcendental intentionality, Levinas's elaboration of the face-to-face relation is nevertheless far from being conclusive. Its inconclusiveness, however, is inherent to its logic and, in a privative way, already implies and requires a dimension beyond the ethical. This incompleteness opens what here will be considered as one of the central questions of Totality and Infinity: How can the face be maintained as absolutely transcendent to the lived experience of consciousness and yet take place and acquire a justification within it? 
Now I claim that that the ethics of the face — at least as outlined in Totality and Infinity —involves a double temporal indeterminacy. This indeterminacy becomes discernable as soon as we try to reproduce the construction of the face-to-face in the perspective of Levinas's critical reactivation of Husserl's analysis of time-consciousness. On the one hand, the face resists comprehension within the constitutive phases of retention and protention. Its occurrence within finite (i.e. objective in the Levinasian sense) time opens an absolute interval as a complete "refusal to be contained" within the a priori forms of intuition. On the other hand, since the face occurs only with respect to what it interrupts, it lacks and demands a condition coming from beyond its proper relation. Such condition would have to secure the transcendence of its primal impression (Urimpression) precisely within the form of objective time. The face therefore requires what Levinas calls "infinite time" outside of its own mode of signification and beyond the time of the living present. Infinite time would justify the truth of subjectivity precisely as an ethical singularity and within the horizon of finite time.

This indeterminacy of the face seems to stay aside of the main focus of Totality and Infinity and thus commonly escapes a thorough reading by commentators. However, when taken as a phenomenological problem, it stands out as one of the turning points of the project and this is precisely what the last section titled "Beyond the Face" deals with. Totality and Infinity, as Levinas admits, presents us with a phenomenological deduction of what he calls "transcendent intention" (TI, 28-29). Yet what its intentional analysis explicates is not merely the signification of the ethical, the signification, which "cuts across" the sensibility (TI, 193) structured by the noesis-noema correlation. Totality and Infinity is a "search for the concrete" (TI, 28) in a more radical sense. It is an inquiry, 
which also concerns the possibility of a sensibility that can be reduced neither to the intuition grasped in noematic form nor to the signification articulated as excess.

I propose here that the temporal alteration, which the ethical relation undergoes through the notions of infinite time and fecundity introduced in the last section of Totality and Infinity, is based precisely on such a distinct concept of sensibility. This concept does not refer to the sensibility experienced in the face-to-face encounter. It indicates rather what is (phenomenologically speaking) "beneath" the face. Such a layer announces itself first in the phenomenon of love, which is, in a necessarily ambiguous way, arranged "at the same time beneath and beyond" the face (TI, 255).

It is only through the simultaneous operation of a sensation, which lies beneath, and an intention which comes from beyond the face that the ethical relation can be preserved and brought into experience. Taken more radically, this argument is tantamount to the claim that infinite time and fecundity present Levinas's attempt to outline a temporal constitution of the singularity of the subject. The latter, apparently aporetic expression designates an intentional structure surpassing, yet not cancelling the asymmetry of the face. It describes a mode of experience which is no longer that of a consciousness put into question but rather one of a subjectivity whose identity is diachronically (re-)constituted. Its main implication is that the phenomenology of infinite time sketches out the structural moments of an intentionality entirely based on transcendence, a completely affective subject constituted as an interiorized material passivity.

One of the outcomes of this argument would concern (as we will see below in this chapter) the continuity between Levinas's two major works. Although the two works 
differ considerably in method, composition, and language, a reflection on the phenomenological explication of sensibility in the last section of Totality and Infinity would show that, in terms of its structure, its argument is significantly consistent with the accounts of sensibility, substitution, and sense in Otherwise than Being. Another closely related and easily distinguishable importance of such an interpretation is that it would provide the ground for a distinctive understanding of Levinas's view of politics and the prospects for its elaboration. What would primarily concern us here, however, is how the dimensions beneath and beyond the face allow for the properly ethical signification to be embedded and articulated in the objectively mediated forms of communication. Clearly, an account of a sensibility beyond the sensibility of the face and distinct from the sensibility represented in totality would illuminate how Levinas would think the possibility of a symbolically institutionalized system of communication which presupposes ethical asymmetry and not objective social determinations (not a "rational" but an "eschatological" peace, as Levinas occasionally defines the difference).

\section{The Intentional Structure of the Face and Its Temporal Indeterminacy}

The production of infinity - the operation that articulates the ethical relation—has, as Levinas points out, an intentional structure (TI, 28-29). ${ }^{104}$ This intentional structure is bound to reveal a transcendence distinct from that of objects. Yet, while Levinas adopts the concept from Husserl, for the articulation of the face, he preserves only its passive core, what Husserl often refers to as "primal intentionality" (Urintentionalität). The latter is a constitutive element of self-temporalization where its function consists in the immediate awareness that composes the stream of primal impressions. This intentionality 
consists only in an extended standing present awareness of the immediate future and past, awareness that forms itself as the flow of primal impressions. It is what, in the first chapter of this dissertation, was discussed as "primally flowing living present" (urströmende lebendige Gegenwart). Such intentionality is "prior" to the noetic-noematic intentional structure unfolding in constitutive acts. It "escapes" the constitution of objects and marks only its limitation in the awareness of the continuous genesis of consciousness, of its own source as the ceaseless passive manifold of the living present. The same kind of primal intentionality Levinas sees in the ethical relation of the face. The face is present in its refusal to be contained. [...] It cannot be comprehended, that is, encompassed. It is neither seen nor touched - for in visual or tactile sensation the identity of the I envelops the alterity of the object, which becomes precisely a content. [...] The Other remains infinitely transcendent, infinitely foreign; his face in which his epiphany is produced and which appeals to me breaks with the world that can be common to us... (TI, 194)

The face appears as a transcendence-relation, a passive temporalization that articulates a transcendence radically different from that of objects: "Every present in its temporal nudity tends toward the future and returns upon the past or resumes that past - is prospection and retrospection" (TI, 122). The "temporal nudity" of the present is Levinas's direct analogy to what Husserl defines as the living present. ${ }^{105}$ The analogy however remains at this level because "already with the first exposition of intentionality $[\ldots]$ there appeared the privilege of representation" (ibid.). Intentionality taken at the level of the living present unfolds the initial extension of the temporal flow. In it the subject resides prior to any intentions directed at the identification of an ideal object as a correlate. Thus, in the face, protention and retention are not taken as representational structures. They characterize the "original temporal field" in which the subject finds itself 
in its affective life, a field that precedes any reduction to noematic sense. In "Intentionality and Metaphysics," an essay that appeared one year before Totality and Infinity, Levinas gives a more detailed description of this structural moment:

Husserl's analysis of the time of consciousness and the consciousness of time brings in an intentionality of protention and of retention. This intentionality is not already an objectifying intention, like memory or hope. The instant is nowise retained or pro-tained in thought. The "retaining" and the "protaining" do not remain immobile as in objectifying intentionality; they follow that toward which they transcend themselves, are determined by what they retain and protain. ${ }^{106}$

This intentional following allows Levinas to locate the presence of the other within the subject. The face is articulated within the "temporal nudity" of the living present and this articulation takes place originally as "prospection and retrospection." This is a moment of absolute signification which becomes possible only because the primary event of exteriority—primal impression —is articulated as an original intentional stream. Primal impression as the "source-point" of this stream is conceived both as a living present and as an absolute transcendence. Its original event is a presentation of what resists presentation. The occurrence of the primal impression is in fact concurrent with its intentional passage: as already past, it is intended in the present moment of retention; as still to come, it is intended in the actuality of protention. The primary event of exteriority is therefore an original modification. It is an intentional relation in which exteriority is presented as an "original temporal field." The primal impression is therefore not a sensation which preexists the temporal phases of retention and protention. It is rather a transcendence that is first made possible and indicated in them. This structure of modification explains how in Totality and Infinity Levinas understands the production of infinity as an asymmetrical relation. Moreover, it makes evident why he elaborates an 
ethical language for this —originally phenomenological—problematic. Insofar as phenomenology is understood as an eidetic science of transcendental consciousness, the articulation of the primal impression in the stream of the living present is, strictly speaking, not part of its thematic. Levinas will set up his analysis in "Ethics and the Face," the key section of Totality and Infinity, by outlining the structural moments of the very same relation:

The presence of a being not entering into, but overflowing, the sphere of the same determines its "status" as infinite. [...] The idea of infinity, the infinitely more contained in the less, is concretely produced in the form of the relation with the face. And the idea of infinity alone maintains the exteriority of the other with respect to the same despite this relation. (TI, 195-96, emphasis mine)

Infinition, as becomes obvious from the phenomenological recount of the ethics of the face, requires intentionality. Yet this is not the intentionality which posits exteriority as the transcendental objectivity of a noema. It is the intentionality of the original life of subjectivity in its relation to exteriority. This relation is structured as a sensibility which, being "still graspable, turns into total resistance to the grasp" (TI, 197). The ethical radicality of this relation, its pre-constitutional significance consists in the fact that the "grasp" itself, the temporal modification of retention and protention is both concurrent and incommensurable with the event of exteriority. This is why Levinas will repeatedly emphasize that that "infinity does not first exist, and then reveal itself," it is produced as a "revelation, as a positing of its idea in $m e$ " (TI, 26). He will refer explicitly to the intentional motif of such "production": "The face is a living presence; it is expression. The life of expression consists in undoing the form in which the existent, exposed as a theme, is thereby dissimulated" (TI, 66). Structured in this way, sensibility emerges in its preeminently ethical function. 
The interpretation of the intentional structure of the face from the perspective of sensibility and temporality uncovers otherwise unnoticeable ambiguities underlying the movement of the argument in Totality and Infinity. Certainly, the intentional relation of infinition takes shape as an interruption of the constitutional tendency inherent in subjective life. But, although the "original temporal field" which maintains this interruption in its asymmetry is prior to objective constitution, it still requires the intentional activity of the subject. Despite the fact that protention and retention structure not only the consciousness of time but also the time of consciousness, their intentionality requires (if not presuppose) a spontaneity with respect to which only the event of exteriority can take place. In order to temporalize, while being itself temporal, intentionality withdraws from its transcendent source and thereby detaches itself from its own original establishment. The intentionality of the face, in this sense, leaves open the regressive possibility for a transcendental reduction. Such reduction, to be sure, would not efface the original ethical experience. Yet it would constantly suspend its interruptive effect within the sphere of constituted experience. Despite the fact that it presupposes infinity, ethical subjectivity remains active in its passivity. Although in the asymmetry of the face-to-face relation exteriority is taken as anterior to the intention that articulates it, the transcendence of the very intentional relation remains unprotected. Thus in the last chapters of Levinas's discussion of the face, it will turn out that the face leaves open the prospect of subjective volition. The face will render the transcendence of the other not as welcoming but as the annihilation of every intention, as the ultimate impossibility of every possibility. This is a dimension of appearance in which the event of exteriority, the temporal interval of primal impression reverberates within the stream of consciousness as 
an originary violence, as death which comes from another will. This relation which Levinas will call "war" proceeds from the tendency and the failure of the intentional modification to form or animate the material of its original affectivity. Clearly, the collision with the other as another will is not an objectively constituted experience. The relation is not mediated by a common logical form. It presupposes asymmetry as its original condition. However, what also becomes discernable in the prospect of war is that - when taken from the perspective of its intentional structure - the possibility of struggle and violence is rooted in the sensibility peculiar to the face, in its temporal indeterminacy. But is this inherent temporal indeterminacy a necessary moment in the operation of the face? Or is it an incorrigible deficit, an effect of an ontological failure that exhibits the ethical relation as primordially deceptive?

\section{Affectivity and Infinite Time}

The problem which acquires crucial importance for Levinas after the central explication of the ethics of the face is the truth of subjectivity as a singular relation to the other and its justification in history. While the elaboration of this theme in Totality and Infinity is largely interpreted as an account of the passage from ethics to politics, its underlying phenomenological structure is scarcely considered. In fact, the exposition of justice and infinite time unfolds a phenomenological problematic which can be understood as Levinas's phenomenological radicalization of the ethical or ethical reactivation of phenomenology. In this sense, its main problem — which, to be sure, overlaps with the problem of politics - appears to be the explication of a sensibility which would provide a phenomenal locus for the face. This is by no means reducible to a search for a bridge over 
the separation with the other. What is at stake is not a transcendental constitution of the possibility of intersubjective peace, a reconciliation in history and totality. What Levinas attempts to achieve is rather, a phenomenology of singularity which transcends the temporal intentionality of the face situating transcendence not within the subject but as the subject whose identity is structured entirely from exteriority as total passivity or passive totality.

The necessity of such elaboration, however, is not a theme which Levinas encounters at a certain point in the movement of his analysis. The singularity of the faceto-face relation is not anterior to the intersubjective experience in the sense in which a fundamental relation, once established, requires a manifestation into the social. In his description of infinition in the Preface to Totality and Infinity, Levinas already speaks of the face as an "essential ambiguity," ambiguity in which transcendence is simultaneously brought about and revealed (TI, 26). In an essentially ambiguous way, the ethical relation already involves all the experiential implications which its bringing about would involve. It situates concretely the event of the face in a series of actual and unrelated encounters of particular individuals. Yet, simultaneously, it reveals transcendence as absolutely exterior to any formally presented experience and therefore as a diachrony of an irreducible interval. This simultaneous diachrony, as Levinas immediately explains, also provides the guiding thread for the consideration of justice:

No prior disclosure illuminates the production of these essentially nocturnal events. The welcoming of the face and the work of justice — which condition the birth of truth itselfare not interpretable in terms of disclosure. (TI, 28)

Thus, it would be a misreading to approach Levinas's justification of the ethical relation as a hermeneutic unfolding of a prior context. The face, he points out, is a "signification 
without a context" (TI, 23). Levinas will make this preliminary outline definitive in his famous discussion of "the third party":

The third party looks at me in the eyes of the other-language is justice. It is not that there first would be the face, and then the being it manifests or expresses would concern himself with justice; the epiphany of the face qua face opens humanity. (TI, 213)

But what is the specific intentional modality in which the "third party" appears? What does Levinas's precursory reference to the notion of fraternity suggest? As pointed out above, the intentionality of the face does not invoke the presence of the other in the perspective of formal givenness. The face is not a theme, neither eidetic nor experiential. The rudimentary phases of protention and retention concur with the event of primal impression and this is precisely what retains the absolute interval between the subject and alterity. It is this "essential ambiguity" and not the natural species relation among individuals that structures Levinas's notion of fraternity. The others are present in the other because the primary signification of the face maintains the absolute asymmetry between me and her. The interval maintains the Thou at an absolute distance by virtue of which it already assumes the "we." The singular individuals, with which I enter into an ethical relation remain separate, yet the ethical transcendence operates simultaneously as a source, as what Levinas calls "the commonness of a father" (TI, 189).

This prefatory account of fraternity however is far from Levinas's actual treatment of the problem. As long as the ethical relation is taken in the intentional modality of concurrence, it will always stay at the level of a singular subjectivity and particular experience. The temporal indeterminacy of the face, in this sense, requires a radical transcendence that comes from the outside. The political is not affirmed within the 
ethical. The necessity of transcending the ethical relation is therefore privative. This necessity becomes itself explicit with the motif of death.

For Levinas, the notion of death presupposes ethics. Both murder and the fear of death invoke the "unforseeableness" of the other. As was shown with respect to Levinas's reception of Husserl's genetic idea of temporality, ethical intentionality maintains absolute difference between anticipation (protention) and transcendence. Primal impression can be articulated only as already modified within the temporal nexus of intentionality as a living present. Yet what is thus articulated is never present itself. This interval is precisely what modifies the experience of death, wrests subjectivity from ontological temporality and brings it into the singularity of its relation to alterity. "I can wish to kill," Levinas says, "only an existent absolutely independent, which exceeds my powers infinitely" (TI, 198) and later emphasizes, "the Other $[\ldots]$ is situated in the region from which death, possibly murder comes" (TI, 233). The occurrence of the ethical outside of every intentional horizon, that is, outside of being and nothingness, restructures the subject and transforms the experience of death within this horizon. Murder presupposes the ethical relation. The face is simultaneously what makes killing possible and what precludes it absolutely. But although in this configuration the face resists murder entirely and even takes the biblical form of commandment, within experience the relation remains essentially ambiguous. The face, as Levinas tells us, still "threatens the eventuality of a struggle" (TI, 199). Thus the ethical modification of death does not prevent war. What is more, it is only through the irreducibility of the other to her particular manifestations that something like another will—and respectively war-is possible. 
The experience of my own death — the impossibility of any intentionality — is also ethically conditioned. My death comes from beyond the total horizon of possibilities and surpasses annihilation. Prior to any intention, including the one which identifies it as nothingness, death presupposes the face. However, although the face is already a certain escape from or an explanation of death, death translates the ethical relation into experience in a peculiar way. What is indeterminate in this translation is precisely the goodness of the face. Within lived experience death appears as originary violence coming from the other. Thus absolute violence becomes one of the modalities of the appearance of the face. It situates the other "against me" as another will. Yet, the fact that the interruption opened by the other separates death from the will inserts a temporal space of deferral. Since the sensibility of the face is not absolutely passive but also involves intentional activity, the imminence of death "is at the same time menace and postponement" (TI, 235). "To be temporal," Levinas declares, "is both to be for death and to still have time, to be against death" (TI, 235). The capacity for such a deferral constitutes the singularity of a subjectivity, which is no longer confined within the time predestined by the self-consciousness. Levinas's term for this capacity is patience:

This situation where the consciousness deprived of all freedom of movement maintains a minimal distance from the present, this ultimate passivity which nonetheless desperately turns into action and into hope, is patience - the passivity of undergoing, and yet mastery itself. (TI, 239)

With death the face enters the world of phenomena as violence and patience. It is still "a relation incommensurate with a power exercised" (TI, 198). But this incommensurability is already open to the exercise of subjective freedom "against someone and for someone" (TI, 240). This is a dimension that escapes and interrupts the total grasp of the ontology 
of society and history within society and history. However, insofar as the ethical resistance takes the sensible form of a temporality that is still within the scope of my intentionality, it always remains indeterminate with respect to this ontology. In order for such determination to take place, the face-to-face relation should, while remaining nonobjective, be validated with respect to objectivity. The indeterminacy of the ethical has thus two aspects: 1) its temporality is not definitively differentiated with respect to the sensibility represented in "noematic sense" and is therefore always open to appropriation within constitutive intentionality; 2) residing between violence and patience, its temporality is still the temporality of the subject and is therefore undecided in terms of goodness, viz., it does not take a conclusive position which is valid beyond the particular ethical relation "in being such that the Other counts more than myself" (TI, 247). Bringing this double temporal indeterminacy to its extreme, Levinas faces the inherently ethical exigency of moving beyond the ethical relation of the face:

The judgment of consciousness must refer to a reality beyond the sentence pronounced by history, which is also a sensation and an end. Hence truth requires as its ultimate condition an infinite time, the condition for both goodness and the transcendence of the face. (TI, 247, emphasis added)

And further:

Hence we must indicate a plane both presupposing and transcending the epiphany of the Other in the face, a plane where the I bears itself beyond death and recovers also from its return to itself. This plane is that of love and fecundity, where subjectivity is posited in function of these movements. (TI, 253)

What are the distinct phenomenal characteristics of the sensibility which involves a "sensation and an end" beyond the indeterminate sensibility of the face and outside the sensibility of the formal a priori of intuition? What is the relation that would justify the 
freedom and goodness of ethical subjectivity beyond it and in a non-objective form capable of substituting objectivity?

A detailed analysis of Levinas's notion of such sensibility seems necessary for the understanding of his idea of ethics in general and of his ethical reactivation of phenomenology in particular. However, for the purpose of the present chapter it suffices to point out the two constitutive moments that distinguish this sensibility from both the face and totality.

Levinas introduces the thematic of love and fecundity by a remarkable structural shift in the mode transcendence is constituted as sensibility. He points out that "in love transcendence goes both further and less far than language" (TI, 254). To start from the latter, in the sensibility of love the other is reached as a kind of sensation which lies "beneath" the face and is, in a certain way prior to it. In his account of murder, Levinas emphasizes that the sensibility of the face is neither that of knowledge nor that of enjoyment (TI, 198). Whereas in love the other appears first precisely as an elemental experience. Such experience does not presuppose an identity of a subject, which is then (somehow posteriorly) to be interrupted by the face. In enjoyment the subject is first constituted as a primary "living from" in which—if we recall Levinas's earlier exposition — intentionality flows in a completely opposite direction and by being "interior to the exteriority it constitutes, somehow comes from the point to which it goes, recognizing itself past in its future" (TI, 129). But, simultaneously with enjoyment, in love there comes an ultimate transcendence which only enjoyment can reflect and which transcends the interruptive and questioning transcendence of the face. 
Now it is entirely in line with what in the first chapter of this dissertation we discussed as Husserl's notion of "primally associative hyletic underground, " that Levinas introduces the dimension of love's ultimate transcendence as "ultramateriality" and "non-signifyingness." The experience of the other as an enjoyed ultramateriality does not permit a subjectively intended time in which a signification would be possible. It comes

as though from farther than the frankness of the face, already profaning and wholly profaned, as if it had forced the interdiction of a secret. The essentially hidden throws itself toward the light, without becoming signification. Not nothingness - but what is not yet. (TI, 256)

The temporality of Eros and fecundity does not combine my intentionality with the materiality that "overflows" this intentionality. It is not an inscription of the infinite into the finite. It is already entirely the temporality of the other, an absolute future beyond any future possible for me, that is to say, infinite time. The simultaneity of two moments, the exposure in enjoyment and the non-signifyingness of ultramateriality, constitute a sensibility that is, in an aporetic way, conclusively determined. This conclusiveness becomes explicit when Levinas shows how in fecundity, infinite time constitutes the very subjectivity of the subject and its intentionality. The identity of the subject is not the finitude in which the infinite is inscribed. It is the interiority of infinite time itself whose enclosure establishes a subject irreversibly transcendent to itself. 


\section{The Ethical Reconstitution of Subjectivity in Levinas and Husserl}

The command is stated by the mouth of him it commands. The infinitely exterior becomes an "inward" voice, but a voice bearing witness to the fission of the inward secrecy that makes signs to another, signs of this very giving of signs. (Levinas, Otherwise than Being)

The above quotation is one of Levinas's descriptions of what could be called conclusive figure of ethical signification. This figure demonstrates the structure of the ethical reconstitution of subjectivity, a structure whose explication seems to determine the main task of Otherwise than Being. It characterizes that conversion in the status of the subject that makes possible the promotion of ethics to the rank of first philosophy. Levinas understands the nature of this conversion as "a movement of the same unto the other which never returns to the same."107 Otherwise than Being brings this movement to its most radical stage at which not only subjectivity, but also consciences, justice, and reason are reconstructed on the basis of the ethical relation to the other. The introduction of such a moment of necessity within the asymmetrical relation of obligation has the capacity to show how the other is accepted as imperative.

In Otherwise than Being this figure is not immediately demonstrated, identified or presupposed. It is carried out and produced through a certain stratification of different arguments, interruptions and procedures within the text. The main reason for this "inevident" character of the exposition is its distinctive departure from and revisiting of phenomenology. At this stage of ethical signification all "constitutional effects" of intentionality are detached from the subject. Moreover, the very self-relationship of the ego is definitively cancelled. The identity of the subject is restructured by the priority of 
transcendence. The subject recurs as the pure "inwardness" of transcendence in which transcendence is itself articulated.

Despite its strong allusions to Husserl's epoché of the Fifth Cartesian Meditation, Levinas is certain that such a conclusive moment is unattainable by a transcendental reduction. Phenomenology is, in principle, unable to achieve a radical stage where the self-relationship of the ego is conclusively suspended. In a certain way, the epoche of the Fifth Meditation, is indeed "an explosion of the other in the same." ${ }^{108}$ However, for Levinas, Husserl's reductions in general, "remain characterized as indubitable knowledge, as the living presence of the Ego Cogito."109 Despite the fact that somehow they "legitimize" the interventions of the other in consciousness, phenomenological reductions fail to interrupt the absolute self-presence of the subject. A reduction of reductions, a phenomenological interruption of interruptions turns out to be impossible. For Levinas, Husserl's "transcendence in immanence" can be maintained only as a residual status of the ego in its relation to its lived experience. The ego is this silent condition of self-presence in which the order imposed by the infinite supremacy of the other can never reverberate irreducibly. "My own mouth" can never articulate the law as absolutely transcendent to it.

In what follows I explore the question whether a conclusive figure of ethical signification similar or transverse to the one employed by Levinas, does, nevertheless, operate in Husserl's notion of subjectivity. In particular, I analyze in both thinkers the moment of "inwardness" as a conclusive stage of ethical signification. This moment is traced throughout Levinas's reading, utilization, and radicalization of key phenomenological constructs. One question is applied to both thinkers in two 
intersectional perspectives: Is it possible for subjectivity to be understood as an interiorized articulation of alterity? The two directions of this question are treated as an integral, yet irreducible structure of signification, repetition, and interruption. If Levinas was able to discover in Husserl's "intersubjective reduction" a "possibility of sobering up," 110 then Husserl's concept of subjectivity must have already preserved a certain priority of the other. Otherwise, Levinas's going beyond Husserl would intermediately return to the same. If the figure of ethical obligation is to be founded "again and recounted in the immanence" it has to be structured as a reiteration signifying precisely the otherness of the other discourse. ${ }^{111}$

\section{Ipseity and Ego}

Ethical signification for Levinas is not a relation structured in consciousness. It is neither a particular state of affairs nor a universal fact of reason. It is not an objective or intersubjective kind of experience. In one word, it is not a relation conditioned by representation. Yet, in a specific sense, ethical signification is inherent to subjectivity and takes place as sensibility. Levinas's famous — and indeed somewhat schematic — formula is that it is a movement to the Other without return to the Same. The ethical priority and phenomenological exceptionality of this movement consists in the double function of its transcendence. In Otherwise than Being Levinas describes this function as a coincidence of two structural moments, the moment of "by-the-other" and the moment of "for-theother." "Proximity" is the key figure he employs to characterize the first moment as a distinctive sensibility established in a pre-intentional temporality:

Proximity, suppression of the distance that consciousness of ... involves, opens the distance of a diachrony without a common present, where difference is the pasts that 
cannot be caught up with, an unimaginable future, the non-representable status of the neighbor behind which I am late and obsessed by the neighbor. This difference is my non-indifference to the other. Proximity is a disturbance of the rememberable time. $(O B$, 89)

The ethical relation configures not only the sensible exposure to the other. It involves equiprimordially a mode of sensible constitution of subjectivity which is prior and irreducible to consciousness as self-presentation. This specific mode of constitution Levinas designates as "substitution." The structure of substitution - which anchors the second moment in the ethical relation - is not only antecedent to intentionality. It is intentionality's complete inversion. In substitution the immediate sensible differentiation established in proximity is in turn "transferred" to the other. Substitution is accordingly not merely a relation to the other. It indicates the primary passivity of subjectivity in which the subject has relinquished the relation itself. The very constitution of the ego is thereby configured as responsibility for the other. The ego is but a replacement for the other by virtue of which it "recurs" "to the hither side" of spontaneity, before any capacity to escape the relation and thus as absolutely singular self. The temporalization that occurs in substitution hence introduces a time older than the time unfolded in intentionality, the time in which the subject itself is constituted. Levinas refers to this temporality as the temporality of creation:

In this context $[\ldots]$ is already effected the absolute diachrony of creation, refractory to assembling into a present and a representation. But in creation, what is called to being answers to a call that could not have reached it since, brought out of nothingness, it obeyed before hearing the order. $(O B, 113)$

In Husserl's analysis of internal time-consciousness, according to Levinas, the event of proximity is already signalled by the fact that "consciousness as such [is] described in the 
temporality of sensation" (OB, 32). However, by admitting the simultaneous work of intentionality, Husserl leaves this moment unsecured and runs the risk of representing and thematizing its original exteriority. By the necessity of an active ego for lived experience (Erlebnis), intentional acts, despite their directedness toward the transcendent, are already identical contents. Anything that appears is, by virtue of its positing act, a return to the same. Any past, future, and punctual presence is already within or at the threshold of consciousness by the "constitutive phases" of "retention" and "protention." Lived experience in general, taken as universal possibility of appearing, reveals the original event of primal impression (Urimpression) in the same plane as being, as the possibility of every possibility. In the movement of responsibility, as Levinas conceives it, nothing is present except the subject in its nuclear purity. Properly speaking, the subject is not. In order to be, it has to become compound, that is, to represent itself, as well as the copula of the verb to be. Prior to any suchlike ontological simultaneity, the subject is set to signify by itself, for the other. This alterity, remaining absolute and irreducible, being neither absorbable nor attainable, is the condition for presence and representation. It is what ultimately holds presence into question and precedes it without any succession and continuity. Never contemporaneous with presence, alterity does not enter into a relationship with it. Prior to being and consciousness, it holds the subject responsible for the other. The subject must have responded before any dialogue has arisen, and indeed, before any question has been presented. The response thus cannot have a phenomenal character and can never be conclusive in itself. The subject is infinitely responsible for the other, and never correspondent to it. It is beforehand, assigned and obedient to what is beyond. 
Levinas however is far from opposing this figure of ethical signification to Husserl's "egology." Indeed, almost paradoxically, phenomenology provides the only possibility for a "proper" thematization of the ethical. In the last chapter of Otherwise than Being Levinas restates this phenomenological legacy:

Our presentation $[\ldots]$ remains faithful to intentional analysis, insofar as it signifies the locating of notions in the horizon of their appearing, a horizon unrecognized, forgotten or displaced in the exhibition of an object, in its notion, in the look absorbed by the notion alone. $(O B, 183)$

Phenomenology is taken as that "ultimate discourse" of philosophy which, by disclosing the world in the totality of its appearing, sets the possibility for its own conclusive interruption. The series of phenomenological reductions have already demonstrated how, as a result of the regressive exclusion of the natural world, psychological subjectivity, eidetic content, and especially objective time, the transcendental ego emerges precisely in its pre-intentional status. ${ }^{112}$ Levinas's notion of substitution, for its part, is the radicalization of this moment. As a movement that signifies "enigmatically," that is "without making appear," it is situated "with respect to the phenomenology it interrupts. ${ }^{113}$ What is noteworthy here is that this perspective of interruption is possible only from within phenomenology, that is as a gesture that takes its point of departure as a recurrence of the subject on the hither side of intentionality. Significantly enough, this is precisely the point at which Husserl arrives every time he attempts to radicalize the phenomenological epoché. As early as in Ideas I he writes:

If we retain a pure Ego as a residuum after our phenomenological exclusion of the world and of the empirical subjectivity included in it [...], then there is presented in the case of that Ego a transcendency of a peculiar kind - one which is not constituted - a transcendency within immanency. Because of the immediately essential role played by 
this transcendency in the case of any cognition, we must not undertake its exclusion...(

Hua 3, 109-110/133)

Obviously, the distinction between phenomenological and ethical sign is not a typical one. Phenomenon and trace are not two types of significatory relations. Moreover, this is not the distinction between "meaningful" and "meaningless" sign, the distinction between "expression" and "indication" that Husserl draws in the First Logical Investigation. The distinction (if this term is still relevant here) seems rather to be a matter of conclusiveness of transcendence. What does this distinction consist in?

It is true that, in the "series of interruptions" carried out through phenomenological reductions, the same is, as Levinas puts it in "Consciousness and Wakefulness," "infinitely brought back in its most intimate identity to the Other."114 However, according to Levinas, this infinite repetition in Husserl is not dismissed by a conclusive ethical gesture. It remains within the constantly reiterated pattern of "retrocendence." By this pattern the ego is unceasingly kept "vigilant" for transcendence, while residing at the doorway, always open for a return to a revision and new purification. This state of "sleeping and not sleeping" can be discerned within the very purity of the ego. The transcendental ego is "transcendence in immanence" precisely by the fact that it can be neither reduced nor constituted. It slumbers in the identity of every intentional act and wakes up in the interruption of every reduction. In Ideas I Husserl himself describes this "peculiar combination" with a much more definitive emphasis:

[T]he Ego living in mental processes is not something taken for itself and which can be made into an Object proper of an investigation. Aside from its "modes of relation" or "modes of comportment," the "Ego" is completely empty of essence-components, has no explicable content, is undescribable in and for itself: it is pure Ego and nothing more. (Hua 3, 160/191) 
Does not this emphasis on the pre-intentional status of the ego already of itself contest the radicality of Levinas's departure from phenomenology? One might hastily assume that in its not-being-for-itself Husserl's "ego" is already inherently hetero-affective, reduced to itself and entirely assigned to signify as substitution for the other. At the stage of the reduction the ego is caught up before being "immediately inverted into activity" (OB, 142). It is not yet "for itself." It is "what remains behind" the rays of its own "constitutive effects," beyond or on the hither side of the sphere of lived experience. But, by not being "for itself" is the transcendental ego in fact irreversibly "for the other"? Is the difference that distinguishes it from its "modes of relation" already the "non-indifference" of ethical subjectivity? Does the ego's “transcendence in immanence" implicate an ultimate passivity that would prevent it from a recuperation back into the for-oneself of the ego's living self-experience in its acts?

The single answer to these questions is given by Husserl himself who acknowledges the incapacity of the phenomenology of the internal time-consciousness to conceive the diachrony of "primal impression" as a structure constitutive of consciousness itself:

What about the beginning-phase of an experience that is in the process of becoming constituted? Does it also come to be given only on the basis of retention, and would it be "unconscious" if no retention were to follow it? We must say in response to this question: The beginning-phase can become an object only after it has elapsed in the indicated way, by means of retention and reflection (or reproduction). (Hua 10, 119/123)

"Primal impression," the proto-temporal event that seems to generate the passive constitution of the time of consciousness, already implies, according to Husserl, a certain thematizing activity. For him consciousness is necessary in each of the phases that constitute temporality and it is not only meaningless, but also impossible to articulate an 
"unconscious content that would only subsequently become conscious."115 Thus "in Husserl," as Levinas concludes, "the time structure of sensibility is a time of what can be recuperated" $(\mathrm{OB}, 34)$.

But what does then Levinas's radical gesture with respect to phenomenology consist in? Such a gesture, to be sure, is one of the main endeavours of Otherwise than Being and, significantly enough, the book remains to a great extent faithful to phenomenology. It will be set off by a reduction which Levinas will still call "phenomenological" and will culminate in substitution in which the ego will have to eventually "concern itself also with itself" $(\mathrm{OB}, 128)$ in order to become valid not only for the neighbour as a particular other but also for "Him" as a third party, and thus to ground justice, consciousness, and reason.

\section{Phenomenological and Ethical Reduction}

Levinas is explicit that the reduction in Otherwise than Being is not a simple rejection of Husserl's transcendental ego. In fact, it presupposes the series of phenomenological reductions and the ego's "transcendence in immanence." Thus Levinas will tell us that, despite its necessary correlation with the noematic forms of apprehension and reproduction, the temporal openness in Husserl allows us for the first time to locate the possibility of a meaning different from the auto-affective intentionality of consciousness. Such a finding will lead Levinas to outline a primal modality of language whose function is not reducible to the identification of the "as-structure." The distinction between "the said" and "the saying" whose operation is crucial for the argument of Otherwise that Being will thus proceed precisely from the "hither side," which is already recognized in 
the phenomenology of lived experience. The problem that requires an urgent consideration, Levinas warns us, lies in the fact that the saying that operates in phenomenological sensibility does not acquire the distinctive capacity to signify "otherwise than being." The reason for this incapacity is that this saying that has already emerged in the "passive synthesis" of "retention" and "protention" still retains a strict correlation to the said constructed in memory and imagination. The only meaning it attains in Husserl is therefore articulated in terms of being and in the form of phenomenon. The unavoidable correlation with the noema of the said maintains the completely reversible status of Husserl's saying. Circulating within "the bad infinity of the Sollen" (OB, 142), it constantly deposits itself in a theme immediately absorbed in the phenomenal how of identification. Thus Levinas seems to be certain that in Husserl—at least in his early writings ${ }^{116}$ - the other is signified only provisionally. Husserl fails to reiterate the signification of the saying in a way different from its own reiterations in the epoché. For him, after all, such reiteration would amount to an effacement of the essence of Erlebnis, of the primary content of philosophy as apodictic and rigorous science.

The purpose of the reduction in Otherwise than Being is to carry out precisely what, according to Levinas, Husserl has undertaken but was unable to bring to completion. The ego's "transcendence in immanence" has to recur "on the hither side of the comprehending activity or passivity in being" $(\mathrm{OB}, 43)$. This recurrence will have to reintroduce its passivity in such a way that it becomes irrecuperable within the selfpresence of intentionality. It should show how the ego signifies conclusively for the other in a signification proper to this precise relation. Thus Levinas writes:

[T] he reduction is reduction of the said to the saying beyond the logos, beyond being and non-being, beyond essence, beyond true and non-true. It is the reduction to signification, 
to the one-for-the-other involved in responsibility (or more exactly in substitution) [...] It is the reduction to restlessness in the literal sense of the term, or to its diachrony ... (OB, 45)

What is unique in this reduction is not simply the fact that it reveals the proper ethical signification in a distinctive purely transcendent sensibility. What is unique in comparison to Husserl's reductions and with respect to the possibility of an actual ethical experience is rather its procedure and its aim. Levinas is explicit that the operation of his reduction does not consist simply in the "bracketing" of the said and the assigning the saying to signify freely. If this were the case, nothing would distinguish it from an alternative and in fact blind positing of a different ontological possibility, a said replacing a prior said. It is precisely because its aim is to demonstrate the recurrence of the subject in itself as diachrony that the ethical reduction requires the presence of the said. This is why Levinas is so insistent in emphasizing that "to expose an otherwise than being will still give an ontological said, in the measure that all monstration exposes an essence" $(\mathrm{OB}, 44)$. In order to be introduced as an ultimate affection and passivity whose signification is never representable, the saying must affirm the said whose presence it outstrips. But what is most important, this affirmation must not be simultaneous to what is affirmed as the indication of Husserl's "primal impression” was for consciousness. Levinas's reduction therefore is a reduction of the very correlation between the saying and the said or, more precisely, of the simultaneity of this correlation. He will definitively point at this unique characteristic:

The reduction then will once again let the otherwise than being be as an eon. As the truth of what does not enter into a theme, it is produced out of time or in two times without entering into either of them, as an endless critique, or skepticism, which in a spiralling 
movement makes possible the boldness of philosophy, destroying the conjunction into which its saying and its said continually enter. $(\mathrm{OB}, 44)$

The exposition of the signifying of the saying does not efface the ego itself and therefore does not simply eliminate the noematic sense constituted in its intentional acts. It effaces rather the incompleteness of the ego's transcendence. That is to say, it puts the subject and its activity completely out of phase. It interrupts nothing but the interruption that has already occurred. It can reduce neither the pure ego nor its lived experience. To be sure, on no account does Levinas's reduction of the contemporaneousness of Husserl's reductions consist in some kind of Hegelian preservation of the sign as a logical moment of the whole. Nor is it a "thrownness" in the world within the horizon of an ecstasis towards being. In ethical signification the self-identity of the phenomenological meaning is completely absolved. However, Levinas's conclusive gesture would lapse into one of these alternatives, if it were not protected by the pre-intentional recurrence of the subject in itself. In order for the I to be absolutely alienated from itself, it must be left absolutely alien to the other. This does not mean only that any synchronic relation must be excluded. What must also be reduced is the possibility of the phenomenal, both concrete and abstract, appearance of the other as a theme. Otherwise, the withdrawal from Husserl's "transcendence in immanence" would bear the "phantom" meaning of a permanently particularized double. "Saying," Levinas points out, "signifies otherwise than an apparitor presenting essence and entities" $(\mathrm{OB}, 46)$. However, this is not to say that the ethical signification happens somehow outside of the world and has no reference to the concrete experience of the other who I merely encounter and to the abstract consideration for the other I never encounter. The reduction of the ego's relation to the world does not mean an exclusion of the world itself. It means rather that the ego and the 
other enter the world otherwise and signify within it by virtue of a sensibility that is not external but diachronic to it. This inherent trait of the reduction gives Levinas reason to declare that the task it assigns to us "is to show that the plot proper to saying does indeed lead to the said, to the putting together of structures which make possible justice and the I think" (ibid.).

Through the ethical reduction of the copula understood as a correlation between the saying and the said, the subject and the noema, we discover a completely different dimension of subjectivity. This is the dimension of "inwardness" in which the subject is structured as an immediate "folding back upon itself" $(\mathrm{OB}, 110)$. Prior to any passage through the for-oneself of consciousness, the subject recurs "on the hither side" of its lived experience. This recurrence is not another, purer self-presentation. It is a doubling of the ego's passivity, “a sign of its very signifyingness, an expression of exposure ... denuding of denuding without this "reflection" or this iteration having to be added afterwards to the denuding" $(\mathrm{OB}, 49)$. As Levinas makes it clear, it is this doubling that secures the proper signification for the other and it is exactly this moment of inwardness what he considers to be the ethical going beyond or radicalization of phenomenology. The structure which Levinas describes as a definitive establishing of this doubling is "substitution," the relation in which I am not only by- or from-the-other but already and conclusively for-the-other.

Obviously, according to this account, in its vigilance Husserl's subject signifies incompletely. It remains at the "frontier of dethematization [...] as a modality of the approach and contact" $(\mathrm{OB}, 47)$. This "openness" to the other which Levinas identifies as the "apophansis" of the signification is therefore already a certain form of proximity. The 
intentionality in this proximity however is not yet inverted to the point at which the subject itself becomes a signification for the other. Husserl thus fails to recognize the structural possibility of substitution. He stops at the stage where, in the "amphibology of being and entities," the other appears as a provisional interruption of auto-affection which, although it comes from the other, is not yet a subjectivity for the other.

But again, following the thread of Levinas's reduction as a way to the recurrence that takes place in substitution we could critically reinforce and deepen the questions concerning the status of subjectivity in Husserl and its ethical radicalization. If, as Levinas assures us, the immediate "reflection" or doubling of the ego's passivity is not "added afterwards" but occurs as the ego's pure inwardness "on the hither side" of the sphere of consciousness, would it not be plausible to assume that such doubling already operates in the transcendental subject? Furthermore, might Husserl not at a certain point have discovered or discerned this immediately close possibility within the structure of the ego? Indeed, the solipsistic "nucleus" of phenomenological expression, that "what remains behind" the possibility of actualization, must first be taken as indifferent, in order then to be conceived as non-indifferent. Non-indifference is not a mere difference. It demonstrates the solipsism of diachrony. But, to be conclusively given to the other means exactly to be conclusively irreducible to the other. "Conclusive" in the latter sense means that the irreducibility to the other is an irreducibility to oneself.

\section{Substitution and the Interiority of the Will}

Levinas is certain however that Husserl's omission to allow for a conclusive ethical figure takes place precisely at the very level of the ego. The transcendental "ownness" of 
the ego is not the definitive "inwardness" of the ethical witness. The "secret place somewhere in me" keeps its exteriority undifferentiated within itself. The ego is, from the outset entangled with its intentionality. The radical non-indifference of signification in substitution has not occurred. Within the transcendental ego, its ultimate passivity is undistinguishable from its constitutional activity. Such distinction however is crucial for the structure of the-one-for-the-other. The status of the subject in substitution is inherently anarchical. "It undoes thematization, and escapes any principle, origin, will, or arche, which are put forth in every ray of consciousness" (OB, 101). Levinas finds the cause for the primary undistinguished status of Husserl's conception of subjectivity precisely in the latter's notion of the ego's living present (lebendigen Gegenwart). Indeed, the status of the ego as a living present already demonstrates its awakening. The living ego never becomes an explicit theme. Nonetheless, this status also conditions the infinite iteration of its self-presence (Selbstgegenwart). The whole rigorousness of phenomenology is embedded in the ego's life because the sense of its life is what allows the subject to be inexhaustible in its constitutional activity. By being a life and not an essence, however, the ego faces what is beyond its acts. It succumbs to its passivity. The "living presence [of the subject is] the absolute traumatism that is inseparable from the spontaneity of its upsurge."

Yet Husserl himself seems to be at least watchful against the possibility of such blending. The main concern of his rejecting of psycho-physical parallelism is to guarantee precisely the distinctive and pure status of the ego in itself prior to its intentional acts. In Appendix XXIV to the Crisis he indicate this primary status of the ego as an initial self-reflection (Ichreflexion): 
Natural self-experience as my psycho-physical being and thus my being as my

"animated" body $[$ Leib] must be sharply distinguished from the self-reflection in which the ego as an ego of my affections, strivings, volitions, and acts takes on and would observes itself $[\ldots]$. The self-reflection of the ego as ego is a condition that precedes the temporal apperception of this ego. (Hua 6, 486)

Husserl explains the structure of naturalization of the ego as a self-observation in which the ego perceives itself as an entity that "animates" the body and establishes a pannaturalistic system. However, he distinguishes strictly this natural self-experience from the self-reflection, in which I conceive myself as the ego of my intentional acts and which is a basic distinctive feature of the phenomenological method. This understanding of the status of the subject is of crucial importance for the interpretation of the transcendental ego as a passive recurrence "on the hither side" of intentionality. The ego discerns itself with respect to the presence of intentionality, exclusively as absolutely distinct from it. By this distinction, strictly speaking, the ego in itself can never be conceived as activity. Its self-reflection is not the phenomenal self-possession and representation of the noesisnoema correlation but an immediate genetic exposure which establishes the ego itself. Yet Levinas does not take Husserl's overcoming of psycho-physical parallelism to be an overcoming of the amphibology of the ontological difference. What he grants Husserl's primal impression is far from the double passivity of substitution. For Levinas, the phenomenological notion of primal impression "lies in the depths of intersubjectivity," and, to be sure, "Husserl does not doubt that such a ground exists. His first certainty is that an origin exists"

In fact, Husserl insists that he has avoided all ontological presuppositions precisely by presupposing the ego as a source of intentional acts and not as a "psyche latent in intentionality". According to Levinas, however, the problem lies in the very 
correlation between subjectivity and intentionality. This correlation does not allow for a strict and irreducible ethical difference because to be a source would already mean to be intentional and this would clearly amount to spontaneity. The saying that is somehow awoken in the transcendental ego remains "negotiable" through the intentional said. Levinas points at the condition and structure of this reversibility:

Despite the extension which phenomenology gives the word intention, intentionality bears the trace of the voluntary and the teleological. Signification is signifying out of a lack, a certain negativity, an aspiration which aims emptily...” (OB, 96)

The parallel between "intentionality" and "intention" is not completely relevant to phenomenology. Not every intentional act presupposes intention (e.g. passive constitution). Being completely aware of this rather terminological distinction, Levinas will still insist that in Husserl intentionality "retains the initiating and inchoative pattern of voluntary intention" $(\mathrm{OB}, 101)$. What unlocks the voluntaristic moment within the transcendental subject is certainly not the fact that it is free in its constitutive acts but the condition that its original genetic passivity is not transcended again so as to reaffirm the subject in itself as a substitution for the other. A notion of a non-voluntaristic ethical subject for Levinas would thus not coincide with the vision of a morality, which is nonfree and constrained by norms. Quite the contrary, a subject, whose passivity is still more passive than any passivity or activity, reaffirms its freedom and its will by virtue of the diachronic inversion of the relation. By "contracting" in itself, ethical subjectivity is precisely "locked" or interiorized outside of itself. This already invokes its freedom otherwise - through an objectivity that comes not from consciousness but from justice based on the irreversibility of substitution. Here is how Levinas describes this movement: Through substitution for others, the oneself escapes relations. At the limit of passivity, the oneself escapes passivity or the inevitable limitation that the terms within relation 
undergo. In the incomparable relationship of responsibility, the other no longer limits the same, it is supported by what it limits. Here the overdetermination of the ontological categories is visible, which transforms them into ethical terms. In this most passive passivity, the self liberates ethically from every other and from itself. (OB, 115)

Regardless of how pure Husserl's Ichreflexion is, it would lack, according to Levinas, this final gesture of re-constitution of consciousness in the mode of substitution. On the best account, it would remain only at the level of the particular proximity of the neighbour without being able to justify the status of the other as a third party, as Ileity "with respect to another who is also a neighbour" (OB, 128) and, thus, to ethically explain freedom, consciousness, and reason.

In fact, it is essential to point out that Levinas bases his critical reevaluation of Husserl mostly on references to the sphere of Erlebnis, that is, to the domain where the ego is taken with regard to its particular tasks. However, Erlebnis could not demonstrate the event in which the ego takes a task upon itself. If a voluntaristic nature were presupposed for the ego, Levinas's reference would be completely relevant. However, we should first ask what makes this presupposition necessary. Is the sphere of Erlebnis valid for experience in general? Certainly, a presupposition of a self-willing will, a will that constitutes itself in its willing can be structured in phenomenology only by the form of a straight teleology, that is, by a progress toward the content of an idea formed in selfconsciousness. But does phenomenology indeed presuppose such an idea? Or rather the order of the telos comes from the outside and is only articulated within my inner sphere? If Husserl himself had implied the latter possibility in his notion of subjectivity, the subject's "transcendence in immanence" would rather mean a conclusive, that is, an interiorized priority of the other. In this sense, the telos in Husserl could have a "positive" 
meaning. Instead of securing the ultimate ground for the infinite iteration of the immanent, it would structure an irreversible recurrence coming from Illeity. The subject would have already been transformed into an example (i.e. an ethical sign) and philosophy into an exemplary (i.e. strict in an ethical sense) science.

\section{Illeity and Telos}

Conceived in its ultimate nature, the irreversible ethical figure introduces a form of ethical necessity arising neither from the autonomy of the will, nor even from the concrete bodily experience of another person. It proceeds entirely from the otherness of the other grasped distinctively in the aporia of diachrony as both the absolute concreteness of passivity and the absolute "abstractness" of its recurrence. It is this "abstractness" inscribed in my sensible passivity that maintains the necessity of the ethical structured through the figure of double signification.

Levinas understands this radical movement from which the necessity of obligation comes in the form of Illeity of the third person. In Illeity the other is irreversibly singled out and configured within the immanence of the subject. The other is not simply the "you," which is immediately present in a situation. Although this would also be another human being contesting and obliging me, suspending my self-identity, still, it is not "the wholly other." In this case my obligation is not yet irreversible. It can "be immediately inverted into activity" (OB, 142-43). While the "you" is the phenomenal blink of transcendence, the "He" is its conclusive sway. As already outlined, Husserl, according to Levinas, could not leave the "you" and remained revolving infinitely between the saying and the said. How do these perspectives illuminate each other? Does Husserl indeed 
remain in the "I-Thou" relation? Is not the specific frame of phenomenological teleology what makes possible a conclusive gesture in Husserl?

In the double signification of Illeity ethical command becomes definitive in a specific way. Its necessity does not arise from a complementary recourse to the moral autonomy of self-determining will. It demonstrates the impossibility of such a return. In it, the very identity of the subject is necessarily put into question. On the other hand, this necessity does not consist simply in the fact that my responsibility for the other is assigned to me entirely by the other and that I find myself accused or contested before any spontaneously originating commitment. In order for this irreversibility to take place, there must be a double assignment, "an exposure of exposure," "a passivity of passivity," or "an interruption of interruptions." The signification of subjectivity must transcend itself and also must mark this transcending as the only moment of its signifyingness. Strictly speaking, this signification does not involve a sign because it cannot appear. Levinas tells us that the very moment of transcending leaves a trace in which the sign stands. ${ }^{119}$ This signification is thus meaningless simply because it signifies nothing more than its own coming from beyond itself. It is formed in an event that never comes to presence and which, in fact, transforms the very presence into its simple sign. This, however, is already a presence "from which an act could not be born anew". (OB, 143) But, paradoxically, this is precisely the reason why, in this emphatic gesture, the particular meaning of the self is not obliterated. On the contrary, the self is itself in an absolute sense. It is the solus ipse that is ultimately separated from the other "by the interval or difference, or by the meanwhile which the non-indifference of responsibility does not nullify" $(\mathrm{OB}, 141)$. Thus not only is the subject "alienated" from itself as a 
natural self-experience, but it is also bound to itself as a sign of the infinite signification of the other. This signification is not structured as intentionality. It can neither indicate something, nor can it express meaning constituted by the acts of consciousness. Precisely because the giving of the sign is itself a sign given to the other, it can never pass to the other denoting its meaning in a correlative relation. The other cannot be disclosed in meta-linguistic invariants and a discourse speaking of the other must be radically closed within itself.

Since, in responsibility, the subject is assigned by the other as this particular "me" and not other, signification has the potential to reintroduce the subject "in the depths of its identity" (OB, 141). Thus the subject is ultimately determined and "irreplaceable" in its uniqueness. This determination reinstalls the self in its difference modifying it into an interiorized transcendence. This is the "supplementary" signification within the first one that defines the self as obedience in the form of an imperative. Through this "supplementary" movement, the constraint coming from the other obtains a strict irreciprocal necessity. My voice cannot recover to the privileged state of being an instrument of appropriation of meaning. It is rather set as an "example" which articulates the Law without presenting it authentically, without pronouncing it. (OB, 147)

Could we assume that the self-reflecting ego in its absolute distinction from intentionality is configured by the subject's double signification for the other? The fact that the ego precedes all its acts and is, by this, irreducible to them does not suffice for such an assumption. Levinas is convinced that Husserl is unable to move to the stage of non-phenomenal signification. Summarizing Levinas's thesis of the voluntaristic preservation of the immanent in phenomenology, we can discern two perspectives 
inherent in the ego. Firstly, the ego's signification is incomplete. Through the bodily preobjective relation of kinaesthesia, the other enters in a sensual relation as "you." The ego, however, returns to identity by the intentions arising towards "this particular other." Remaining only a sensually experienced proximity, this signification is provisional. It occurs ad infinitum being reiterated in consciousness by every stage of uncertainty. Secondly, through the infinity of this iteration the ego signifies "emptily in its activity," that is, it signifies only its finitude, its death, and the lack of the other. Thus, according to Levinas, Husserl never allowed Illeity to dislocate transcendental subjectivity from the infinity of its finitude to the infinity of Glory.

Obviously, Husserl seems to remain faithful, even in the Crisis, to the return to the Sachen selbst. The teleological critique worked out in this later work is a fulfillment of the task of philosophy in the horizon of intentionally conceived "total unity of history" (Hua 6,71-72/70-71). The meaning which is to be elaborated and clarified in this historical analysis arises from the intentional possibility of my intentional life. This is in fact the telos of philosophy grasped in the a priori sense-intuition of my self-reflection. The starting point of philosophy is thus its empty and general theme, its own thematization. (Hua 6, 161/157) And since transcendental attitude "is the achievement of experiencing, pre-scientific life" (Hua 6, 70/69), transcendental philosophy begins with a pure anticipation of the sense of my life. Conceived as a noematic content or a task, this anticipation takes the form of a universal will and becomes an ultimate regulative of my personal life, a ground of my personal project (cf., Hua 6, Beilage XXIV, 485-491). The "constant teleological critique" of Western science that Husserl undertakes in the Crisis, thus seems to presuppose a presence that precedes any moment of my acts as an 
individual subject. In other words, the intentional attitude which is constitutive of the will as a norm is at the same time regulated by it. And this is nothing other, Husserl says, "than the philosopher's genuine self-reflection on what he is truly seeking, on what is in him as a will coming from the will” (Hua 6, 72/71).

This structure, if we are to take Levinas's perspective, demonstrates the constant passage of the saying to the said. It reflects completely the ambiguity embedded in the "living present of the ego." The "general theme" of the will is essentially perceived within the egos' self-reflection whereby it is taken as a basis of the totality of history and personal life. The passive aspect of the subject, the exposure to tradition and the others should thus be gradually reduced in the epoche through the process of fulfillment of the task. By this procedure, as Husserl believes, can be explicated their original ethical meaning: their correlate within the pure sphere of the self-reflecting subject. But, insofar as the task of philosophy is thus placed within a presence projected beyond the immediate experience of the other, passivity is from the outset, subservient to the totality of the will.

Indeed, Husserl emphasizes the opening of the teleological structure starting from the individual and corporeal correlate and pointing at the passive and concrete kinaesthetic moment of its emergence:

Every first description here is of necessity rough, and soon one is faced with the enigmas caused by this implication of nonactive manifoulds of appearances, without which no things, no world of experience, would be given to us. And soon we are also faced with the difficulties of concretely unfolding this a priori of correlation. (Hua 6, 163/159)

And also:

Here my own living body alone, and never an alien living body, can be perceived as living; the latter is perceived only as a physical body. In my perceptual field I find myself 
holding sway as ego through my organs and generally through everything belonging to me as an ego in my ego acts and faculties. (Hua 6, 111/107-108)

It is in this kinaesthetic sensation that Levinas recognizes the genuine possibility of ethical signification in Husserl. Through the Leib, the ego is not only situated and individualized as a Körper. It is also immediately exposed to transcendence. The living body opens the ego towards the world and at the same time keeps it "prior" to the world. Despite the fact that the immanent aspect of the ego instantly unfolds itself into series of intentional horizons and purifications, by this "transcendental aesthetic" (as Levinas often calls it) ${ }^{120}$ underlying the teleological structure of infinite tasks, the experience of the living body is a "liberation of the subject ... a gait, a freedom that demolishes structure." ${ }^{121}$ Yet, as suggested above with regard to "the living presence of the ego," Levinas would not admit that within its peculiar structure, within its "inwardness," the ego signifies conclusively for the other. Corporeity in Husserl signifies provisionally precisely because it still remains pierced by the intentional "radiation." Moreover, it is beforehand comprehended within the ideal totality of the "thesis" of sense-intuition. Kinaesthetic phenomenological experience would, therefore, remain a "consciousness of the possible, ${ }^{122}$ that is a transcendental signification for transcendence. Husserl's Leiblich-keit is already the body conceived in its transcendental structurality, that is, in its indifference to the other. The immediacy of the meaning of the body, its being the "original iteration" ${ }^{, 23}$ cannot maintain the difference necessary for an absolute signification. The infinity of iterations of the same goal-setting (Zielstellung) can never pass to the Illeity of the other. It remains entangled in the "bad infinity" of the "you."

Did Husserl not make a conclusive ethical gesture? Did he not, at a certain point, allow for a repetition, traverse to the iterative intentional procedure? To him the 
possibility of infinite repetition remained, even in the Crisis, "part of the essence" of the phenomenological reduction. In a sense, in the later Husserl, it only acquires an ethical validity. In Kaizo III Husserl conceives repetition as a distinctive characteristic of man. The ethical essence of repetition consists in the capacity of human beings to direct their acts towards an ideal content established as a task or a norm (cf. Hua 27, 25). This is an intentional structure, allowing them to devote their lives to certain value-complexes arising from the primary sense of their lives. And this is the meaning in which Husserl uses the expression "Beruf," "vocation." Through "vocation" I am able to discern in my inner sphere the particular habitual interest, value-complex, idea or professional field to which I should devote my life. Can we say that "vocation" comes entirely from the other and, resounding in my "inwardness," signifies entirely for Him?

Husserl points out that the endless stages of reflections, corrections, and accomplishments, in general, the repeating practices in which I constantly pursue my personal task, still remain only part of my activities as an individual subject. Despite being devoted entirely to my vocational task, in actuality, my personal life is not totally subordinated to it. Vocation thus has a "special sense." "[A]s normal human beings we are constantly ... involved in many "vocations" ... Every such vocation has its time of actualizing" (Hua 6, 139/136). We could say, with Levinas, that vocation still involves only a provisional ethical signification. But Husserl's suggestion is somewhat more complex. He points out that vocation should be approached in two steps: "first in respect to human beings and then universally" (Hua 6, 192/188). Can we say, then, that the "universal" vocational step introduces a conclusive stage of obligation? Toward the end of the main text of the Crisis Husserl writes: 
$[\mathrm{P}]$ henomenological reduction — and this is part of its essence — could reveal its sense, its inner necessary requirements, and its scope only in steps. Each step required new reflections, new considerations, which in turn were possible only through the selfunderstanding and the practiced accomplishment of the other steps. ... In order to attain its total horizon, the phenomenological reduction would require a "phenomenology of the phenomenological reduction.” (Hua 6, 252/247, my emphasis)

For Husserl, no doubt, the second movement has a definitive and finalizing character. The task of a philosopher, no matter how general it seems, "finds its place among the other life-interests or vocations and it has its "proper time'” (Hua 6, 139/136). In Kaizo III Husserl even suggests that without this total movement, vocational forms are still "pre-ethical." 124 To be sure, the universality of the radical epoché is not a result of a total self-reflective act. What puts philosophy into question is not philosophy itself. The radical epoché is rather the very consciousness of crisis. To indicate this radically different moment, Husserl introduces in the Kaizo articles a concept distinct from that of iteration: renewal (Erneuerung). The teleological task announced by renewal is assigned by history, by a certain epoch and a certain moment. "Renewal is the universal call in our present sorrowful age, and through the entire domain of European culture" (Hua 27, 92). ${ }^{125}$ The role of the epoché is here a unique one. It is that initial reflection which purifies and establishes this task as my own personal necessity. In this sense, epoché is precisely this "original iteration" which always appears to be secondary. In this step, however, the epoché does not exclude the task itself. It rather interiorizes it, making it my own without assimilating its transcendence. What remains thus resistant to immanence even within consciousness, Husserl calls "primal institution" (Urstiftung). However, while "primal institution" is never fully thematizable, it must not remain a simple motif 
of the transcendental aesthetic. Its historical occurrence imposes on us the practical demand to interiorize it into a transcendental teleology.

At this point, it seems immediately discernable that a conclusive figure of ethical obligation never occurred within the movement of Husserl's ethical work. Even in the bottomless depth of the radical epoché, Husserl — the philosopher and the person — could not tear off from the flesh of the ego the correlate which never belonged to it: the world and language. However, by remaining in his "vigilance," in a conclusive inconclusiveness or teleological phenomenology, Husserl resisted Levinas's reading in a specific way. The impossibility of conclusive ethical gesture in Husserl is at the same time a possibility of a certain moral practice.

\section{The Problem of Communication in Levinas and Husserl}

The problem of temporality is crucial to Levinas's account of the relation between ethics and politics. It reveals the skeptical urgency at the center of his philosophizing as a tension between two times: singular and plural. By radicalizing the temporal aspect of Levinas's continuous debate with Husserl, I propose to translate the problem of the communication between ethical and political time in phenomenological terms: How can a relation of responsibility to the other be maintained as diachronically transcendent to the living present of the ego and yet take place and acquire a justification in the synchronic intersubjectivity of social order? My claim is that Levinas's answer stays at best with his skepticism. A more practicable answer is sought in Husserl's concepts of "primal institution" and "renewal." 


\section{Ethical and Phenomenological Reduction}

One of the turning points in the exposition of Otherwise than Being is marked by the already discussed procedure of "the reduction." The "methodological" input this procedure brings to Levinas's argument is quite different from the role the transcendental reduction plays in Husserl. One can even say that what the ethical reduction suspends are some of the key accomplishments of the phenomenological epoché. What is the nature of the relation between the two reductions? Did not Levinas discover in Husserl's intersubjective reduction a "possibility of awakening" for the alterity of the other?"126 Does this not hint at a more complex interconnectedness?

The notion of phenomenological reduction developed in Ideas I has become almost commonplace in the traditional philosophical discourse. It is well known how this methodological technique_- "the entrance-gate of phenomenology" (Hua 3, 52/56) as Husserl calls it — opens up and secures the access to the sphere of pure consciousness. It is precisely the main result of this procedure, the intentional correlation that is suspended in Levinas's ethical reduction. We must go back from the "amphibology of being and beings" based on this correlation to what is prior to it: the sensibility of the primal temporal experience of the alterity of the other.

Levinas is explicit however that the reduction in Otherwise than Being is not a simple rejection of Husserl's concept of subjectivity. In fact, it presupposes in a distinct way the purely subjective side of the correlation, the noetic sphere of lived experiences (Erlebnisse). Thus Levinas will tell us that, despite its inevitable representation in 
memory and anticipation, the primal impression in Husserl's phenomenology of time, "the primal source of all further consciousness and being" (Hua 10,68/70), is what allows Husserl for the first time to locate the possibility for a properly ethical signification. It is this discovery that will lead Levinas to outline a primal modality of language whose function is not reducible to the identification of the "as-structure." The distinction between "the said" and "the saying" whose function is crucial for the argument of Otherwise that Being therefore proceeds precisely from the already recognized in phenomenology "hither side" of consciousness.

Still, Levinas will insist that the saying operative in phenomenological sensibility does not acquire the distinctive capacity to signify "otherwise than being."

Despite the complete overlapping of the perceived and the perception in the $U r$ impression, [...], despite the non-modification of this "absolute beginning of this generation - the primal source, that from which all others are continually generated," this today without a yesterday or a tomorrow - the primal impression is nonetheless not impressed without consciousness. (OB, 33)

We can thus summarize the implications of Levinas's critique in two major points. 1) Despite the separate region Husserl allocates to the pre-reflective life of the ego, the contents of its temporalization are always and in advance apprehended in the perspective of objectifying intentionality; 2) Even if the flux of lived experiences were able to temporalize itself in a concrete unity — a possibility which Levinas is also ready to admit—it will always be liable to a lapse in the representations of memory and anticipation. It is not difficult to recognize in each of these objections an indication of a possible infinite regress. In the first case the regress proceeds from objectifying consciousness, in the second, from the temporal stream itself. 
The purpose of the reduction in Otherwise than Being is thus to carry out precisely what, according to Levinas, Husserl had undertaken but was unable to bring to completion. The flow of internal time-consciousness has to recur "on the hither side of the comprehending activity or passivity" (OB, 43). Such recurrence, as Levinas repeatedly emphasizes, must not be the recurrence of the reflective givenness of the "foritself." It will have to reintroduce the pre-objectifying impressional passivity of subjective time.

Husserl himself was not unaware of the possibility for a similar reduction. "The Introduction" to the lecture course on time-consciousness is early evidence of such consideration. Husserl's purpose there was to shift theoretical attention from the objective time of experiences to the domain of their immanent phenomenological contents. In this operation the factual existence of world time, as well as everything that might be experienced on the basis of its direct assumption is suspended. The procedure involves two moments. First, we "abstract from every interpretation that goes beyond what is given" (Hua 10,5/5). And second, within the sphere of what is given we "reduce the perceptual appearance to the given primary contents" (ibid.). That is to say, we reduce the aspect of apprehension and retain the sensual contents of the temporal field. What remains after the two moments of the procedure are carried out is an original quasitemporal field that has no relation to objective time. This field is structured entirely as a temporal succession of act-contents whose identity does not depend on the apprehension of a transcendent object. There is no objectifying intention running through the multiplicity of adumbrations (Abschatungen) that would render them present in secondorder unities. Put in Levinasian terms this is a temporal domain which is originally 
diachronic, material and out of phase. Husserl indicates the moments of this result by distinguishing them from those of the objective perspective:

Here we have contents separated in time; we even see, phenomenologically, a separation or division in time. But there is no division as far as the object is concerned: it is the same. In the object there is duration; in the phenomenon, alteration. Thus we can also sense, subjectively, a temporal succession where, objectively, we must confirm a coexistence. (Hua 10, 8/8)

At the time of his lectures on time-consciousness, Husserl had not developed the concept of transcendental reduction in the form we know it from Ideas I. But this is exactly what makes it significant. Husserl does not conceive of the intentional grasp of a transcendent object as an immanent intentional content. All that figures in the domain of subjective temporality is the phenomenological datum, the real (reell) contents that are immanent to the act itself. What he later formulated as irreal (irreell) immanent content and then termed noema is not taken into account. But this circumstance points at a feature of even greater significance: the reduction of objective time does not have as its result the explication of the intentional correlation. It is a reduction to what is prior to the correlation, to "hyletic data" or "sensuous contents" whose temporal unity is carried out as retentional modification exclusively based on impressional presentation.

What is the converging point between Husserl's suspension of objective time and Levinas's reduction of the said? In what sense can we say that the latter presupposes the former? And what is the new dimension discovered in Levinas's procedure? It is evident that a domain of constantly altering, dephasing itself, impressional temporality is already made accessible in Husserl's reduction. And this is clearly the proto-form of what Levinas calls diachrony, the sensible temporality that already does justice to alterity. But 
what then does the novelty of Levinas's reduction consist in? Does Levinas not point out that it must be a reduction of the said to the saying, showing "the signification proper to the saying on the hither side of the thematization of the said?" Well, actually this is not exactly the case.

What is unique in this reduction is not simply the fact that it reveals the proper ethical signification distinctive in a purely transcendent sensibility. What is unique is that it does not simply exclude the presence of the intentional object. Nor does it take the noema as an immanent, yet irreal, intentional content. It is precisely because its aim is to demonstrate the recurrence of the subject in itself as diachrony that the ethical reduction requires the presence of the said. Levinas will repeatedly emphasize this key moment: "The saying is both an affirmation and retraction of the said. [...] To expose an otherwise than being will still give an ontological said, in the measure that all monstration exposes an essence" $(\mathrm{OB}, 44)$. In other words, the ethical relation already contains the requirement that it be made communicable. It must be of itself already representable beyond its singular significations. It must be translatable in properly phenomenological terms, within consciousness, within the realm of politics and justice, in the synchrony of objective duration. In order for this to be possible the saying must affirm the said whose presence it outstrips. But this affirmation should not be simultaneous to what is affirmed. Levinas's reduction is therefore not a reduction of the said to the saying, but of the very correlation between them or, of their simultaneity.

The reduction then will once again let the otherwise than being be as an eon. As the truth of what does not enter into a theme, it is produced out of time or in two times without entering into either of them, as an endless critique, or skepticism, which in a spiraling movement makes possible the boldness of philosophy, destroying the conjunction into which its saying and its said continually enter. $(\mathrm{OB}, 44)$ 


\section{Proximity and Primal Impression}

"Our task," Levinas writes, "is to show that the plot proper to saying does indeed lead it to the said, to the putting together of structures which make possible justice and the 'I think"' $(\mathrm{OB}, 46)$. This passage reveals a political urgency at the center of Levinas's ethical thinking. It is not only possible but also necessary for us to account for justice in the realm of the social and this account must be based on its ethical exigency. But it becomes clear in the light of the ethical reduction that this transition can by no means consist in a mere deduction. In order to provide such account we must be able first to "fix the meaning" of the "plot" of the saying and reaffirm its irreducible difference from the said. What is at stake here is nothing less than the need to constitute subjectivity as a temporal singularity. Such fixing, according to Levinas, must take place as recurrence, as an immediate pre-reflective doubling of the subject "on the hither side" of intentional sense. Recurrence, according to Levinas, has a fundamentally temporal structure. It articulates what one can call passive self-temporalization. Otherwise than Being mobilizes to its extremes this aporetic schema. It puts the subject at work in separating and transversing, in desynchronizing and doubling. This work is carried out between the two main structural moments in the exposition of the book: the "by-the-other" of

proximity and the "for-the-other" of substitution. Proximity is the very opening of the 
signification distinctive of sensibility, a signification established in the passive synthesis of pre-intentional temporality:

Proximity as a suppression of distance suppresses the distance of consciousness of ... The neighbor excludes himself from the thought that seeks him and this exclusion has a positive side to it: my exposure to him antecedent to his appearing, my delay behind him, my undergoing, undo the core of what is identity in me. $(\mathrm{OB}, 89)$

But the proximity of the neighbor already points at and, in a privative way, implies the quasi-“equiprimordiality” (if we may twist here a Heideggerian term) of substitution. “Saying," Levinas writes, "is communication but as a condition for all communication." $(\mathrm{OB}, 48)$ What would be the temporal form that enables him to account not only for the signification proper to alterity, but also for its communicability, for all communication, and for the intersubjectively shared world of objects and institutions? Does Levinas have a "theory of political praxis"? And must not such a theory involve a kind of metaphenomenology? Should we not try to explicate the necessary reactivation of intentionality within the framework of a (im)possible institutionalization of ethics? In order to address these questions we should inquire whether a similar theory could not take shape in a Husserlian context.

The problem of a signification proper to the saying and, even of recurrence and substitution comes down to the possibility of an entirely impressional temporality. This notion is by no means foreign to Husserl's philosophizing; nor are the attempts to solve problems of infinite regress. In fact both themes are central to his analyses of time and appear in a closely intertwined way under the rubric of passive self-constitution and selftemporalization. It is the difficulty of infinite regress surfacing in the lectures on timeconsciousness that lead Husserl to introduce the notion of a subject entirely structured in 
the passive synthesis of time. The schema apprehension-content (Auffassung-Gehalt) that is initially used in these lectures turns out unable to eliminate the problem of the consciousness of time being itself of a temporal nature. Husserl attempts to address the issue by reworking Meinong's observation that "the duration of perception is not the perception of duration" (Hua 10, 66-72). If the temporal succession of sensual contents is apprehended in consciousness, then this apprehension itself must be in time. This would entail that the apprehension also involves a temporal content that requires another apprehension. Husserl realizes that this endless chain proceeds precisely from the structure of the schema. As far as apprehensions are conceived in an Aristotelian vein as mater-forming intentions, the problem will persist. This brings Husserl to the elaboration of the notion of an "absolute" or "primal consciousness" (Urbewußtsein). Primal consciousness designates nothing but the original sphere of the pre-reflective life of the ego, the flow of its Erlebnisse. Husserl introduces it in his lectures on Logic and Theory of Knowledge:

Now we engage in an eidetic analysis and by this we constitute the concept of experience that applies to every datum or dabile extended in phenomenological temporality. We constitute the concept of mere experience as that of the primal consciousness (Urbewußtsein) in which the datum has not yet become objective and yet is [exists], in which it has, and with evidence must have, its pre-phenomenal being (Sein). (Hua 24, 245)

A consciousness coinciding with the original eventness and passive synthesis of impressional alterations cannot be but a consciousness that temporalizes itself. Such selftemporalization has nothing to do with the constitution of time as an immanent object. Primal impression - which Husserl began to use as a concept in the very same lectures articulates the original passivity of the lived body that is prior to any interiority. It is only 
with the folding back of phases of primal impression, their doubling in retentions something like an inner sphere takes shape. Thus primal impression must be conceived as the "source point" (Quellpunkt) of all intentional consciousness including the intentionality that modifies and reproduces phases.

"Intentionality and Sensation," a text published a decade before Otherwise than Being marks the highest point in Levinas's acknowledgment of this dimension in Husserl. Yet after having recognized there "the unforseeable novelty" ${ }^{127}$ of primal impression, its "diachrony stronger than structural synchronism,," Otherwise than Being Levinas will already discern at the bottom of intentionality the sign of "the voluntary and the teleological" and across the impressional time-consciousness he will detect the recuperative work of representation.

As controversial and scattered as they may seem, Husserl's explications of primal consciousness in the lecture course on time and in the subsequent manuscripts, allow for at least one possible reading that may reveal in this concept a potential greater than Levinas was ready to admit. Such reading takes its bearings from Husserl's notion of self-awareness and is developed in his theory of the double intentionality of retention, its so-called transverse (Quer-) and length intentionality (Lengsintentionalität). What he calls noetic temporalization or self-temporalization would be possible only if "our regard can be directed, in the one case, through the phases that "coincide" in the continuous progression of the flow" together with this "can also be aimed at the flow, at the section of the flow, at the passage of the flowing consciousness from the beginning [...] to its end. Just as the retentional phase is conscious of the preceding phase without making it into an object, so too, the primal datum is already intended - specifically in the original 
form of the 'now' - without being something objective" (Hua 10, 119/123). Does this mean that the original temporal field involves something like folding back without making itself thematic? Put in the terms of Otherwise than Being, does this temporalization involve the anarchic passivity of a recurrence prior to and distinct from the temporalization of objects?

\section{Substitution or Institution}

The assumption that pre-reflective self-awareness in Husserl delineates a field similar to that of Levinas's temporal recurrence opens up a new set of questions. If Levinas's main purpose in outlining the diachrony of the subject was to establish the irreducibility of the ethical to the phenomenal, how should we understand his claim that "my responsibility for all has to manifest itself also in limiting itself' $(\mathrm{OB}, 128)$ ? Does his appeal to the third party require a properly phenomenological account? Would such exposition require the betrayal of the saying by the said? Or is there a mode of givenness proper to the third party? The translatability of ethical problems in phenomenological terms that becomes obvious here is by no means coincidence. It brings yet another perspective to the problem: must not the very questioning of the necessary passage from non-apparition to appearance already presuppose a dimension of historically conditioned communicability? Substitution in Otherwise than Being is a turning point, a condition for both separation and transition between ethics and politics. In a quasi-hermeneutic manner, Levinas will already have discerned its key aspects in recurrence: ethical experience is the experience of the singular and irreversible. I - the ethical subject - am a completely singular "I," an "ego" with no possible recourse to action. But Levinas will go further and 
stress a constitutive potential latent in this figure: "The oneself takes refuge or is exiled in its own fullness to the point of explosion or fission, in view of its own reconstitution $[\ldots] "(\mathrm{OB}, 104)$

But neither recurrence nor proximity would exhaust the full significance of alterity. Neither of them would articulate the separation and transition between the bilateral singularity of the ethical and the omnilateral phenomenality of the political. Levinas will have to ask "how does the passivity of the self become a "hold on oneself"? [...] [D]oes it not presuppose an activity behind the absolutely anarchical passivity of obsession, a clandestine and dissimulated freedom?" (OB, 113).

Substitution - Levinas's outright answer to these questions - takes place as a radical doubling of the relation. "In the incomparable relationship of responsibility, the other no longer limits the same, it is supported by what it limits. [...] In this most passive passivity, the self liberates itself ethically from every other and from itself. [...] Outside of any mysticism in this respiration [...] activity and passivity coincide." (OB, 115) The other will figure as both the absolute concreteness of the ethical and the absolute "abstractness" of its reactivation in the social. It is in coincidence and doubling of this "abstractness" and this "concreteness" that the moment of the third party will be articulated in Otherwise than Being. Yet this awakens one final and very simple question. To what extend can we account for the transcendence of the ethical within the social, if we abstract ourselves from the historical context of intended or intentional acts? In one of the formulations of his (as I would call it) "principle of uncertainty" Husserl claims that "to philosophize means not to know yet whether philosophy is a practicable project at all.” This uncertainty, ensuing from the radical epoché, provides the 
freedom to intervene in history. However, the entelechy of what Husserl calls primal instituting (Urstiftung) is not cancelled by the epoché. It is but rather interiorized; such interiorization is in fact necessary, if institution is to be "primal" in a genetic sense and not just in the sequence of exterior history. As a result, I-the-philosopher gain the ability to modify the telos of philosophy and thus to determine the course of its history out of my freedom. It is remarkable that such modification takes place within my reduced inner sphere, but still I perform it as having been taught (instructed) by history. The epoché of all tradition, the reduction to absolute interiority, entails neither reduction of history, nor some voluntaristic dominance of a will having no other measure except itself. What might here seem to be a lack of radicalism in Husserl should lead towards the conclusions of this text. To speak of relative justice or relative truth of certain formations of sense, among which the sense of the historical primal institution of philosophy, would mean that they are not treated as abstract. 


\section{CONCLUSION}

When he speaks of an instinctual and passive connection between monads, Husserl uses the terms of Mitteilung and Kommunikation rather loosely. But, in choosing them, he must have had in mind something along the lines that, regardless of the level at which it occurs, whether it is instinctual and passive or mediated and active, communication is inherently and acutely temporal; that its "flowing" is its constitutive characteristic and that, without this "flowing," it would not be communication at all. What is more, he must have thought that communication is marked by temporality in a greater degree than empathy and objectively mediated intersubjectivity, that indeed, it is intersubjectivity in its concrete becoming.

In this dissertation I have attempted to give an account precisely of this concrete becoming by tracing the operation of Mitteilung and Kommunikation back to Husserl's radical grounding of temporality in the pre-affective and pre-intentional dimension of the flowing living present. I suggested that, taking place "beneath and beyond" the affective awakening of the ego, instinctive communication, understood as a passive and associative Ineinander, is a generative condition for the transcendental becoming of empathy and sociality, which are relationships based on intentional acts. The concepts of Mitteilung 
and Kommunikation thus afford a developmental-phenomenological explanation of intersubjectivity and allow us to grasp the interpersonal relationship at the level of social potentialities and habitualities where "community is in its deepest ground already produced" (Hua 14, 405).

If we return to the clinical case cited in the introduction, we would be able to distinguish in the silent therapeutic engagement between Matsuo and his patient the subtle functioning of a non-thematic and indiscrete continuity, the continuity to which Husserl refers when he speaks of the pre-temporalization in the primal living flow. This flowing background continuity is precisely what we often find to be breached in cases of autism. By establishing a passive and habitualized communicative setting between himself and T., Matsuo managed to suspend the self-affective stimulation of egoic activity and to bring the relationship with T. to a level "prior" to the stream of experiences. This is a dimension presupposed, as Husserl convinces us, by both egoic passivity and egoic activity, by affections and actions, an "association and preconsciousness in the form of an ultimate hyletic underground" (Hua Mat 8, 53). 


\section{Notes}

\footnotetext{
${ }^{1}$ T. Matsuo, Chinmoku to jihei, bunretsubyosha no genshogakuteki chiryoron, Tokyo, 1987. The case is ${ }^{2}$ A bounty of research has been produced in an increasingly interdisciplinary framework, driven most notably by the encounter of phenomenology and cognitive science and attracting scholarship from numerous particular disciplines. Cf. Dan Zahavi \& Shaun Gallagher, The Phenomenological Mind: An Introduction to Philosophy of Mind and Cognitive Science (London: Routledge, 2008); Natalie Depraz, Francisco J. Varela, Pierre Vermersch, On Becoming Aware: A Pragmatics of Experiencing (Amsterdam: John Benjamins Pub., 2003); Shaun Gallagher, "Direct Perception in Intersubjective Context" in Consciousness and Cognition, 17 (2008), 535-543; Hanne De Jaegher \& Ezequiel Di Paolo, "Participatory sense-making: An enactive approach to social cognition", Phenomenology and Cognitive Sciences (2007) 6:485-507; Vittorio Gallese, "The Roots of Empathy: The Shared Manifold Hypothesis and the Neural Basis of Intersubjectivity", Psychopathology, 36/4 (2003): 171-80; Dan Zahavi, "Empathy and Mirroring: Husserl and Gallese", in R. Breeur and U. Melle (eds.), Life, Subjectivity and Art: Essays in Honor of Rudolf Bernet (Dordrecht: Springer, 2012); Dan Zahavi, "Empathy and Other-Directed Intentionality", Topoi, (2014) 33/1: 129-142; Michael Tomasello, Origins of Human Communication (Cambridge, MA : MIT Press, 2008); Vsudevi Reddy, How Infants Know Minds (Harvard University Press, 2008); C. Trevarthen, \& K.J. Aitken, "Infant intersubjectivity: research, theory, and clinical applications", Journal of Child Psychology and Psychiatry, (2001) 42, 3-48; Shaun Gallagher, "Inference or interaction: Social cognition without precursors". Philosophical Explorations (2008) 11, 163174; Shaun Gallagher \& Daniel Hutto, "Understanding others through primary interaction and narrative practice", in The Shared Mind: Perspectives on Intersubjectivity, eds. Zlatev, J. et al., (John Benjamins, 2008); L. Murray \& C. Trevarthen,, "Emotional regulation of interactions between 2-month-olds and their mothers", in Social Perception in Infant,. eds. T.M. Field, and N.A. Fox (Ablex, 1985); F.J. Varela et al. The Embodied Mind: Cognitive Science and Human Experience. (Cambridge, MA: MIT Press, 1991); Evan Thompson, Mind in Life: Biology, Phenomenology, and the Sciences of Mind (Harvard University Press, 2007); Andy Clark, Being There: Putting Mind, Body, and World Together Again (Cambridge, MA: MIT Press), 1997; Philip Rochat, Others in Mind: Social Origins of Self-Consciousness (New York, N.Y.: Cambridge University Press, 2009).

${ }^{3}$ Yamaguchi, Ki als leibhaftige Vernunft, 69-78.

4 "The Problem of Transcendental Intersubjectivity in Husserl”. in Schutzian Research, 2/ 2010, p. 40.

${ }^{5}$ To be sure, there is no evidence that Schütz was familiar with Husserl's late manuscripts where this distinction has mainly been worked out. Cf. J.N. Mohanty, Edmund Husserl's Freiburg Years, 1916-1938 (New Haven: Yale University Press, 2011).

${ }^{6}$ The distinction between those is elaborated in detail in chapter 3 .

${ }^{7}$ Jacques Derrida, Voice and Phenomenon, trans. Leonard Lawlor (Evanston: Northwestern University Press, 2011), p. 59.

${ }^{8}$ This expression was introduced by Husserl in his later manuscripts as part of his reflections back on the earlier work on time-consciousness. Yet the concept of the primal life of the ego is already present in these early lectures. See On the Phenomenology of the Consciousness of Internal Time, $\S \S 11-15 \& 25$. In his Analyses Concerning Passive Synthesis, Husserl elaborates this concept in relation to affection. Cf. .
} 
Analysen zur passiven Synthesis. Aus Vorlesungs- und Forschungsmanuskripten, 1918-1926, ed. Margot Fleischer (The Hague, Netherlands: Martinus Nijhoff, 1966), §§ 36-41. For an even later elaboration of the same concept see Experience and Judgment. Investigations in a Genealogy of Logic, trans. James S. Churchill \& Karl Ameriks (Evanston: Northwestern University Press, 1873), § 38.

${ }^{9}$ Husserl uses various terms to designate this same structure, the most important of which are die (ur)lebendige Gegenwart, das Erleben, das Strömen and das Urströmen.

${ }^{10}$ It is worth noting that in the lectures on time-consciousness of 1905 Husserl remains constrained exclusively to the sphere of Erlebnisse. In a later appendix he writes using Logical Investigations as a common reference for his thinking of this period: "The entire phenomenology I had in view in the Logical Investigations was a phenomenology of experiences (Erlebnisse) in the sense of data of internal consciousness and this, in any event, is a closed field." (Hua 10, 127/130)

${ }^{11}$ In sections 4 and 5 I clarify in more detail some of the necessary features distinguishing the primal flow from the stream of experiences. Here I only recourse to three of them in order to outline the systematic makeup of Husserl's theory of inner time-consciousness.

${ }^{12}$ Man sieht den Unterschied zwischen derjenigen Vor-Intentionalität, in der sich das Strömen des Erlebnisstroms konstituiert und sich darin konstituiert im strömenden Leben selbst: Gegenwart, Vergangenheit, Zukunft, und derjenigen Intentionalität - die jeder eigentlichen Intention, jedes eigentlichen Aktus -, in dem sich auf dem Grund des strömenden Lebens (des Bewusstseins und seiner Bewusstseinseinheiten im ersten Sinne) Aktbewusstsein als Ich bewusstsein von irgendetwas ergibt und darin Seiendes und Zeit als Form von Seiendem mit den noetischen Aktmodis der Zeitigung und mit Gegenwart als Gegenwart von Seiendem, Vergangenheit und Zukunft von Seiendem konstituiert.

${ }^{13}$ While the multiple reductions Husserl speaks of in Ideas I are all variations of one, phenomenological, reduction, in the subsequent revisions of this work, he differentiates three distinct general types of reduction: transcendental-phenomenological, psychological-phenomenological and eidetic. What in Ideas I he calls phenomenological epoché serves there as a negative preparatory stage for the transcendental phenomenological reduction. It deals with the identification and "exclusion" of the different aspects of the general naïve positing of the existence of the world. Here I focus only on the transcendentalphenomenological reduction and the subsequent stages of its radicalization. For an up-to-date, systematic and in-depth exposition of these three types of reduction see Panos Theodorou, Husserl and Heidegger on Reduction, Primordiality, and the Categorial: Phenomenology Beyond its Original Divide (New York: Springer, 2015). For Husserl's own elaborations and reflections on the many variants of the phenomenological reduction see Husserliana 34: Zur phänomenologischen Reduktion. Texte aus dem Nachlass (1926-1935), ed. Sebastian Luft (Dordrecht, Netherlands: Kluwer Academic Publishers, 2002). ${ }^{14}$ It is relevant here to parallel Husserl's understanding of the "natural attitude" (natülichen Einstellung) with Heidegger's thematization of everydayness (Altäglichkeit). It is no coincidence that Heidegger points at exactly the same structural characteristic when he discusses the inauthentic modes of Dasein's everyday Being-in-the-world: "Dasein is never to be taken ontologically as an instance or special case of some genus of entities as things that are present-at-hand (als Vorhandenem). To entities such as these their Being is 'a matter of indifference'; [...] In each case Dasein is its possibility, and 'has' this possibility, but not just as a property, as something present-at-hand (als ein Vorhandenes) would." Martin Heidegger, Being and Time, trans. John Macquarrie \& Edward Robinson (Oxford: Blackwell, 1996), pp. 67-68.

${ }^{15}$ To avoid a possible confusion, we need to mention that, in his various accounts of the three levels, Husserl often inverses the order of listing (e.g. in Husserliana 10 he starts with the objective level).

${ }^{16}$ As mentioned above, in Ideas I, Husserl allocates only a brief excursus to this separate domain of inquiry and only to explain why it must be left "out of account" (Hua 3, 193-194/163)

${ }^{17}$ For the sake of the particular argument pursued in this section, the central explication of the Fifth Meditation, the accounts of empathy and the intersubjective constitution of the world, are left out consideration. These are addressed in the following chapter.

${ }^{18}$ As might be obvious, this argument also follows loosely the logic of Husserl's eidetic reduction. If, using the technic of "imaginative variation," we can think of an entity without considering a certain trait, then this trait is not constitutively essential to this entity.

${ }^{19}$ Ms. B I 5 XIV, p. 10. Quoted in Klaus Held, Lebendige Gegenwart. Die Frage nach der Seinsweise des Transzendentalen Ich bei Edmund Husserl, Entwickelt am Leitfaden der Zeitproblematik (Den Haag: Martinus Nijhoff, 1966), p. 75.

${ }^{20}$ Ibid. 
${ }^{21}$ It is relevant here to adduce Heidegger's insightful remark about the nature of intentionality in his forward to the 1928 edition of Husserl's Vorlesungen zur Phänomenologie des inneren Zeitbewussteins: "Even today, this term "intentionality" is not a slogan for a solution but the designation of a central problem." Cf. Edmund Husserl, Zur Phänomenologie des inneren Zeitbewusstseins, Husserliana X, ed. Rudolf Boehm (The Hague, Netherlands: Martinus Nijhoff, 1969), p. xxv; english translation: Edmund Husserl, The Phenomenology of Internal Time-Consciousness, trans. James S. Churchill (Bloomington: Indiana University Press, 1964), p. 15.

${ }^{22}$ Cf. Logical Investigations, trans. J.N. Findlay (New York, NY: Humanities Press, 1970), 'Appendix to $\S \S 11$ and 20, pp. 593-96.

${ }^{23}$ Logical Investigations, pp. 594-95

${ }^{24}$ Logical Investigations, pp. 597-98, my emphasis.

${ }^{25}$ Logical Investigations, p. 595.

${ }^{26}$ Logical Investigations, p. 576.

${ }^{27}$ Logical Investigations, p. 578.

${ }^{28}$ Logical Investigations, p. 586.

${ }^{29}$ Logical Investigations, p. 598.

${ }^{30}$ For the sake of the continuity of the exposition I hasten here to utilize a much later employment of the Selbst in Husserl. One of the main motifs of his genetic analyses was the two-sided directedness of intentionality. According to this notion, because of the affective presentation of the object in the correlation, the object is itself one of the sources of experience. It "gives itself" to consciousness by exercising its affective powers on it and, respectively, has its own, transcendent self. The purpose of the allusion here is to suggest that such meaning is already implicit in the Logical Investigations. This issue will be addressed at length below.

${ }^{31}$ Logical Investigations, pp. 595-96.

${ }^{32}$ Logical Investigations, p. 580.

${ }^{33}$ Ibid.

${ }^{34}$ Held, Lebendige Gegenwart, p.19.

${ }^{35}$ To be sure, the positing of an absolute consciousness was for a period of time one of Husserl's attempts to solve the problem of infinite regress. Yet he realized that this solution poses further issues and discarded it moving onto the explanation I discuss here. For his account of the mode of absolute consciousness see Husserliana 33. Die 'Bernauer Manuskripte' über das Zeitbewußtsein (1917/18), ed.Rudolf Bernet \& Dieter Lohmar (Dordrecht, Netherlands: Kluwer Academic Publishers, 2001).

${ }^{36}$ Husserl uses numerous diagrams to explain different aspects of time-consciousness. Here I resort to this particular one as it represents the key features of his mature analysis. For a comprehensive account of Husserl's schematic representations of temporality see Alexander Schnell, "Das Problem der Zeit bei Husserl. Eine Untersuchung über die husserlschen Zeitdiagramme", Husserl Studies 18: 89-122, 2002.

${ }^{37}$ Significantly enough, to indicate the current of self-temporalization, in this particular account, Husserl uses neither Strom nor Strömen, which designate respectively the stream and the flow. Instead, he uses $F l u \beta$, which also suggests a conceptual diversion.

${ }^{38} \mathrm{Cf}$. Dan Zahavi, Self-awareness and alterity. A phenomenological investigation (Evanston: Northwestern University Press, 1999); Dan Zahavi, "Time and consciousness in the Bernau manuscripts", Husserl Studies, , 20(2), 99-118 (2004); Dan Zahavi, "Inner (time-)consciousness", in D. Lohmar \& I. Yamaguchi (eds.), On time- new contributions to the Husserlian phenomenology of time (Springer: Dordrecht, 2010), pp. 319-339; Dan Zahavi, "Objects and Levels: Reflections on the Relation Between Time-Consciousness and Self-Consciousness", Husserl Studies 27 (1):13-25 (2011)

${ }^{39}$ Zahavi, Self-awareness and alterity, p. 110.

${ }^{40}$ Zahavi, Self-awareness and alterity, p. 75.

${ }^{41}$ Zahavi, Self-awareness and alterity, p. 80.

${ }^{42}$ Besides the fact that this division is more or less consistently carried out by Husserl himself (especially the one between static and genetic approaches), probably the most comprehensive and clear presentation of Husserl's phenomenology of intersubjectivity in the context of this systematization can be found in Anthony Steinbock's Home and Beyond: Generative Phenomenology after Husserl (Evanston: Northwestern University Press, 1995), pp. 5-6.

${ }^{43}$ Among the scholars who make use of this distinction the name of Dan Zahavi stands out. His Husserl und die transzendentale Intersubjektivität (Netherlands: Kluwer Academic Publishers, 1996) was 
explicitly focused on the problem of the constituting "open intersubjectivity." In his later work Zahavi specifically addresses the "lacuna" in this book by analysing in detail the concept of empathy and face-toface social interaction in Husserl. Cf. Dan Zahavi's "Empathy and Mirroring: Husserl and Gallese" in R. Breeur and U. Melle (eds.), Life, Subjectivity and Art: Essays in Honor of Rudolf Bernet (Dordrecht: Springer, 2012); "Empathy and Other-Directed Intentionality" Topoi, 33/1: 129-142 (2014); Self and Other: Exploring Subjectivity, Empathy, and Shame (Oxford: Oxford University Press, 2014).

${ }^{44}$ Husserl often refers to it skeptically as "the so-called "empathy" (Hua 1, 173) hinting at his discontent with Lipps' use of the term.

45 " $[\mathrm{T}]$ he plurality of monads in actual and possible communication" (Hua 14, 265), in an "intermonadic relationship" (Hua 14, 367).

${ }^{46}$ The internal bodily awareness and coordination of the system of movements and perceptions would not exist if they were composed as a series of punctual occurrences. There is a developmental continuity that connects with past and sedimented experiences, which shape expertise related to future events.

Habitualities are often "awaken" by new experiences and thus function as automatized skills, like the basic ability to walk or to ride a bicycle. For a more detailed, though not entirely concurring account of the concept of embodied 'expertise' see: Dreyfus: 2007. For a very insightful contemporary analysis of this developmental kinaesthetic dynamics see Gallagher: 2005.

${ }^{47}$ Cf. J. St B. Evans,. "Dual-processing accounts of reasoning, judgment, and social cognition", Annual Review of Psychology, 59, (2008) 255-278.

${ }^{48}$ Among those critics who, by following Husserl, developed the phenomenological project in their own directions we can mention Merleau-Ponty, Schütz, Gurwitsch, and Levinas (cf. Merleau-Ponty 1964, 2002; 2010a, 2010b; Levinas 1992, 1998, 2002; Schutz 1975, 1996). A strong critique comes also from the dialogical standpoint, best represented in by Theunissen and Waldenfels (cf. Theunissen 1984; Waldenfels 1971). The "immanent" critics who try to save Husserl's theory of intersubjectivity from its solipsistic consequences include Held, Aguirre, Stroker, and Yamaguchi (cf. Held 1966, 1972; Aguirre 1970 Stroker 1987; Yamaguchi 1982)

${ }^{49} \mathrm{He}$ is as explicit as to introduce the contradictory pair "primordinal Eigenes" and "Nichteigenes," "primordinally own" and "non-own" (Hua 15, 15)

${ }^{50}$ Cf. Fink's "Operative Concepts in Husserl's Phenomenology",Apriori and World 6/33: (1987) 56-70..

${ }^{51}$ Husserl often speaks generally of "style of experience" (Erfahrungsstil), "style of the experience of the world" (Welterfahrungsstil and Weltstil) but also of Aligemeinstil, Geltungsstil, Wesensstil, Stil der Erfahrungswelt, Stiles der menschlichen Umwelt, Lebensstil, Einheitsstil, Erfahrungsstiles der Welt, Gegebenheitsstil, Zukunftsstil, Stil der Vergangenheit, Gegenwartsstil, Horizontstil, Stil der Konstitution, Veränderungsstil. We can easily say that "style" is one of the most important concepts for the genetic explanation of constitution.

${ }^{52}$ For an illuminating presentation of the concept of fulfilment in Husserl see Dorion Cairns, The Philosophy of Edmund Husserl (Springer, Dordrecht, 2013), 87-95.

53 "The child who already sees physical things understands, let us say, for the first time the final sense of scissors; and from now on he sees scissors at the first glance as scissors but naturally not in an explicit reproducing, comparing, and inferring. Yet the manner in which apperceptions arise and consequently in themselves, by their sense and sense-horizon, point back to their genesis varies greatly." (Hua 1, 141/111) ${ }^{54}$ As pointed out above, unlike my own (self-)awareness of/within my living present, with respect to the other I, have a "verifiable accessibility of what is not originally accessible" (Hua 1,144/114).

${ }^{55}$ To my knowledge, besides Beilage 45 in Hua 15, he uses it in the unpublished D Manuscripts of 1931 (D 12 I, transcribed by Fink). Most regularly, to refer to this level of passive synthesis he uses the term zeropoint (Nullpunkt).

${ }^{56}$ There has been an extensive debate running back as early as to Lipps and Scheler (and still ongoing in its contemporary versions) regarding the role of analogy in empathic apperception. Dan Zahavi gives it its due attention in his discussions of the relevance of Husserl's theory to current social cognition research. He however attempts to undermine the role of analogy in Husserl's account of empathy since he sees in it an obstacle to the argument for direct social perception. The implication of my treatment (whose elaboration falls out of the scope of the present chapter) is that analogy has a distinct and necessary function in Husserl's account of intersubjectivity. This function however can be adequately grasped only in generative contexts and does not hinder the case of direct social perception. See Zahavi, "Empathy and Mirroring: 
Husserl and Gallese", in R. Breeur and U. Melle (eds.), Life, Subjectivity and Art: Essays in Honor of Rudolf Bernet (Dordrecht: Springer, 2012).

${ }^{57}$ And this is where one clearly sees Husserl's radical departure from Hume.

${ }^{58} \mathrm{Cf}$. Hua 33, 38: "The further an event, the more it offers itself for more differentiated protentions, "the style of the past is projected into the future."

${ }^{59}$ Cairns' translation of Deckung is inconsistent throughout the Cartesian Meditations. In this particular case he translates it as "overlapping." The sentence in German reads: "Mit der assoziativen Deckung der die Apperzeption fundierenden Daten vollzieht sich eine höherstufige Assoziation." I would translate it as follows, "With the associative overlaying of the data founding the apperception, takes place a higher-level association."

${ }^{60}$ This is Husserl's typical expression until about the time of the Fifth Meditation. With it he emphasizes how the intentional contents of self and other remain distinct while overlaying each other. Later on he adopts an expression devised to strictly avoid possible spatial connotations: "overlaying in difference" (Deckung in Differenz, cf. Hua 15, 641). As I will argue in the following chapter, he had serious reasons for redefining the relationship in this way.

${ }^{61}$ Kant-Studien, Vol 38, 1933, pp. 319-383. English trans. "Husserl's Philosophy and Contemporary Criticism," in The Phenomenology of Husserl, edited and translated by R. O. Elveton (Chicago: Quadrangle Press, 1970), pp. 141-178.

${ }^{62}$ More specifically, those of Zocher and Kreis. Cf. Rudolf Zocher, Husserls Phänomenologie und Schuppes Logik: Ein Beitrag zur Kritik des intuitionistischen Ontologismus in der Immanenzidee (München: E. Reinhardt, 1932); Friedrich Kreis, "Phänomenologie und Kritizismus," in Heidelberger Abhandlungen zur Philosophie und ihrer Geschichte 21 (Tübingen, 1930).

63 "Husserl's Philosophy and Contemporary Criticism," pp. 142-143.

${ }^{64}$ Ibid., p. 143-144.

${ }^{65}$ Richard Kozlowski, Die Aporien der Intersubjektiwität (Königshausen und Neuman, 1991), p. 267-269.

${ }^{66}$ A detailed discussion of Husserl's later elaborations akin to the resolution of the paradox will be the topic of the following chapter. Here it suffices to use it as a leading clue for the interpretation of his theory of communication of the 1920 's.

${ }^{67}$ See also Schütz's earlier but more explicit discussion of the paradox in a manuscript titled "The Paradox of the Transcendental Ego," in Alfred Schütz, Collected Papers, Vol IV (Dordrecht: Kluwer, 1996), pp. 190-193.

${ }^{68}$ Alfred Schütz, . Collected Papers, Vol III (Dordrecht: Kluwer, 1966), pp. 68-72.

${ }^{69}$ Ibid., p. 75.

${ }^{70}$ Ibid., p. 76.

${ }^{71}$ Husserliana $13,17$.

${ }^{72}$ In fact, Husserl tries to tackle some of the basic sociological concepts used in the social thought of his time, mainly those of Ferdinand Tönnies, Georg Simmel and Max Weber. See Iso Kern's introduction to Husserliana 14 (Hua 14, XVII-XXXV).

${ }^{73}$ See Logical Investigations v. II, Part 1, Investigation 1, §§ 1-23, Hua 19, 30-83/181-233. See also Derrida's famous critical analysis in Voice and Phenomena. English translation: Jacques Derrida, Voice and Phenomenon: Introduction to the Problem of the Sign in Husserl's Phenomenology, trans. Leonard Lawlor (Evanston: Northwestern University Press, 2011).

${ }^{74} \mathrm{Cf}$. Hua 1,156 , and more broadly $\S 56$. Like most of the dogmatic views on Husserl's theory of intersubjectivity, this one is also shaped by a certain narrow reading of the Fifth Cartesian Meditation. The latter, however, can, as Nicolas de Warren puts it, "be seen as the weakest Husserlian formulation of the transcendence of the Other" (de Warren 1912, 267).

${ }^{75}$ Cf. Husserl's Analysen zur passiven Synthesis. Aus Vorlesungs- und Forschungsmanuskripten, 19181926. (Husserliana 11) and Die 'Bernauer Manuskripte' über das Zeitbewußtsein 1917/18 (Husserliana $33)$.

${ }^{76}$ For this explanatory model of mutual genetic foundation I am indebted to Anthony Steinbock's remarkable analysis of the non-foundational trends in Husserl's generative phenomenology (cf. Home and Beyond, p. 11).

${ }^{77}$ Although Husserl pays special attention to the distinct intentional structure of social acts, the thinker who first developed a systematic theory of social acts was in fact his disciple, Adolf Reinach. Almost a decade prior to Husserl's drafting of the Gemeingeist manuscripts, Reinach in his monograph, "Die apriorischen 
Grundlagen des bürgerlichen Rechts" (1913) defined social acts as "the spontaneous and examinationrequiring acts [... that are] projected [zugeworfen] toward another [person] as the one who lets the full performance itself catch onto his mind" (Reinach 1913, 706-707). The central characteristics of social acts, according to him, are therefore the "request for an examination" (Vernehmungsbedürftigkeit) directed at the receiver of the act and the external expression of this request. We will see below how Husserl incorporates elements of this definition into his own account. See Adolf Reinach, "Die apriorischen Grundlagen des bürgerlichen Rechts," in Jahrbuch für Philosophie und phänomenologische Forschung 1, Hg. von E. Husserl et al. (Halle: Max Niemeyer, 1913). On the specific interconnections between Husserl's and Reinach's accounts of social acts see Alessandro Salice, "Social Ontology as Embedded in the Tradition of Phenomenological Realism," in The Background of Social Reality. (Springer: Heidelberg New York Dordrecht London, 2013) and Esteban Marín Ávila, "Social Acts as Intersubjective Willing Actions," in Feeling and Value, Willing and Action: Essays in the Context of a Phenomenological Psychology. Eds. Marta Ubiali \& Maren Wehrle (Springer: Heidelberg New York Dordrecht London, 2015), pp. 245-263.

${ }^{78}$ Triebintentionalität is a concept which Husserl starts using at a later stage of his analyses of instincts. I, nevertheless, use it here because I think it captures quite accurately what he means in Gemeingeist I by "intentionality of instinctual spontaneity" as defining a special constitution of a subject. Cf. Hua 15, 148: "The ego as a specific subject of instinctual drives (as drive-habitualities), drive-habitualities running through all the living present; as the subject of waking and living out affections and actions and with them newly instituting act-habitualities."

${ }^{79}$ At this point he still uses "solipsistic" or "egoic" to characterize a sphere with attributes that are quite similar to what after the Fifth Meditation he begins calling the "primordial" or the sphere of "ownness."

${ }^{80}$ Here Husserl explicitly refers to the phenomenon of infant imitation, although he does not engage in a particular analysis. The relevance of his argument to recent experimental work in developmental psychology however is striking. See for example: A. Meltzoff \& M. K. Moore, "Imitation of facial and manual gestures by human neonates," Science 198 (1977), 75-78; "Imitation, memory, and the representation of persons," Infant Behavior and Development 17 (1994), 83-99; "Infant intersubjectivity: broadening the dialogue to include imitation, identity and intention," in Stein Bråten, Intersubjective Communication and Emotion in Early Ontogeny (Cambridge University Press, 2006), 47-62. In this case, Husserl's claim would imply that newborns do not perform actual communicative acts and do not yet enter a social relationship. However, as we will see below, his view on the issue evolved considerably.

${ }^{81}$ Husserl is not sufficiently clear about the relationship between sexual love and what he calls "personal love" (personale Liebe) in terms of their communicative status. As I argue below in an analysis specially focused on personal love, this unclearness articulates the ambiguity prevailing in the manuscript. I claim, however, that Husserl's account of personal love is at the same time key to the sorting out of this ambiguity. The ambiguity seems to be a result of the confusion between the two distinct kinds of phenomenological analysis of communication, the static and the genetic (generative) ones.

${ }^{82}$ The polysemy of the term Geist and its derivatives (geistlich, geistig, etc) can be seen here to parallel the one of Berührung. Neither of these metaphorical constructions, however, pursues a contingent rhetorical effect. In the context of Husserl's account of communication, their polysemy is rather a necessary one. It grasps the generative speculative relationship by virtue of which the process of I-Thou communication acquires "ideal objectivity" through cultural production and formation of ideal sense. Geistige Hände designates the socially generated material forms that carry meaning across generations. Therefore, Geist, geistlich, geistig must necessarily involve both literal and figurative sides, temporal-subjective and idealobjective dimensions. The original polysemy of the German term "Geist," which has no English analogue clearly displays this ambiguous character. Geist can be translated as "spirit," "mind," "ghost," "intellect," or "culture." This manifold of meanings, which has commonly presented a problem for the rendition of traditionally German philosophical discourses in English (The translation of Hegel's Phänomenologie des Geistes as both "Phenomenology of Mind" and "Phenomenology of Spirit" is probably the most illustrative case), lies at the root of Husserl's conception of Gemeingeist. The latter bares the index of sociality precisely in the sense of a twofold, embodied correlation where the surrounding world is always conceived as an intersubjective accomplishment. Yet, notwithstanding this inherent duality, I believe that there is a systematic reason within Husserl's phenomenology to avoid the translation of the terms Geist, geistlich, and geistig with constructs such as "spirit/mind," "spiritual/mental," or "mental/spiritual." I suggest that Husserl best explains the reason in Ideas II. There he systematically differentiates the "naturalistic" and the "personalistic" attitudes and their respective constitutions of the world (Hua 4, 173-211/181-223). 
According to this distinction, subjectivity can also be understood in the perspective of either the naturalistic or the personalistic attitude (Hua 4, 340-401/351-405). In the context of the former, Husserl terms it Seele, in the context of the latter, Geist. Seele designates subjectivity understood as part of nature and is thus studied by natural sciences (Naturwissenschaften) such as (naturalistic) psychology. Geist, for its part, indicates subjectivity in its proper, egological and intersubjective sense. This is the domain of human sciences (Geisteswissenschaften). Husserl does not use Seele in the traditional way as "soul." The connotations he ascribes to it correspond precisely to what in the analytic philosophical tradition is called "mind." Crucial to point out here is that Husserl by no means conceives of Geist as of something disembodied. As he puts it "[i]f I am interested in the human being as a human subject, as a person in a personal association, then he is admittedly also something bound to the body; [...] But my interest does not go toward nature but precisely toward the subject; and it is only a prejudice to maintain that nature is the true being of the subject." (Hua 4, 346/357) The latter consideration is also a reason for Husserl to attribute priority to the spiritual attitude over the naturalistic one.

${ }^{83}$ In the same way, we can naturally say that when reflecting upon his theories of intersubjectivity and communicative acts, we ourselves also shake spiritual hands with Husserl.

${ }^{84}$ The German reads: "Gemäss der in der Bestätigung der reinen monadischen (phänomenologischen) Erfahrung (Selbst- und Fremderfahrung) liegenden Seinswirklichkeit - als evidenter, als von jeder Monade aus notwendige "zweifellose" Gewissheit, ist jede Monade für sich selbst und in sich selbst auf die andere seinsmässig bezogen. Diese Grundbeziehung des Seins im Füreinander-sein ist evident als Beziehung des Koexistierens in einer intersubjektiven Zeit. Das ist hier nicht objektive, sondern immanent-intersubjektive Zeit des Koexistierens nach allen subjektiven Zeitmodis, danach nach identifizierbaren Zeitstrecken und Zeitstellen. Diese Grundbeziehung ist das Fundament für die intersubjektiven sonstigen Beziehungen, für eine intersubjektive und rein geistige Ka u salität ..."

${ }^{85}$ In an insightful analysis of Husserl's notion of dreamless sleep Nicolas de Warren shows how the bottom sedimentation of lived experiences, which Husserl explores in his analyses of inner time-consciousness and passive synthesis, can in fact be understood as a continuous constitutive process of "de-presentification." He describes this process as follows: "We can understand this suspension of the original presentation as a radical de-presentification of self, or self-abstention. We have the temporary suspension of the arc of the living present, but we still have the dimensions of far retention and far protention. In this manner, we can understand, from a phenomenological standpoint, how the self does not retire to itself, but retires from itself in succumbing, or falling, into its own self-oblivion; nothing appears since I am not here, for which something could appear. And yet, when I awake and open my eyes, I find all of my yesterdays in far retention return to me as well as all my tomorrows there before me, as if, despite the self-oblivion from which I am just emerging, the unity of my life, as a project of temporalization that has been and still will be, returns to itself, but not from where I had, the evening before, taken leave of myself." (de Warren, Nicolas, "The Inner Night: Towards a Phenomenology of (Dreamless) Sleep," in On time: New Contributions to the Husserlian Phenomenology of Time. Dordrecht; New York: Springer, 2010, p. 239) ${ }^{86}$ See the last section of the present chapter where this topic is discussed at more length and in a different context.

${ }^{87}$ It is easy to recognize here the origin of central motifs in Derrida's early thought. Husserl's generative reflections on communication, language, tradition, birth, and death clearly foreshadow Derrida's understanding of the "economy of différance" in the function of writing as an "economy of death." Two passages - the first from Voice and Phenomena and the second from "Signature Event Context"- suffice to bear witness to this legacy: "It is therefore the relation to my death (to my disappearance in general) that is hidden in this determination of being as presence, ideality, as the absolute possibility of repetition. The possibility of the sign is this relation to death. The determination and the erasure of the sign in metaphysics is the dissimulation of this relation to death which nevertheless was producing signification. (Derrida 2011, 46).

In order to examine the pure eidetic capacity for renewal of the sign, Derrida further considers the formal possibility for the death not only of the addresser but also of the addressee: "Can it still be said that upon the death of the addressee, that is, of the two partners, the mark left by one of them is still a writing? Yes, to the extent to which, governed by a code, even if unknown and nonlinguistic, it is constituted, in its identity as a mark, by its iterability in the absence of whoever, and therefore ultimately in the absence of every empirically determinable "subject." This implies that there is no code — an organon of iterabilitythat is structurally secret. The possibility of repeating, and therefore of identifying, marks is implied in 
every code, making of it a communicable, transmittable, decipherable grid that is iterable for a third party, and thus for any possible user in genera. All writing, therefore, in order to be what it is, must be able to function in the radical absence of every empirically determined addressee in general. [...] What holds for the addressee holds also, for the same reasons, for the sender or the producer." ("Signature, Event, Context," in Margins of Philosophy. Chicago: University of Chicago Press, 1982, pp. 315-316)

${ }^{88}$ In the Gemeingeist texts Husserl does not pay particular attention to the problems of birth and death. However, since the manuscript quoted here is from nearly the same period (1922-1923), we can presume that it marks pretty accurately the contextual framework of the account of the communicative constitution of personality. On the same connection see also Husserl's earliest treatment of the problems of natality and mortality in an appendix to the Passive Synthesis Lectures named "The Apodicticity of Remembering" (Hua 11, 365-383/451-473).

${ }^{89}$ One should be aware here that whenever Husserl refers to "the so called "unconscious'," he means something quite different from the Freudian notion. On the different sense of "unconscious" in Husserl and Freud see Fink's Appendix (XXI) to $§ 46$ of Krisis (Fink 1976, 473-476) as well as Mishara's seminal, yet largely overlooked article "Husserl and Freud: Time, Memory and the Unconscious" (Mishara 1990)

${ }^{90}$ Husserl does not use the notion of style in his explication of "personal love." However, as I will show below, this notion, used by him in various other contexts, affords an interpretation that proves both relevant and productive with respect to the concept of personal love.

${ }^{91}$ Cf. the condition of fulfillment of sexual drive in Hua 15: "In the simple primally modal fulfillment we do not have two separated fulfillments, each in its own primordiality, but an in-one-another [Ineinander] of the fulfillments through the productive unity of the two primordialities" (Hua 15, 594).

${ }^{92}$ The translators have chosen here to render the German Intuition by "intuitive flair." The English "intuition" has traditionally been used to translate Anschauung, which has a strictly defined meaning, not only in Husserl's work but in the German philosophical tradition in general (See for example Kant's Critique of Pure Reason). There, it signifies the integral formal-sensory grasp of what is immediately given in experience. The translators' choice seems justified because the German word Intuition carries much more than Anschauung, the sense of natural anticipatory acumen, which does not require a verifying fullness of sensorial data.

${ }^{93}$ In logical terms, Husserl construes the "absolute concretum" as a pure individual whole without abstract and general parts. Toward the end of the Fourth Cartesian Mediation he states that the possible knowledge and possible evidence (i.e. immanence and transcendence, intention and fulfillment) belong together in the only absolute concretum, which is the transcendental subjectivity. Understood in the genetic context of Ineinander this statement does not contradict the possibility that the "You" is an absolute concretum. The main reason for this is that it is part of the structure of the I's living present.

${ }^{94}$ One can add that the Gemeingeist manuscripts were written during the period Husserl delivered the Passive Synthesis Lectures.

${ }^{95}$ In the 1930's Husserl uses the same analogy to speak in an entirely generative sense of "homeworld" (Heimwelt) and "alienworld" (Fremdwelt, Hua 15, 613-627) and of intercultural communication (Hua 27, 59-94).

${ }^{96}$ Gemeingeist is a concept, which occupies a distinct place in Hegel's ethical and legal philosophy. In the Encyclopaedia, it designates the moment in the self-consciousness of a particular community in which its communal will acquires a proper objective actuality (e.g. a constitution for a nation; cf. § 540). Though not without kinship with Hegel's understanding of this concept, Husserl's notion of Gemeingeist - as will become clear in the following reflections - exhibits significantly different attributes.

${ }^{97}$ Hegel seems to treat these two components indiscriminately under the title of "objective spirit." See Hegel's account of the latter notion in the section in the Encyclopaedia "Philosophy of Spirit" (Werke, Band 10 - Enzyklopädie der philosophischen Wissenschaften im Grundrisse III, §§ 483-552, pp. 303-366)

${ }^{98}$ It is relevant here to dispel the widespread misunderstanding among both Husserl scholars and critics that Husserl's argument regarding the primordiality of empathy is self-contradictory (Derrida 2003, 2011, Schutz 1975, 1996; Theunissen 1984). The gist of their critique is that, since in the primordial sphere we abstract from all constitutive accomplishments of the intentionality related to other subjects, we could not have constituted within it the other in the mode alter ego, as Husserl seems to claim. In the context of my account, however, we can say that Husserl refers to two different senses of "other." What is actually to be excluded from the sphere of ownness are others as far as they are conceived in terms of community 
subjectivity. The empathized others, on the other hand, clearly belong in this sphere because I apprehend them solely in my original experiences. A similar claim is made by Nam-in Lee in his "StaticPhenomenological and Genetic-Phenomenological Concept of Primordiality in Husserl's Fifth Cartesian Meditation" (Husserl Studies, 18/3, 2002), although the context and the structure of the argument substantiating this claim differ from mine.

${ }^{99}$ It is not difficult to recognize here the source of the tradition of social construction analysis. Through the work of Schütz, one of Husserl's direct successors, the authors of the influential The Social Construction of Reality (Garden City: Anchor Books, 1967) Peter L. Berger and Thomas Luckmann draw back precisely on Husserl's theory of intersubjective constitution and personal unities of a higher order.

${ }^{100}$ See my discussion of Husserl's notion of "individual style" in the previous section.

${ }^{101}$ The scope of the present work does not permit us to take on an exhaustive analysis of this late constructive transcendental-metaphysical dimension of Husserl's phenomenology in relation with the topic of communication. For a fundamental presentation of this dimension see Marc Richir, Phenomenologie et institution symbolique - Phénoménes, temps et étres II (Jéróme Millón, coll. "Krisis" Grenoble, 1988); L'institution de l'idealite - des schematismes phenomenologique (Association pour la Promotion de la Phénoménologie - Coll. Mémoires des Annales: Beauvais, 2002); Alexander Schnell, Husserl et les fondements de la phénoménologie constructive (Coll. "Krisis", Grenoble, J. Millon, 2007); Hinaus. Entwürfe zu einer phänomenologischen Metaphysik und Anthropologie (Würzburg: Verlag Königshausen \& Neumann, Band 24, 2011); Le sens se faisant. Marc Richir et la refondation de la phénoménologie transcendantale (Bruxelles: Ousia, 2001).

${ }^{102}$ This is what permits him to later develop a generative theory of symbolic institution of idealities. In "The Origin of Geometry," for example, he writes, "The important function of written, documenting linguistic expression is that it makes communications possible without immediate or mediate personal address; it is, so to speak, communication become virtual. Through this, the communalization of man is lifted to a new level." (Hua 6, 371/360)

${ }^{103}$ Cf. Text No 21 in Husserliana 14 titled "The Phenomenological Reduction of the Alter Ego and on Intersubjectivity: The Social and Instinctive Connectedness of Subjects as a Pure Subjective Unity in the Pure Psychological Experience" (Hua 14, 400-412).

${ }^{104}$ For Husserl's general definition of the concept of intentionality see Ideas Pertaining to a Pure Phenomenology and to a Phenomenological Philosophy Book I (Hua 3, 58/64).

${ }^{105}$ This expression was introduced by Husserl in his later manuscripts as part of his reflections back on the earlier work on time-consciousness. Yet the concept of the primal life of the ego is already present in his early thought. One of its proto-forms is Husserl's notion of the ego's transcendence in immanence carried out in Ideas I (Cf., for example, § 57). For the original temporal account of this idea see On the

Phenomenology of the Consciousness of Internal Time. trans. John Brough (Netherlands: Kluwer Academic Publishers, 1991), §§ 11-15 \& 25. For a later elaboration of the same concept see Experience And Judgment. Investigations In A Genealogy Of Logic, trans. James S. Churchill \& Karl Ameriks (Evanston: Northwestern University Press, 1873), § 38.

${ }^{106}$ Emanuel Levinas, "Intentionality and Metaphysics," in Discovering Existence with Husserl, trans. Richard A. Cohen and Michael B. Smith. (Evanston: Northwestern University Press, 1998), p. 125.

${ }^{107}$ Emanuel Levinas, "The Trace of the Other," trans. Alphonso Lingis, in Deconstruction in Context, ed. Mark Taylor (Chicago: University of Chicago Press, 1986), p. 348.

${ }^{108}$ Emanuel Levinas, "Philosophy and Awakening," in Discovering Existence with Husserl (Evanston: Northwestern University Press, 1998), p. 178.

${ }^{109}$ Emanuel Levinas, "From Consciousness to Wakefulness," in Discovering Existence with Husserl, p. 165 .

110 "Philosophy and Awakening," p. 177, emphasis added.

${ }^{111}$ Emanuel Levinas, (OB) Otherwise than Being or Beyond Essence, trans. Alphonso Lingis (Pittsburgh: Duquesne University Press), 2002, p. 142. References to this edition are henceforth given parenthetically within the text by the abbreviation indication of and the page number.

${ }^{112}$ The firs three reductions are major themes of Ideas I. Cf. Hua 3 , $\S ~ 27-32$ and $\S \S 56-62$. The reduction of objective time is Husserl's point of departure in his Phenomenology of the Internal Time-consciousness. (cf. Hua 10, §1).

113 "The Trace of the Other," p. 356.

114 "From Consciousness to Wakefulness," p. 161. 
115 Ibid.

${ }^{116}$ Clearly, Levinas concerns himself predominantly with Husserl's "static" period but often notices the importance the later "genetic analysis" (and especially the manuscripts) might have with respect to the ethical problematic. Cf. OB, 33.

117 "From Consciousness to Wakefulness," p. 161.

118 "Intentionality and Sensation" in Discovering Existence with Husserl, p. 150

119 "The Trace of the Other," p. 357.

${ }^{120}$ Cf. "Intentionality and Sensation," p.146.

121 Ibid., p. 150

122 Ibid., p. 148

${ }^{123}$ Ibid., p. 148

${ }^{124}$ Hua XXVII, p.26

${ }^{125}$ English translation: "Renewal: Its Problem and Method," trans. Jeffner Allen, in Shorter Works, ed. P. McCormic \& F. A. Ellison. (Notre Dame: University of Notre Dame Press \& The Harvester Press, 1981), p. 326.

126 "Philosophy and Awakening," p. 177, emphasis added.

127 "Intentionality and Sensation," 144.

128 "Intentionality and Sensation," 148. 


\section{Bibliography}

\section{Primary sources:}

Collected works of Husserl: Husserliana Gesammelte Werke (Hua) vols. 1-42. Martinus Nijhoff/ Kluwer/Springer, (1952-)

(Hua 1) Husserliana 1. Cartesianische Meditationen und Pariser Vorträge. Edited by S.

Strasser. The Hague, Netherlands: Martinus Nijhoff, 1973.

(Hua 3) Husserliana 3. Ideen zu einer reinen Phänomenlogie und phänomenlogischen

Philosophie. Erstes Buch: Allgemeine Einführung in die reine Phänomenologie. Edited by Walter Biemel. The Hague, Netherlands: Martinus Nijhoff Publishers, 1950.

(Hua 4) Husserliana 4. Ideen zur einer reinen Phänomenologie und phänomenologischen Philosophie. Zweites Buch: Phänomenologische Untersuchungen zur Konstitution. Edited by Marly Biemel. The Hague, Netherlands: Martinus Nijhoff, 1952.

(Hua 5) Husserliana 5. Ideen zur einer reinen Phänomenologie und phänomenologischen Philosophie. Drittes Buch: Die Phänomenologie und die Fundamente der Wissenschaften. Edited by Marly Biemel. The Hague, Netherlands: Martinus Nijhoff, 1971. 
(Hua 6) Husserliana 6. Die Krisis der europäischen Wissenschaften und die transzendentale Phänomenologie. Eine Einleitung in die phänomenologische Philosophie. Edited by Walter Biemel. The Hague, Netherlands: Martinus Nijhoff, 1976.

(Hua 7) Husserliana 7. Erste Philosophie (1923/4). Erste Teil: Kritische Ideengeschichte. Edited by Rudolf Böhm. The Hague, Nether- Netherlands: Martinus Nijhoff, 1956.

(Hua 8) Husserliana 8. Erste Philosophie (1923/4). Zweiter Teil: Theorie der phänomenologischen Reduktion. Edited by Rudolf Böhm. The Hague, Netherlands: Martinus Nijhoff, 1959.

(Hua 9) Husserliana 9. Phänomenologische Psychologie. Vorlesungen Som- Sommersemester 1925. Edited by Walter Biemel. The Hague, Netherlands: Martinus Nijhoff, 1968.

(Hua 10) Husserliana 10. Zur Phänomenologie des inneren Zeitbewusstesens (1893-1917). Edited by Rudolf Böhm. The Hague, Netherlands: Martinus Nijhoff, 1969.

(Hua 11) Husserliana 11. Analysen zur passiven Synthesis. Aus Vorlesungs- und Forschungsmanuskripten, 1918-1926. Edited by Margot Fleischer. The Hague, Netherlands: Martinus Nijhoff, 1966.

(Hua 13) Husserliana 13. Zur Phänomenologie der Intersubjektivität. Texte aus dem Nachlass. Erster Teil. 1905-1920. Edited by Iso Kern. The Hague, Netherlands: Martinus Nijhoff, 1973.

(Hua 14) Husserliana 14. Zur Phänomenologie der Intersubjektivität. Texte aus dem Nachlass. Zweiter Teil. 1921-28. Edited by Iso Kern. The Hague, Netherlands: Martinus Nijhoff, 1973. 
(Hua 15) Husserliana 15. Zur Phänomenologie der Intersubjektivität. Texte aus dem Nachlass. Dritter Teil. 1929-35. Edited by Iso Kern. The Hague, Netherlands: Martinus Nijhoff, 1973.

(Hua 17) Husserliana 17. Formale and transzendentale Logik. Versuch einer Kritik der logischen Vernunft. Edited by Paul Janssen. The Hague, Netherlands: Martinus Nijhoff, 1974.

(Hua 19) Husserliana 19. Logische Untersuchungen. Zweiter Teil. Untersuchungen zur Phänomenologie und Theorie der Erkenntnis. In zwei Bänden. Edited by Ursula Panzer. Halle: 1901; rev. ed. 1922. The Hague, Netherlands: Martinus Nijhoff, 1984.

(Hua 23) Husserliana 23. Phäntasie, Bildbewusstsein, Erinnerung. Zur Phänomenologie der anschaulichen Vergegenwartigungen. Texte aus dem Nachlass (1898-1925). Edited by Eduard Marbach. The Hague, Netherlands: Martinus Nijhoff, 1980.

(Hua 27) Husserliana 27. Aufsätze und Vorträge. 1922-1937. Edited by T. Nenon H.R. Sepp.

The Hague, Netherlands: Kluwer Academic Publishers, 1988.

(Hua 29) Husserliana 29. Die Krisis der europaischen Wissenschaften und die transzendentale Phänomenologie. Ergänzungsband. Texte aus dem Nachlass 1934-1937. Edited by Reinhold N. Smid. The Hague, Netherlands: Kluwer Academic Publishers, 1992 (Hua 33) Husserliana 33. Die ”Bernauer Manuskripte” über das Zeitbewußtsein (1917/18). Edited by Rudolf Bernet \& Dieter Lohmar. Dordrecht, Netherlands: Kluwer Academic Publishers, 2001.

(Hua 34) Husserliana 34. Zur phänomenologischen Reduktion. Texte aus dem Nachlass (19261935). Edited by Sebastian Luft. Dordrecht, Netherlands: Kluwer Academic Publishers, 2002. 
(Hua 39) Husserliana 39. Die Lebenswelt. Auslegungen der vorgegebenen Welt und ihrer

Konstitution. Texte aus dem Nachlass (1916-1937). Edited by Rochus Sowa. New York: Springer, 2008.

(Hua 42) Husserliana 42. Grenzprobleme der Phänomenologie. Analysen des Unbewusstseins und der Instinkte. Metaphysik. Späte Ethik (Texte aus dem Nachlass 1908 - 1937). New York: Springer, 2014.

\section{Works by Husserl in English}

Husserl, Edmund. Logical Investigations, trans. J. N. Findlay. New Jersey: Humanities Press, 1970. . Ideas Pertaining to a Pure Phenomenology and to a Phenomenological Philosophy:

Book I, trans. Fred Kerston. The Hague: Martinus Nijhoff, 1982.

. On the Phenomenology of the Consciousness of Internal Time, trans. John Brough.

Netherlands: Kluwer Academic Publishers, 1991.

. Cartesian Meditations. Trans. Dorion Cairns. The Hague: Martinus Nijhoff, 1970.

. Experience and Judgment: Investigations in a Genealogy of Logic. Trans. James S.

Churchill \& Karl Ameriks. Evanston: Northwestern University Press, 1973.

. The Crisis of European Sciences and Transcendental Phenomenology, trans. David Carr.

Martinus Nijhoff, 1970.

. Shorter Works, ed. P. McCormic \& F. A. Ellison. University of Notre Dame Press \& The Harvester Press, 1981.

\section{Works by Levinas}

(TI) Totality and Infinity, trans. Alphonso Lingis, Dordrecht: Kluwer Academic, 1992. 
(OB) Otherwise than Being or Beyond Essence, trans. Alphonso Lingis, Pittsburgh: Duquesne University Press, 2002.

Discovering Existence with Husserl, trans. Richard A. Cohen and Michael B. Smith, Evanston: Northwestern University Press, 1998.

'The Trace of the Other', trans. Alphonso Lingis, in Deconstruction in Context: Literature and Philosophy, ed. Mark Taylor. Chicago: University of Chicago Press, 1986.

\section{Other Primary Sources}

Heidegger, Martin. Being and Time. Trans. John Macquarrie \& Edward Robinson. Oxford: Blackwell 1962.

Schutz, Alfred. (1975) Collected Papers III: Studies in Phenomenological Philosophy. Netherlands: Springer.

. (1996) Collected Papers IV. Boston: Kluwer Academic Publishers,.

\section{Secondary sources:}

Aguirre, A. F. (1970) Genetische Phänomenologie und Reduktion. den Haag.

Aguirre, A. F. (1982) Die Phänomenologie Husserls im Licht ihrer gegenwärtigen Interpretation und Kritik. Darmstadt.

Ávila, Esteban Marín. (2015) Social Acts as Intersubjective Willing Actions. In Feeling and Value, Willing and Action: Essays in the Context of a Phenomenological Psychology. 
Eds. Marta Ubiali \& Wehrle, Maren. Springer: Heidelberg New York Dordrecht London. $245-263$.

Berger, Peter L. \& Luckmann, Thomas. (1967) The Social Construction of Reality: a treatise in the sociology of knowledge. Garden City: Anchor Books.

Bernasconi, Robert. (1999) 'The Third Party: Levinas on the Intersection of the Ethical and the Political,' Journal of the British Society for Phenomenology. Vol. 30, No 1, January.

Clark, Andy. (1997) Being There: Putting Mind, Body, and World Together Again. Cambridge, MA: MIT Press.

De Jaegher, Hanne \& Di Paolo, Ezequiel. (2007) 'Participatory Sense-making: An Enactive approach to social cognition'. Phenomenology and Cognitive Sciences 6:485-507

Depraz , Natalie, Varela, Francisco J., Vermersch, Pierre. (2003) On Becoming Aware: A Pragmatics of Experiencing. Amsterdam: John Benjamins Publishing.

Derrida, Jacques. (2011) Voice and Phenomenon: Introduction to the Problem of the Sign in Husserl's Phenomenology. Trans. Leonard Lawlor. Evanston: Northwestern University Press, 2011. . (1982) Margins of Philosophy. Chicago: University of Chicago Press. . (2003) The problem of Genesis in Husserl's philosophy. Chicago: University of Chicago Press. . (1978) Edmund Husserl's Origin of Geometry: An Introduction. Stony Brook, N.Y. : Nicholas Hays,. de Warren, Nicolas. (2010) 'The Inner Night: Towards a Phenomenology of (Dreamless) Sleep'. In On time: New Contributions to the Husserlian Phenomenology of Time. Dordrecht; New York: Springer. 
Dodd, James. (1997) Idealism and Corporeity: An Essay on the Problem of the Body in Husserl's Phenomenology. Netherlands: Kluwer Academic Publishers.

Dreyfus, Hubert L. (2007). 'Response to McDowell'. Inquiry, 50: 371-377.

Fink, Eugen. (1933) 'Die phänomenologische Philosophie Edmund Husserls'. In Kant-Studien, Vol 38, 1933, pp. 319-383. English trans. in The Phenomenology of Husserl, edited and translated by R. O. Elveton (Chicago: Quadrangle Press, 1970), pp. 141-178 . (1976) 'Beilage zum Problem des Unbewussten, zu § 46’. In Die Krisis der europäischen Wissenschaften und die transzendentale Phänomenologie. Eine Einleitung in die phänomenologische Philosophie. Edited by Walter Biemel. The Hague, Netherlands: Martinus Nijhoff, 473-476. . (1987) Operative Concepts in Husserl's Phenomenology'. In Apriori and World 6/33: $56-70$

Drabinski, John. (2001) Sensibility and Singularity. New York: State University of New York Press,. Evans, J. St B. T. (2008). 'Dual-processing accounts of reasoning, judgment, and social cognition'. Annual Review of Psychology, 59: 255-278.

Gallagher, Shaun. (2005) How the Body Shapes the Mind. Oxford : Clarendon. - (2008a) 'Direct Perception in Intersubjective Context', Consciousness and Cognition, 17: 535-543.

Gallagher, Shaun. (2008b) 'Inference or interaction: Social cognition without precursors'. Philosophical Explorations 11, 163-174.

Gallagher, Shaun and Hutto, Daniel. (2008c) 'Understanding others through primary interaction and narrative practice'. In The Shared Mind: Perspectives on Intersubjectivity. Eds. Zlatev, J. et al., John Benjamins. 
Gallese, Vittorio. (2003) 'The Roots of Empathy: The Shared Manifold Hypothesis and the Neural Basis of Intersubjectivity', Psychopathology, 36/4 171-80.

Gurwitsch, Aron. Human encounters in the social world. Translated by Fred Kersten. Pittsburgh:

Duquesne University Press, c1979

Hegel, G.W.F. (1986) Werke, Band 10 - Enzyklopädie der philosophischen Wissenschaften im Grundrisse III. Frankfurt: Suhrkamp. . (1991) Elements of the Philosophy of Right. Translated by H.B. Nisbet. Cambridge:

Cambridge University Press.

Hegel, G.W.F. Phänomenologie des Geistes. Gesammelte Werke 9. Edited by Wolfgang Bonsiepen and Reinhard Heede. Hamburg: Felix Meiner Verlag.

Held, Klaus. (1966) Lebendige Gegenwart: die Frage nach der Seinsweise des transzendentalen Ich bei Edmund Husserl, entwickelt am Leitfaden der Zeitproblematik. Den Haag: Martinus Nijhoff,. . (1972) 'Das Problem der Intersubjektivität und die Idee Einer Phänomenologischen

Transzendentalphilosophie'. In Perspektiven transzendentalphänomenologischer Forschung Phaenomenologica. Bd. 49, pp. 3-60.

Kortooms, Toine. (2002) Phenomenology of Time: Edmund Husserl's Analysis of Time Consciousness. The Hague: Kluwer Academic Publishers,. Kozlowski, Richard. (1971) Die Aporien der Intersubjektiwität. Königshausen und Neuman, 1991. Lee, Nam-in. (1993) Edmund Husserls Phänomenologie der Instinkte. Dordrecht ; Boston : Kluwer Academic Publishers. . (2002) Static-Phenomenological and Genetic-Phenomenological Concept of Primordiality in Husserl's Fifth Cartesian Meditation. Husserl Studies, 18/3. 
Lohmar, Deiter and Ichiro Yamaguchi, eds. (2010) On Time: New Contributions to the Husserlian Phenomenology of Time. New York: Springer.

Maye, Harun and Hans Rainer Sepp, eds. Phänomenologie und Gewalt. Würzburg: Königshausen \& Neumann, 2005.

Merleau-Ponty, Maurice. Phenomenology of Perception. Trans. Colin Smith. New York: Routledge, 1962. . (1977) Signs. Evanston, Ill: Northwestern University Press 1964. . (2002) Husserl at the Limits of Phenomenology: Including Texts by Edmund Husserl.

Leonard Lawlor (ed.), transl. Bettina Bergo. Evanston, Ill.: Northwestern University Press. . (2010a) Child psychology and pedagogy: the Sorbonne lectures, 1949-1952. Talia Welsh (trans1.). Evanston, Ill. : Northwestern University Press, . Institution and passivity: course notes from the Collège de France (1954-1955).

Transl. Leonard Lawlor and Heath Massey. Evanston, Ill. : Northwestern University Press, 2010b

Meltzoff, A. \& Moore, M. K. (1977), Imitation of facial and manual gestures by human neonates. Science, 1977, 198, 75-78. . (1994) Imitation, memory, and the representation of persons. Infant Behavior and Development, 17, 83-99. . (1998) Infant intersubjectivity: broadening the dialogue to include imitation, identity and intention. In Bråten, Stein. Intersubjective Communication and Emotion in Early Ontogeny. Cambridge University Press, 47-62. 
Mishara, Aaron. (1990) Husserl and Freud: Time, Memory and the Unconscious. Husserl Studies 7: 29-58.

Mohanty, N., (2011) Edmund Husserl's Freiburg Years, 1916-1938. New Haven: Yale University Press.

Murray, L. and Trevarthen, C. 'Emotional regulation of interactions between 2-month-olds and their mothers'. In Social Perception in Infants. Eds. Field, T.M. and Fox, N.A.,177197, Ablex, 1985.

Vsudevi Reddy, (2008) How Infants Know Minds. Harvard University Press,.

Reinach, A. (1913) "Die apriorischen Grundlagen des bürgerlichen Rechts," in Jahrbuch für Philosophie und phänomenologische Forschung 1, Hg. von E. Husserl et al. Halle: Max Niemeyer.

Richir, Marc. (1988) Phenomenologie et institution symbolique - Phénoménes, temps et étres II. Jéróme Millón, coll. "Krisis" Grenoble. . (2002) L'institution de l'idealite - des schematismes phenomenologique.

Association pour la Promotion de la Phénoménologie - Coll. Mémoires des Annales: Beauvais.

Philip Rochat, Others in Mind: Social Origins of Self-Consciousness. New York, N.Y.: Cambridge University Press, 2009

Salice, Alessandro. (2013) Social Ontology as Embedded in the Tradition of Phenomenological Realism. In The Background of Social Reality. Springer: Heidelberg New York Dordrecht London.

Schnell, Alexander. (2007) Husserl et les fondements de la phénoménologie constructive. Coll. "Krisis", Grenoble, J. Millon. 
. (2011a) Hinaus. Entwürfe zu einer phänomenologischen Metaphysik und

Anthropologie. Würzburg: Verlag Königshausen \& Neumann, Band 24.

. (2011b) Le sens se faisant. Marc Richir et la refondation de la phénoménologie

transcendantale. Bruxelles: Ousia.

Sepp, Hans Rainer and Ichiro Yamaguchi (eds.) Leben als Phänomen: die Freiburger

Phänomenologie im Ost-West-Dialog. Würzburg: Königshausen \& Neumann, 2006.

Steinbock, Anthony. Home and Beyond: Generative Phenomenology after Husserl.

Evanston: Northwestern University Press, 1995.

Ströker, E., 1987, Husserls transzendentale Phänomenologie, Frankfurt/M.

Theunissen, Michael. (1984) The Other: Studies in the Social Ontology of Husserl,

Heidegger, Sartre, and Buber. Trans. Christopher Macann. Cambridge, Mass: MIT Press.

Tomasello, Michael. (2008) Origins of Human Communication. Cambridge, MA: MIT

Press.

Evan Thompson. (2007) Mind in Life: Biology, Phenomenology, and the Sciences of Mind.

Harvard University Press,

Trevarthen, C. and Aitken, K.J. (2001) 'Infant intersubjectivity: research, theory, and

clinical applications'. Journal of Child Psychology and Psychiatry, 42, 3-48

Varela, F.J. et al. (1991) The Embodied Mind: Cognitive Science and Human Experience.

MIT Press.

Waldenfeis, Bernard. Das Zwischenreich Des Dialogs: Sozialphilosophische

Untersuchungen in Anschluss an Edmund Husserl. The Hague: Martinus Nijhoff, 1971.

Welton, Donn. The Other Husserl: The Horizons of Transcendental Phenomenology.

Bloomington: Indiana University Press, 2001. 
Yamaguchi, Ichiro. Passive Synthesis und Intersubjektivität bei Edmund Husserl. The Hague: Martinus Nijhoff, 1982. . Ki als leibhaftige Vernunft: Beitrag zur interkulturellen Phänomenologie der Leiblichkeit. Munich: Fink, 1997.

Zahavi, Dan. (1996) Husserl und die transzendentale Intersubjektivität. Phaenomenologica 135. Netherlands: Kluwer Academic Publishers. . (1999) Self-Awareness and Alterity: A Phenomenological Investigation. Evanston, Ill.: Northwestern University Press. . (2001), 'Beyond Empathy: Phenomenological Approaches to Intersubjectivity'. Journal of Consciousness Studies, 8/5-7: 151-67. . (2003), 'Inner Time-Consciousness and Pre-Reflective Self-Awareness', in D.

Welton (ed.), The New Husserl: A Critical Reader. Bloomington: Indiana University Press, $157-80$. . (2007), 'Expression and Empathy', in D. D. Hutto and M. Ratcliffe (eds.), Folk

Psychology Re-Assessed. Dordrecht: Springer, 25-40. . (2008), 'Simulation, Projection and Empathy', Consciousness and Cognition, 17/2: 514-22. . (2012) 'Empathy and Mirroring: Husserl and Gallese', in R. Breeur and U. Melle (eds.), Life, Subjectivity and Art: Essays in Honor of Rudolf Bernet. Dordrecht: Springer . (2014b) ‘Empathy and Other-Directed Intentionality’ Topoi, 33/1: 129-142 . (2014b) Self and Other: Exploring Subjectivity, Empathy, and Shame. Oxford:

Oxford University Press. 
Zahavi, Dan, ed. Self-Awareness, Temporality and Alterity: Central Topics in Phenomenology. Boston: Kluwer Academic Publishers, 1998.

Zahavi, Dan \& Gallagher, Shaun (2008) The Phenomenological Mind: An Introduction to Philosophy of Mind and Cognitive Science. London: Routledge. 